$$
\begin{aligned}
& \text { HORSES } \\
& \text { ON BOARD SHIP }
\end{aligned}
$$

CAPTAIN M. H. HAXES 


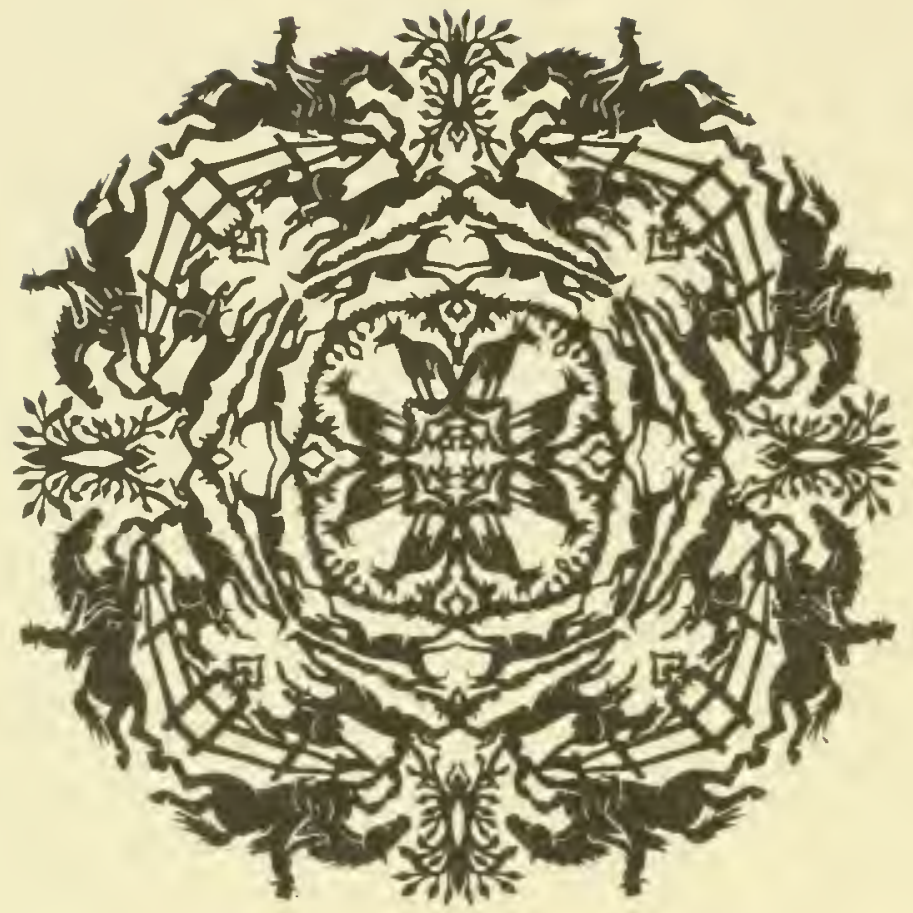

JOHN A.SEAVERNS 



HORSES ON BOARD SHIP 



\section{Horses on Board Ship}

A GUIDE TO THEIR MANAGEMENT

BY

M. HORACE HAYES, F.R.C.V.S (LATE CAPTAIN "THE BUFFs")

AUTHOR OF

"Veterinary Notes for Horse-owners,"

"Points of the Horse," "Riding and Hunting,"

"Stable Managenent and Exercise," Etc.

WITH TWENTY-FOUR PHOTOGRAPHIC ILLUSTRATIONS

\section{LONDON}

\section{HURST AND BLACKETT, LIMITED}

I3, GREAT MARLBOROUGH STREET

1902

All rights reserved 



\section{P R E F A C E.}

DURING voyages with horses to and from India and to Russia, I often wished to write a book about the management of these animals on board ship for the benefit of men who were new to the work; but I felt I was not competent to do so, because my experience had been restricted to not more than half-a-dozen horses at a time. As my animals had been conveyed in portable horse-boxes, I knew nothing of the special requirements of large numbers of horses in stalls at sea. Fortunately, at the beginning of this year, I obtained veterinary charge of 498 remounts proceeding from England to South Africa, on board the hired cattle steamer Kelvingrove, on which there were thirty-three nondescript men and boys to look after the animals; and after a most instructive passage I returned to England. Wishing to see how things were managed on board ship with troops, I again applied to Colonel Duck, DirectorGeneral, A.V.D., who very kindly sent me in veterinary charge of 248 remounts going to South Africa on H.M.T. Idako, which also carried a large number of infantry and I IO men of the Ioth Hussars. I therefore obtained an insight into both the civil and military methods of horse management at sea. 
The gentlemen to whom I am particularly inclebted for information which has been utilised in the following pages are: Captain O'Neal, of the S.S. Kelvingrove, and his chief officer, Mr. Simpson; Captain Newman, of H.M.T. Idaho, and his chief officer, Mr. Norton; Captain Powles, of H.M.T. Tagus ; Captain RossSmith, Military Landing Officer at Port Elizabeth; Mr. Desmond, who is Chief Government Veterinary Surgeon of Adelaide, South Australia; and Lieut.Colonel Nunn, D.S.O., C.I.E., Deputy Director General of the A.V.D., who has been most kind in furnishing me with various statistics.

The photographs in this book were taken by me, while I was on Government transport duty.

The existence of the South African war is my excuse for giving as much prominence as I have done to military horse transport and allied subjects.

As this book is the outcome of practical experience among horses on board ship, I trust it may be of use to readers who are interested in its important subject.

$$
\text { M. H. HAYES, F.R.C.V.S. }
$$

Authors' Club,

3, Whitehall Court,

London, S.W.

Ist Jamuary', 1902. 


\section{O N T E N T S.}

PAGF:

Ability of Horses to Bear Transit by Sea . I Percentage of Equine Mortality at Sea. . i I Horse-Carrying Ships . . . . . . . I 5 Ventilation . • . . • . . . 37

Preparation of Horses Before Going on Board - 5 I Embariking and Disembarking Horses . . . 56 Portable Horse-Boxes . . . . . . 83 Arrangement of Horses on Board Ship . . IO2 Head-collars and Halters . . . . . IO9 Clothing . . . . . . . . . Stalls . . . . . . . . TYING-UP . . . . . . . . . 135 Stationary Slinging of Horses . . . . I4 I FOOT-HOLD . . . . . . . . . 145 Watering HorSes . . . . . . 149 Feeding Utensils. . . . . . . . 156 Food and Feeding. . . . . . . ${ }_{167}$ Horse Attendants and Stable Duties . . I 80 Mucking-OUt . • . . . • • . 193 Changing Horses from one Stall to Another Stall . . . . . . . 202 Grooming . . . . . . . . . 204 Exercise. . . . . . . 206 Precautions after Disembarking. . . . 208 Cost of Transhort . . . . . . . . 2 I 5 Veterinary REMarks . . . . . . 22 I The War Office and Horse Transport • . 24 I $\operatorname{INDEX}$. . . . . . . . 267 



\section{LIST OF ILLUSTRATIONS.}

FIG.

PAGE

r. Horses in double stalls . . . . . $\quad$ r 9

2. Bow of steamer . . . . . . 4 I

3. Side of steamer . . . . . . 45

4. Gangway . . . . . . 59

5. Disembarking sling . . . . . 63

6. Raising horse out of lighter . . . . 65

7. Disembarking horses . . . . . 67

8. $\quad, \quad$. . . . . . 69

9. $\quad, \quad$, . . . . . $\quad$. 7 I

ı. Landing horse on pier . . . . . 73

I I. Removing slings . . . . . . 75

I2. Portable horse-box . . . . . . $\$_{5}$

13. $, \quad, \quad . \quad . \quad . \quad . \quad 87$

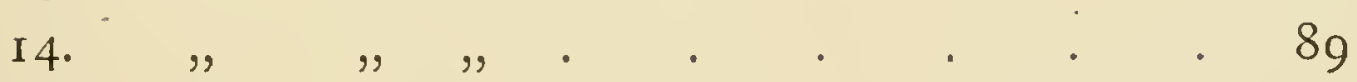

15.,$\quad$, . . . . . . . . . 93

I6. Main deck . . . . . . . 105

I 7. Halter . . . . . . . . I I I

18. Stalls with single breast-boards. . : . I 2 I

19. A round turn and two half hitches . . . I37

20. A slippery hitch . . . . . . 137

2r. A clove hitch . . . . . . . 137

22. Bad type of feeding bucket . . . . 159

23. Vacant double stall, with freeing port . . 197

24. Horse with his tail badly rubbed . . . 23 I 



\section{HORSES ON BOARD SHIP.}

ABILITY OF HORSES TO BEAR TRANSIT BY SEA.

UNDER favourable arrangements and in small numbers, horses bear a sea voyage almost as well as a sojourn in a loose box for a similar period; but their percentage of mortality is generally high when the shipment is large. In this respect, their power of resistance is much less than that of mules; apparently because they are as a rule bigger ; the weight of their bodies, as compared to the strength of their legs and feet, is heavier; and they are not so hardy. 
The history of long distance pedestrianism amply proves that small men greatly excel tall ones in endurance; probably because their circulation is quicker, on account of their heart having to send the blood through a shorter circuit. My experience is that the same rule holds good with horses. The average rate of the pulse of a small pony is about 45 beats in a minute; and that of a heavy cart horse, about 35 beats. Hence the supply of material for repair and development, and the removal of waste and deleterious products are carried on more quickly, and consequently more effectively in the former, than in the latter animal.

The chief artificial habit of the domesticated horse which militates against his well-being at sea, is that of eating grain. Dr. Luff 
Ability of Horses to Bear Transit by Sea. 3

has proved that the mineral matter (ash) of green vegetables aids in the elimination, from the human body, of uric acid, which is the cause of gout, and which is one of the waste nitrogenous products that seriously endanger health if retained in the system; but, that the mineral matter of grain is powerless to effect this good end. Besides, the consumption of grain is productive of a far larger: quantity of waste nitrogenous matter than that of green vegetables. Experience strongly supports the assumption that the mineral matter of green vegetables not only acts on uric acid in the manner stated, but is also an indispensable aid to health in the removal of other deleterious products which are allied to uric acid. Herein, I think, we have the explanation 
of the fact that green fodder and hay are much less "heating" than grain. Exercise, by quickening the circulation and increasing the supply of oxygen to the lungs, greatly assists in the elimination of the hurtful products in question. Hence, although a horse in strong work can remain healthy while consuming a large daily ration of corn, he will be unable to do so, when kept in idleness, as he would be on board ship.

When horses which have been liberally fed on corn are suddenly thrown out of work, their systems will retain for a considerable time an excess of unhealthy material, which evil will be proportionately increased by continuing to give corn. All veterinary surgeons and the majority of experienced horsemen are aware that the combined action 
Ability of Horses to Bear Transit by Sea. 5

of corn and idleness is a fruitful cause of lymphangitis (weed), azoturia, laminitis (fever in the feet), and other diseases. Viewed solely from the standpoint of health, an idle horse should not get any corn, the continued deprivation of which might impair his physical powers to some extent. Consequently, if working efficiency has to be considered as well as health, we may give a small amount of corn, as well as a liberal supply of hay, and, if possible, carrots, which contain the beneficial mineral matter that makes grass, hay, and similar fodder, a necessity of équine life.

Horses, like men, being the product of their surroundings, can accommodate themselves more or less perfectly to new conditions; but the alteration has to be 
made gradually. Also, the greater the change, the longer is the time required to attain this end.

We are all aware that horses have to be previously fed for a considerable time on a liberal amount of corn, in order to make them capable of enduring severe and prolonged labour; but we should not overlook the equally important fact, that corn without hard work is powerless to effect that object. In fact, the more corn they get while they are idle, the longer time will they take to become fit for work, after their period of rest has expired.

While giving full consideration to the shortness of the voyage and the fineness and coolness of the weather, I cannot help thinking that a large proportion of the comparative 
Ability of Horses to Bear Transit by Sea. 7

immunity from loss enjoyed by the Argentine shipments (p. I 2) during the present war, has been due to the fact that they got little or no corn up to their time of landing. I amı, of course, aware that Argentine remounts have done badly, as a rule, in South Africa; the chief reasons for their failure being that they were injudiciously selected, that their food in South Africa was entirely different to that in South America, and that the condition of their feet was neglected (pp. I 47 and I 48).

A point in these considerations which wellto-do English horse-owners (like the majority of our cavalry officers) are apt to neglect, is that although horses of all breeds require corn for severe and continued work, they can, as a rule, do a fair amount of labour on grass alone, and still better on hay, as all practical horse- 
keepers can testify. For instance, it is a common practice among English farmers to use horses at grass for their own trap purposes. As I am now living in the Midlands, I frequently see such animals go ten miles or more to market and the same distance home in a day, at a smart trot, and drawing four or five portly individuals, without any bad effect on the quadruped. Colonial friends tell me that in Australia, men often ride similarly fed animals from thirty to fifty miles in a day without distressing either themselves or their mount. Naturally, the drier grass of the Australian Colonies is better than the moistureladen herbage of Great Britain and Ireland, for enabling a horse to do hard work.

Stuffing horses with corn on board ship, and then expecting them when landed to 
Ability of Horses to Bear Transit by Sea. 9

successfully undergo semi-starvation on a long campaign, is a display of ignorance for which the unfortunate animals and the public have generally to pay the penalty.

The following are the chief favourable conditions for the welfare of horses on board ship :

I. Security of fittings.-I need hardly say that if the fittings, whether of boxes or stalls, give way during bad weather, death or serious accident will be the almost inevitable result.

2. Absence of over-crowding.-Horses are extremely susceptible to the bad effects of over-crowding, even when the ventilation appears sufficiently good for the health of human beings. I am inclined to think that the emanations from the bodies of horses 
have a particularly injurious effect on them and on their fellows.

3. Ventilation of the most ample kind.

4. Good foot-hold.

5. Suitable food and an unlimited amount of drinking water.

6. Facilities for exercise.

7. Facilities for lying down.-This is not of much consequence if exercise can be given. No provisions for allowing horses to lie down or for giving them exercise need be made, if the length of the voyage does not exceed fourteen days.

8. Shortness of voyage. 


\section{PERCENTAGE OF EQUINE MOR-}

\section{TALITY AT SEA.}

Although I can offer no details respecting the death rate of horses carried in small numbers, statistics most kindly furnished to me by the A.V.D. enable me to supply my readers with the following very interesting table, which refers to remounts shipped to South Africa from various countries, from November, I899, to July, I90I. Unfortunately, it is only an approximation; because, in many cases, reports of several shipments were not sent in to the War Office or were imperfect. Their omission does not materially affect the 
averages I give, considering the large number of instances upon which they are based.

Table of Mortality of Remounts Shipped to South Africa FROM NoveMBER, I899, TO JULY, I9OI.

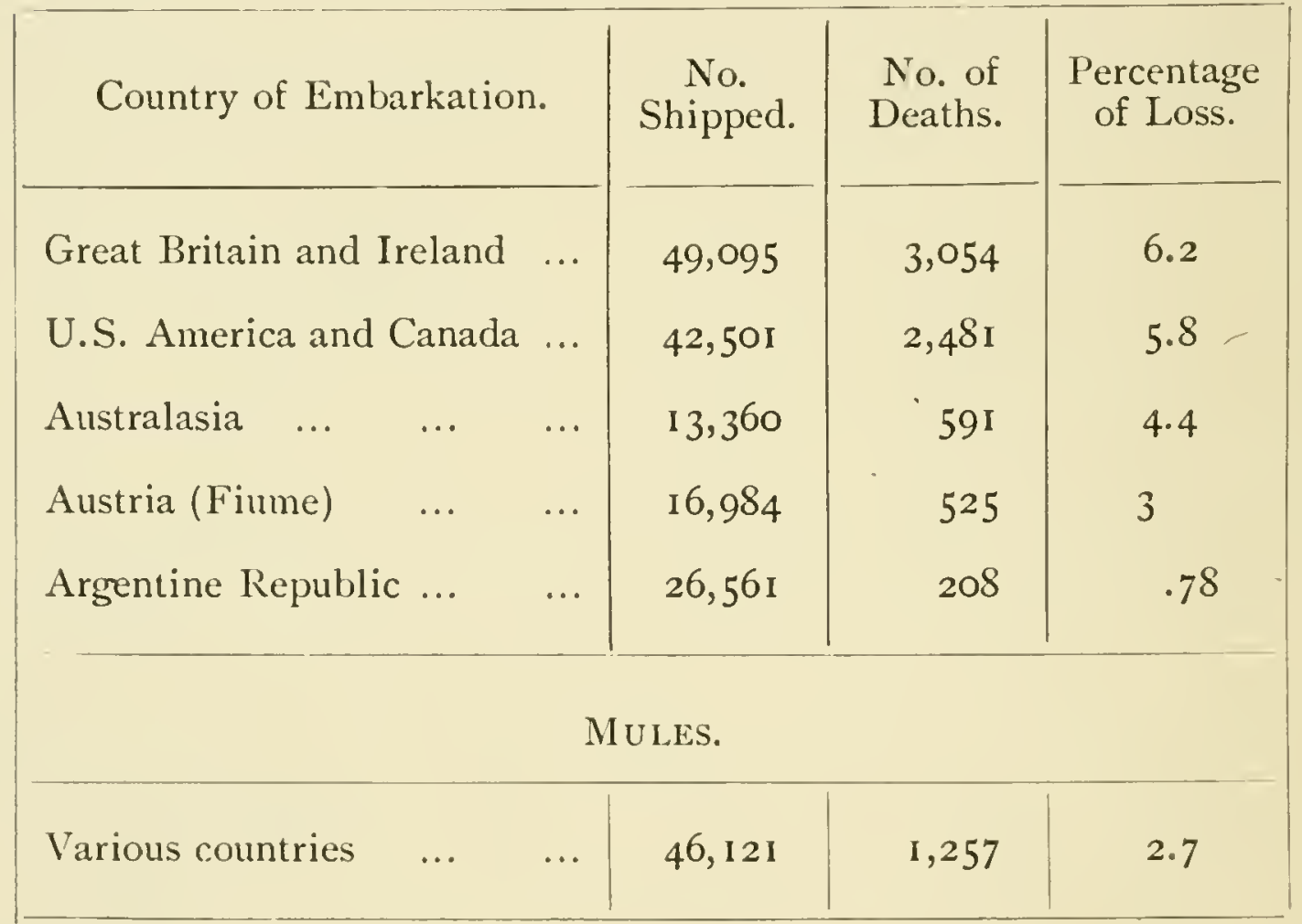

In comparing these figures, we should bear in mind the following points :-

I. Horses going to South Africa from Australasia and the Argentine Republic have not to pass through the tropics, which is a serious 
Percentage of Equine Mortality at Sea. I 3

danger that animals proceeding from Europe and North America have to encounter.

2. Horses embarked at Fiume escape the perils of the Bay of Biscay and Portuguese coast, to which those leaving Great Britain and Ireland are subjected.

3. The length of the voyage from Buenos Ayres to Cape Town is only about half that from England.

4. Usually the weather is finer on voyages from Buenos Ayres and Australia to South Africa than from England and North America (New Orleans and Montreal). 
The following instances of successful voyages are well worthy of honourable mention :-

\begin{tabular}{|c|c|c|c|c|c|}
\hline \multicolumn{2}{|l|}{ Name of Ship. } & \multicolumn{2}{|c|}{$\begin{array}{c}\text { Country of Embarka- } \\
\text { tion. }\end{array}$} & $\begin{array}{c}\text { No. } \\
\text { Shipped. }\end{array}$ & Loss. \\
\hline Surrey $\quad \ldots$ & .. & South America & $\therefore$ & 938 & nil \\
\hline Hyson & .. & Australia & $\cdots$ & 533 & I \\
\hline Iona... & ... & Austria & $\ldots$ & 760 & 4 \\
\hline Mount Royal & .. & North America & ... & 464 & 3 \\
\hline Cymric & ... & England & ... & $44 \mathrm{I}$ & 3 \\
\hline Fremona (Mules) & $\ldots$ & Italy (Naples) & $\ldots$ & 1,000 & I \\
\hline
\end{tabular}




\section{HORSE-CARRYING SHIPS.}

ONLY steamers will be considered in the following observations, because sailing vessels do not travel with sufficient speed and punctuality for modern horse requirements.

Ships vary in type according to the purpose for which they are built. Walton, in his instructive book, Know Your Own Ship, points out that the greater the weight of the cargo as compared to its bulk, the more severe will be the bending and twisting strains experienced at sea, and hence the greater necessity for increased structural strength. The three-decker is the strongest 
type of marine weight carrier. In a fairly large three-decker, the deck which has bulwarks is called the main deck; the deck below it, the 'tween deck; the next deck, the orlop; and the lowest deck, the lower hold. A ship with one deck less would have a main deck, 'tween deck, and lower hold. The orlop is generally the store deck. The space between any two adjacent decks is called 'tween decks.

The spar-deck type of steamer is of lighter construction than the three-decker, because she is designed to carry cargoes of less specific gravity. On these steamers, the deck which has bulwarks to keep water off it, is called the spar deck; and the deck below it, the main deck. Large spar-deck steamers have an upper 'tween deck below 
the main deck, and a lower 'tween deck or orlop below the upper 'tween cleck. In the Atlantic cattle trade, the spar deck is often called the cattle deck.

The foregoing names of decks are generally used in horse-carrying ships. Large passenger steamers have several decks. The Celtic, for instance, has the captain's bridge, promenade deck, boat deck, upper bridge deck, bridge deck, main deck, upper deck, middle deck, lower deck, orlop deck, and lower orlop deck.

In cattle steamers, which are generally used for the conveyance of large numbers of horses, the spar deck or main deck (in a three-decker) is usually protected by an awning deck, which is of comparatively light construction, and is, of course, the upper- 
most (exposed) deck. As it is considered to be too weak to carry cargo, it is not included in the registered tonnage of the ship, and is therefore not looked upon as a regular deck. The policy of excluding the awning deck from tonnage computation, is explained by the fact that the lower the registered tonnage, the lighter will be the dues. In cattle steamers, the awning deck is usually called a shelter deck, or a shade deck; the only difference between these two kinds of decks being the amount of ventilation provided by openings in the sides of the respective ships, between these decks and the deck immediately underneath them. A shade deck affords more ventilation to the deck it covers than a shelter deck, and is therefore used in cattle ships which have to 


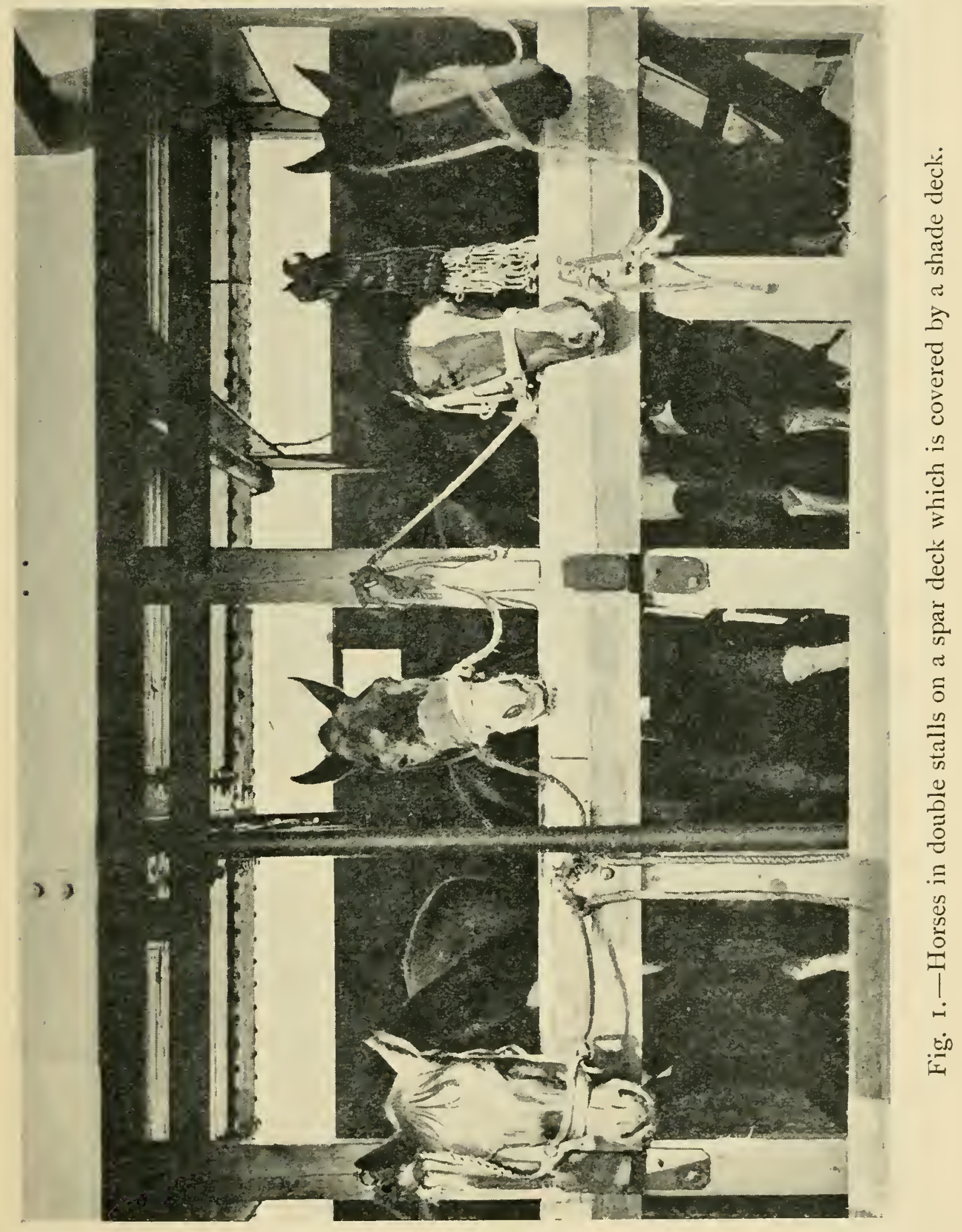



encounter tropical weather, such as that met with by steamers trading between South America and England. The horses shown in Fig. I are standing on a spar deck which is covered by a shade deck, as we may see by the presence of openings above the heads of the animals. Almost all the big Atlantic lines have three-deckers furnished with a shelter deck for the cattle trade.

As a rule, cattle steamers are the best for the conveyance of large numbers of horses, because they generally have large ports on the spar or main deck (Figs. 3 and 4), according as the steamer is a spar-decker or three-decker. The presence of these ports will naturally promote good ventilation - (p. 37 et seq.), which is one of the most 
important points in horse-carrying ships; and besides it will facilitate mucking-out (p. 193). Freeboard is the term applied to the height of the sides of a ship above the waterline at the middle of her length, measured from the top of the deck at the side, and is a margin of safety given to a vessel (Walton). The comparative amount of freeboard allowed by the Board of Trade to a ship is inversely proportionate to her structural strength. Hence, as a rule, a fully-laden spar-decker would have more freeboard than a fully-laden three-decker.

Stability (righting leverage) is the power a ship has of righting herself when inclined out of the upright position by some external force or forces, such as, for instance, wind and waves; and it depends chiefly on her 


\section{Horse-carrying Ships.}

width of beam and on the fact of her centre of gravity being low down. The term stiff is applied to a ship which has a good deal of stability, and is the opposite of tender.

A ship which rolls comparatively little is said to be steady or easy (slow roller) in a sea way.

Walton tells us that the stiff ship is generally the one which rolls most, and that a steady steamer is usually tender. The man-o'-war, The Captain, whose great want of stability was the cause of her loss by upsetting, was remarkably free from rolling under ordinary circumstances. Also, it has been noticed in the case of a lightship that she rolled much less at night, when her lantern, which weighed several hundredweights was hoisted up on her mast, than by 
day, when it was kept on her deck. The high masts which many steamers formerly carried, decreased their stiffness, and also their tendency to roll. Bilge keels check rolling to a considerable extent, but without affecting the stability of a ship. They usually vary in depth from one to two feet and extend for about two-thirds of the length of a ship.

The class of ship required for the transport of horses greatly depends on the number of animals. In all cases speed is an advantage, for it reduces the length of the voyage, and the consequent ill-effects of a sea journey on the equine passengers. An average speed of 240 miles a day may be taken as a minimum; supposing that the voyage is not less than 6,000 miles long. 
If a choice of position on board be available, any ordinary steamer (a mail boat for preference) will do for the carrying of a few horses, especially if they be taken in portable boxes (p. 83). Therefore, the observations I am going to make on horse ships will refer chiefly to those which are intended for the conveyance of large numbers of horses, in which case the animals will be in stalls as a rule. The carrying. of horses in pens, which are generally used in place of stalls for mules, is so exceptional that I need not consider it here.

In a well-deck ship, the deck which is provided with bulwarks is the exposed deck, and such a steamer is, therefore, not so suitable for the carrying of horses as it would be if it were protected by a shade or shelter deck. 
In all well-deck ships and those that have shade or shelter decks, the deck with bulwarks has freeing-ports, which are rectangular openings made in the bulwarks for freeing the deck from water shipped during rough weather. A ship with a fursh deck has no bulwarks, and consequently does not need freeing-ports, because her exposed deck offers no impediment to the escape of water over the side. In Fig. 23, p. 197, a freeing-port may be seen in the vacant double stall.

A well-deck ship which has a high stern, bridge and bow, is sometimes called a three island ship.

It is a great advantage for a steamer which is carrying horses below, to be light in the water, so that she may be as free as possible from the danger of shipping 
heavy seas; for if she begins to do this, the hatches (of the spar deck, for instance) will have to be put on, and the horses which are thus deprived of fresh air will be rapidly suffocated. Also, if any horses are on the exposed deck, they will be liable to be washed overboard.

A steamer taking a full complement of horses, would naturally be more unsteady than a carefully loaded cargo boat; because the greater part of her weight would be below the lower deck. Thus, a ship of, say, 3,000 tons gross, taking horses for a voyage of a month's duration, would probably have in her hold at the time of sailing, I, 000 tons of water and 2,000 tons of coal and fodder.

For purposes of stability and for the comfortable carriage of horses, a steamer should 
not as a rule be less than 44 feet in the beam. Her accommodation in this respect will depend to a certain extent on the size of her hatches; for the larger they are, the less space will there be for the stalls which face them.

The presence of large hatches are a necessity for the well-being of the horses on board, both for purposes of ventilation and for providing spaces which can be utilised for standing horses on, as a temporary measure, as in cases of sickness, or when mucking out.

Considerable width of beam is of great advantage, in the event of the extra space not being fully taken up by mid-ship stalls; not only for purposes of ventilation, but also to admit of horses being exercised, and readily shifted. 
A cargo of 600 horses would, as a rule, be a full complement for a steamer of 3,000 tons gross, in which case she would require to have a shade or shelter deck that would be more or less occupied by horses, as well as stalls on two decks below. As an increase of gross tonnage does not give a corresponding increase of length to a ship, a large steamer will not be able to take a proportionately greater number of horses than a smaller one. For instance, a ship of 4,000 tons gross would probably be able to take only about I 20 horses more than a ship of 3,000 tons. As a rule, 1,000 horses would be a full cargo for a steamer of 9,000 tons gross. Of course a large Atlantic cattle boat of, say, $5^{6}$ or $5^{8}$ feet beam, would be able to carry on some of her decks a row of 
stalls more than a steamer of 44 or 45 feet beam.

"To ascertain roughly the number of horses that can be carried on a deck, cut off all parts where there is less than I 2 feet clear out from the ship's side, and the remaining length in feet divided by three will give the number of horses that can be taken, allowing for spare stalls." (Regulations for H.M. Transport Service.) This estimate is made on the supposition that each horse is allowed $2 \mathrm{r} / 2$ feet, including the thickness of the division boards.

All alley ways (bridge spaces) and other passages over which horses may have to pass, should be covered with boards; for if this be not done, a horse will be apt to slip and fall, if his feet come in contact with the iron deck. 
Even if matting be put down on an iron deck, a horse may easily get off it, especially if he be fidgetty or weak on his legs, or if the ship is rolling.

There should be at least $7 \mathrm{~T} / 2$ feet from deck to deck, of which space 4 inches will be occupied, according to Government regulations, by a one inch flooring laid on scantlings 3 inches by 3 inches. The overhead iron beams will be 8 or 9 inches in depth. No passage for a horse to go through should be less than 6 feet in height. This minimum will be met with as a rule only at bunker hatches in alley ways.

It is an advantage for the exposed deck to be covered with wood, which being a bad conductor of heat, will prevent the iron deck from becoming unduly hot, and thus raising 
the temperature of the atmosphere underneath it.

Captain Ross-Smith tells me that "concrete should never be used on horse decks, because it cuts up easily and forms pit-holes, into which urine settles, and the deck then becomes foul and difficult to be cleaned. Scuppers on horse decks are generally much too small, and consequently they often become blocked up. They should be about 15 inches in diameter, and they could then be fitted with air scoops, so as to promote ventilation. Brows (p. 6r), if employed, should run fore and aft, and not thwart ship. Electric lights should be provided on all horse decks, with connections and plugs at frequent intervals, so as to avoid the use of a small lamp attached to the end of a long insulated wire, which almost invariably 
gets caught in some object, and then becomes more of a danger than a convenience. The best type of steamers I have seen for carrying large loads of horses, are the European, Michigan, Magician, and Politician, all of which could carry more than a thousand horses comfortably. There is no better type of ship for the conveyance of horses and troops than the Victorian. A great advantage which these big liners possess, is that they are capable of steaming $\mathrm{I}_{3}$ knots an hour with the comparatively small consumption of from 45 to 60 tons of coal a day; and besides, their carrying capacity is enormous."

Captain Ross-Smith is the military landing officer at Port Elizabeth, and has had an immensely large experience in the inspection of horse-carrying ships. 
The ordinary type of mail steamer, however well adapted it might be for the conveyance of horses on its exposed deck, would not have sufficient ventilation for carrying large numbers of them below.

For purposes of ventilation, it is an advantage to have-as in the case of some modern built steamers-no bulk-heads on' the upper deck (the spar deck for instance). Lloyd's rule renders it imperative to have bulk-heads on all the lower decks.

On steamers intended for the carriage of horses, mooring bits should be present only on the exposed deck; for if they be also on the deck under it, they will more or less block up the passage in front of the stalls near which they are placed, and will thus cause inconvenience when horses are led past them. 
All decks which carry horses, and which are below the exposed deck, should be kept perfectly dry, so that the hay which happens to fall out of the hay nets or feeding troughs may not become wet, the decks slippery, and the dung saturated with water. With this object, no cook houses or washing houses should be allowed on these decks.

A ship painted white is cooler when exposed to the rays of the sun than a similar ship of a darker colour, because white objects reflect light better than darker ones. The rays of the sun consist partly of rays of heat, and partly of rays of light, the latter being converted into the former when they fall on an object which does not reflect them.

If a ship is rolling so much as to endanger the safety of the horses on board, she should 
be put head to sea and her speed reduced. Running in the trough of the sea will of course make her roll. When a ship is steaming against a head sea, the faster she goes, the more violently will she pitch. In such a case her speed should be diminished, if the pitching be dangerous to the horses. As a rule, a long ship will not pitch so much as a shorter one. 


\section{VENTILATION.}

WITH reference to cold and temperate climates, we may define ventilation as the process of removing foul air and substituting pure air for it. In very hot weather, not only is this change of air necessary, but we must also, if posssible, produce currents of air, the velocity of which should be proportionate to the atmospheric heat, so as to utilise the cooling effect of evaporation from the skin. Hence we find that draughts, which are justly regarded in English stables as a frequent cause of disease, are essential to the health of horses, for cooling them down, 
on a voyage into the tropics. On board ship, the removal of foul air has to be more rapid as a rule than on land; because at sea, the injurious emanations from the excreta and bodies of the horses are supplemented by those from the cargo, and mucking-out is more difficult than on land. As the sides of a steamer are of iron, and are unprotected by the shade of trees, etc.; a ship as a rule is a much hotter abode than an ordinary stable in the same latitude, and consequently it requires better ventilation. Also, in the case of a large number of horses, economy of space has to be practised far more at sea than on land. These considerations point to the necessity of obtaining the freest possible ventilation on board ships which have to encounter hot weather. This of course 
cannot be done, unless the construction of the ship is favourable, which is a subject outside the scope of the present remarks. Respecting very free ventilation, I can state that horses I have taken to Revel, vi $\hat{a}$ the North Sea and Baltic during winter, suffered no ill consequences from a ten days' sojourn on an exposed deck with their heads uncovered, while the thermometer at times went several degrees below zero Fahrenheit.

Although the principles of ventilation are the same on board ship as on land, the details necessary for carrying them out, vary to some extent, especially as regards the establishment of inlets and outlets for air. As a rule we may assume that the atmosphere inside a ship is warmer than that outside her, and consequently the tendency 
of the inside currents of air will be to ascend. At the same time we must bear in mind, that the comparatively high specific gravity of carbonic acid gas will tend to cause that gas to accumulate in positions which are low down and ill-ventilated. When the wind is blowing in a direction parallel to the sides of a ship, it will tend to draw air out of all port-holes and freeing ports which are unprovided with air-scoops; but when it impinges on the side, or when it is directed inwards by an air-scoop, it will naturally tend to force its way into the ship, and will thus convert these openings into inlets. Air-scoops (p. 44) can be utilised with advantage in various ways.

Hatchways act both as inlets and outlets. Dividing them vertically by means of a 


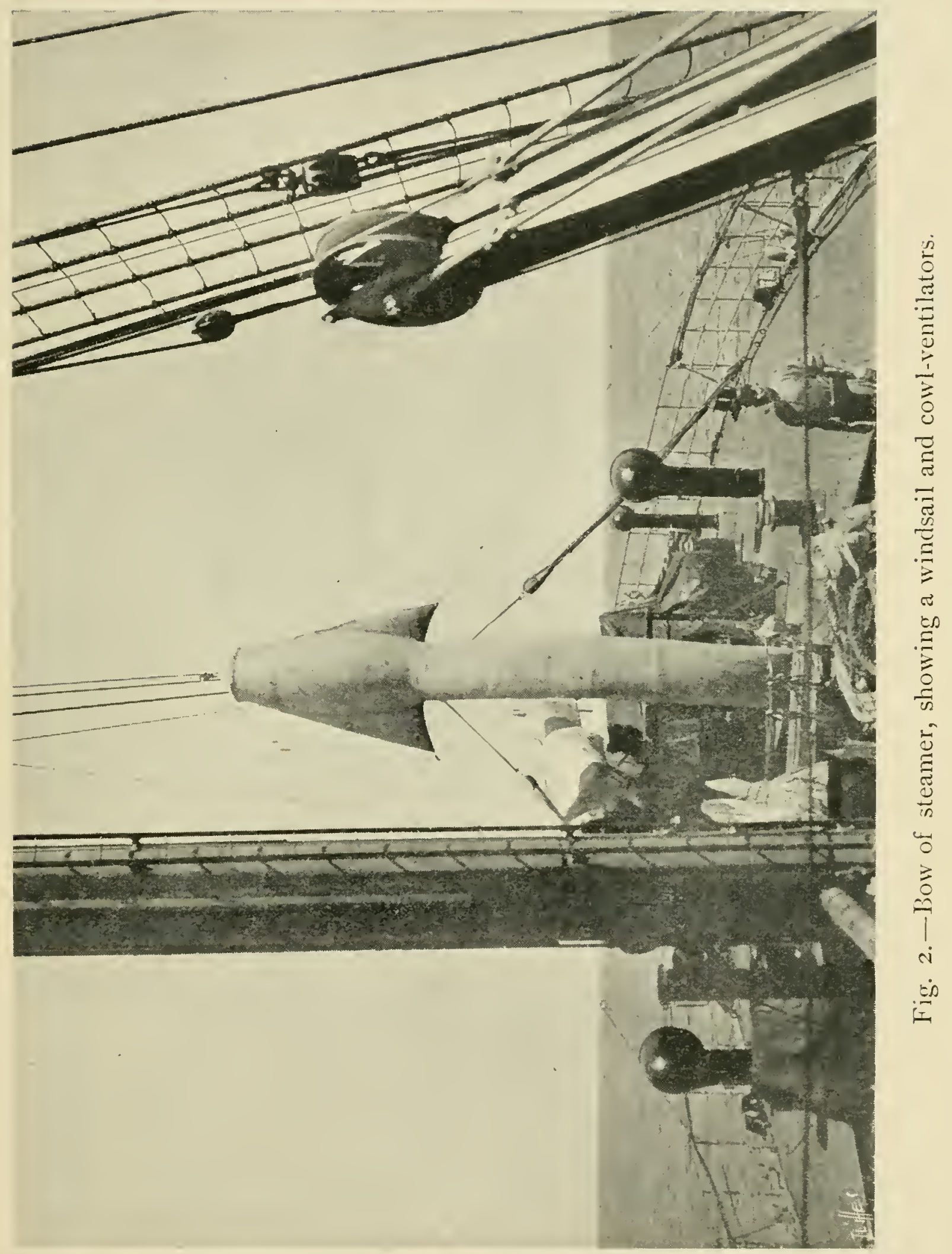



canvas sheet or other suitable material will often greatly help them in performing this dual office.

The chief mechanical means by which ventilation on board ship is facilita:ed, are : Windsails, air-scoops, ordinary cowl ventilators, steam ventilators, and electric ventilators. Windsails and cowl ventilators are shown in Fig. 2. As a rule, a windsail is only an inlet, and should therefore be kept trimmed towards the wind. It is generally used to ventilate hatchways. Its diameter should not be less than 30 inches, and its lower end should be kept at about a foot above the deck it is supposed to ventilate. When a horse which is standing on or near a hatch, requires more fresh air than he is getting, a windsail or two may be trimmed on him. 
Air-scoops are almost always used with port-holes and scuttles, in which case they are made of sheet iron, are about 20 inches long, and look like a tube cut longitudinally in two, blocked in at one end and furnished at the other end with a rim which fits into the port-hole. Openings in the side (generally on the main deck, or on the spar deck, according to the type of ship) may be provided with air-scoops, either by means of the door of the opening (Fig. 3) or by boards. Air - scoops being inlets should of course be kept trimmed towards the wind. In Fig. I8, p. I $2 \mathrm{r}$, an air-scoop may be seen out of use, below the scuttle (small port-hole).

The usual form of a cowel ventilator is that of a vertical iron tube provided with a 


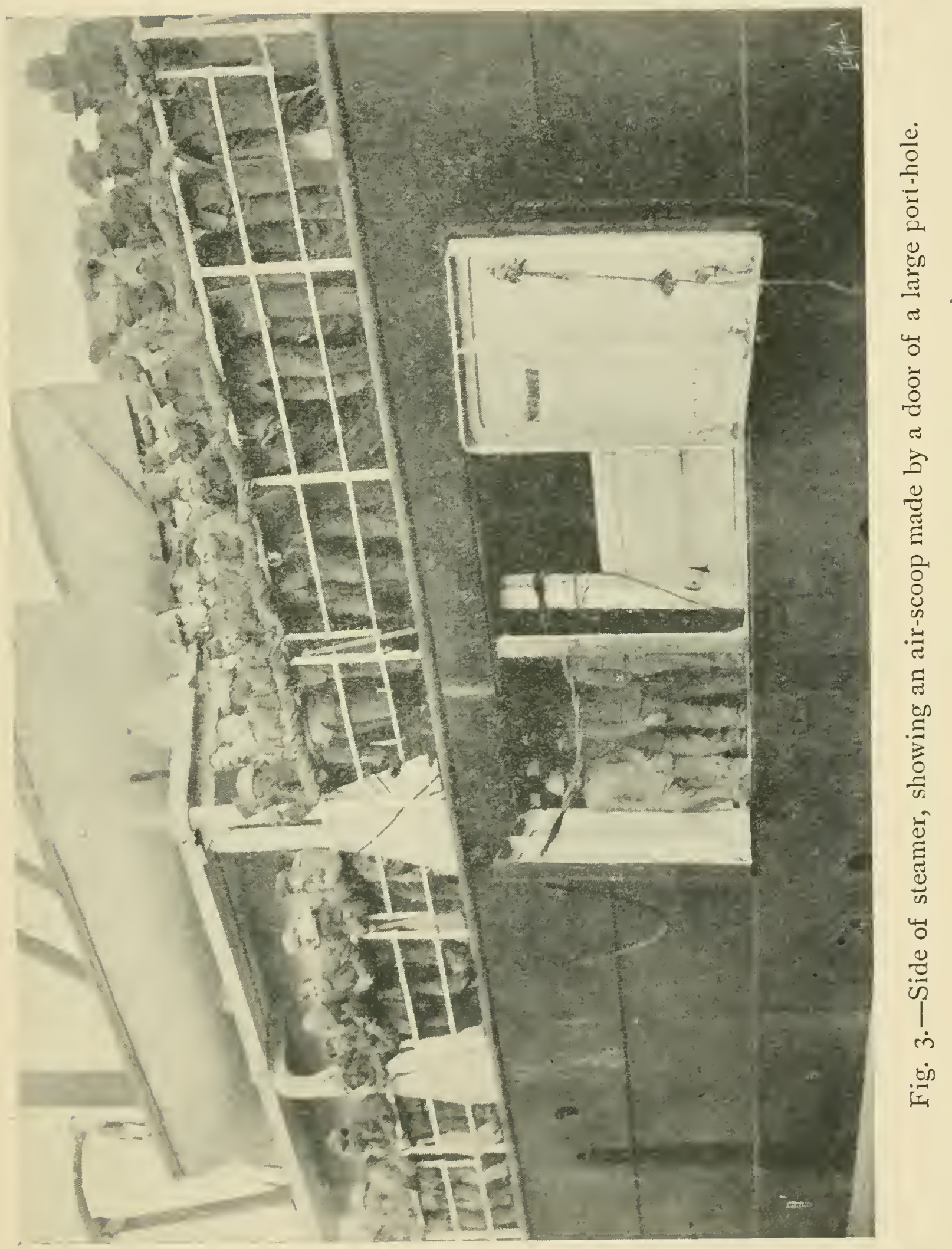



large cowl, which forms an effective inlet when it is kept trimmed to the wind. If the cowl is turned in a direction opposite to that of the wind, it will generally act as an outlet. We may, often beneficially employ one of two adjacent ventilators in the former way, and the other in the latter manner. Cowl ventilators are sometimes provided with an arrangement which prevents water going down them, but which offers no impediment to the entrance of air.

Exhaust fans are worked either by steam or electricity; the latter being the better form of propelling force, because its conducting wires are free from the objection possessed by the pipes which convey steam, of raising the temperature of the stalls near which they pass, and of thus endangering the health of 
the horses which occupy these stalls, during hot weather. Also, these pipes often leak.

A steam ventilator or an electric ventilator usually consists of a vertical iron tube, inside the upper end of which there is a fan that can be employed for promoting either an ascending or a descending current of air; the former being, as a rule, much the better. ventilating method. The tube, which is from 20 to 36 inches in diameter, projects above the exposed deck, through which it passes, and extends in a vertical direction below. At its full length, it passes through the lowest deck but one, and can then be used to ventilate the lowest deck. By shortening this tube, we can make it ventilate any deck above the lowest deck, and below he exposed deck. These exhaust fans 
are efficient, not only for removing contaminated air, but also for promoting draughts which will have a cooling effect on horses during hot weather. They are of special use in a calm, or when there is a light wind aft, the velocity of which is about equal to that of the steamer; or at anchor when no wind is blowing, in which case during tropical heat it might be advisable to keep the ship moving, so as to promote the circulation of air through her. It is evident that the smaller the area of the openings in the side of a ship, the more useful will be the action of these fans. Of course they cannot produce a good result unless they are kept revolving at a high rate of speed. In a poor class of ship, the transference of power from the engines to the fans might diminish 
the progress of the ship, when she is at full speed. In any case, the working of the fans will entail an increased expenditure of coal, especially when they are kept at full speed, and consequently this method of ventilation is not usually regarded with favour by masters and chief engineers who are forced by their employers to practise rigid economy. Dr. Edmond's system of obtaining an outlet for ventilation by means of a "steam jetter" placed inside a cowl ventilator, acts well. When there is a strong breeze, the steam can be shut off, and the cowl of the ventilator trimmed to the wind, in which case the ventilator will torm an efficient inlet. The steam in the boiler should be kept at a pressure of at least 4olbs. 


\section{PREPARATION OF HORSES BEFORE GOING ON BOARD.}

IF broken-in horses are taken fresh off grass, or if the duration of the intended voyage is not supposed to be longer than, say, ten days, little or no preparation will be required as regards food and exercise. On a longer journey and proportionately to its duration, corn-fed and hard-worked horses-agreeably to the remarks made on pages 2 to 9 should have their corn and exercise gradually diminished, so as to prepare them as thoroughly as possible for their new conditions of life, under which, hay and roots will 
be their most healthy food. I need hardly say that the keeping qualities of green grass are not sufficiently good to admit of its use at sea, and consequently dried grass (hay) is employed. If the animals in question have a voyage of about a month's duration in front of them, I do not think that they should have less than a fortnight's preparation.

I am informed that horses which have been brought up in a wild state and which have never been handled, suffer far more from the effects of their new surroundings on board ship, than animals which are accustomed to stable life. Hence it is well, for at least ten days or a fortnight previous to embarkation, to stable and handle these animals, to teach them to feed out of mangers and to drink out of buckets, and to accustom them to be tied up. If 
stable accommodation cannot be procured, it is advisable, if practicable, to tie them up, and feed and water them for a similar period in the open, or in stock yards, kraals, or paddocks. I am told that Australian shippers who send horses to India act on this principle.

If the journey is likely to extend to three weeks, or longer, the heels of the fore feet should be lowered, supposing that they are of the ordinary height, so as to reduce to some extent the weight on the toes, and thus to diminish the danger of laminitis (fever in the feet), which, on board ship, is a disease that is almost entirely confined to the fore feet. The fore shoes should be replaced, in order to prevent the animals wearing down the fore feet by pawing in their stalls or boxes, which they are very apt to do from im- 
patience, and particularly when anticipating being watered and fed. Under ordinary conditions it is generally advisable to remove the hind shoes and keep them off during the voyage, so as to lessen the risk of horses breaking their stall fittings and injuring their companions, especially if the animals have to be unloaded into a lighter (p. 78). Besides, if the fittings of a stall are not correctly made, a horse, when kicking, may get hung up by a hind leg. My experience is that if a horse is barefoot behind, he will be much less apt to kick than if he was shod behind. With remounts during warfare, the question of efficiency soon after landing and the difficulty of shoeing a large number of animals would naturally outweigh the advantage to be obtained from decreased liability to accidents from kicking, 
which are seldom of a serious nature. Hence, the hind shoes of such animals should not be taken off as a rule, and they should have new shoes put on their feet before being sent on board. We have also the fact that if the floor cannot be kept dry, the feet of unshod horses standing on it will suffer much more from thrush and rotting of the sole, than those of shod horses under similar conditions.

Horses, before leaving a cold or temperate climate, especially in winter, to be carried into a hot one by ship, should be clipped, unless their coats are quite short; for, as a rule, there would be great difficulty in using the machine on board. Also, care should be taken that the sheaths of the animals are clean before embarking them. 


\section{EMBARKING AND DISEMBARKING HORSES.}

Besides the advisability of a "cooling down" preparation (p. 5I), it is well to keep horses without food and water, for, say, three or four hours before taking them on board, in which case a drink and a feed soon after they have been shipped will help to reconcile them to their new place of abode. Also, when their stomach and intestines are comparatively empty, they will not be so liable to become injured, as they would be, if full of food, especially if they are slung. Each horse should be provided with a stout halter or 
head-collar, to which is attached two strong ropes to act as leading reins. A bridle (snaffle) is necessary only when a horse has to be walked on board; but even in that case, a halter or head-collar will almost always be sufficient.

Mr. Desmond, G.M.V.C., draws my attention to the fact that in hot climates, horses should be put on board last, so that the interval between their embarkation and the sailing of the ship may be as short as possible. He tells me that the horses belonging to the contingent of South Australian Imperial Bushmen, with which he came over from Adelaide to South Africa, were put on board first, and had consequently to wait for twenty-four hours without a breath of air to cool them; the result being that ten per cent. of the animals 
were attacked with pneumonia during the first three days.

Horses, when it is practicable, are best taken on board or disembarked by means of a gangway (Fig. 4), the gradient of which should be easy; and the floor should be covered with cocoanut matting or other suitable material so as to afford the animals secure foot-hold. Colonel Nunn tells me that "the sides of the gangway should be high enough to prevent horses seeing over them, and consequently getting frightened at strange sights about the ship, in the docks, or on the shore. Gangways should not have a roof, because horses, as a rule, object to go into a tunnel. Mules will usually walk up a gangway by themselves, if some soiled bedding and dung are spread over it, and 


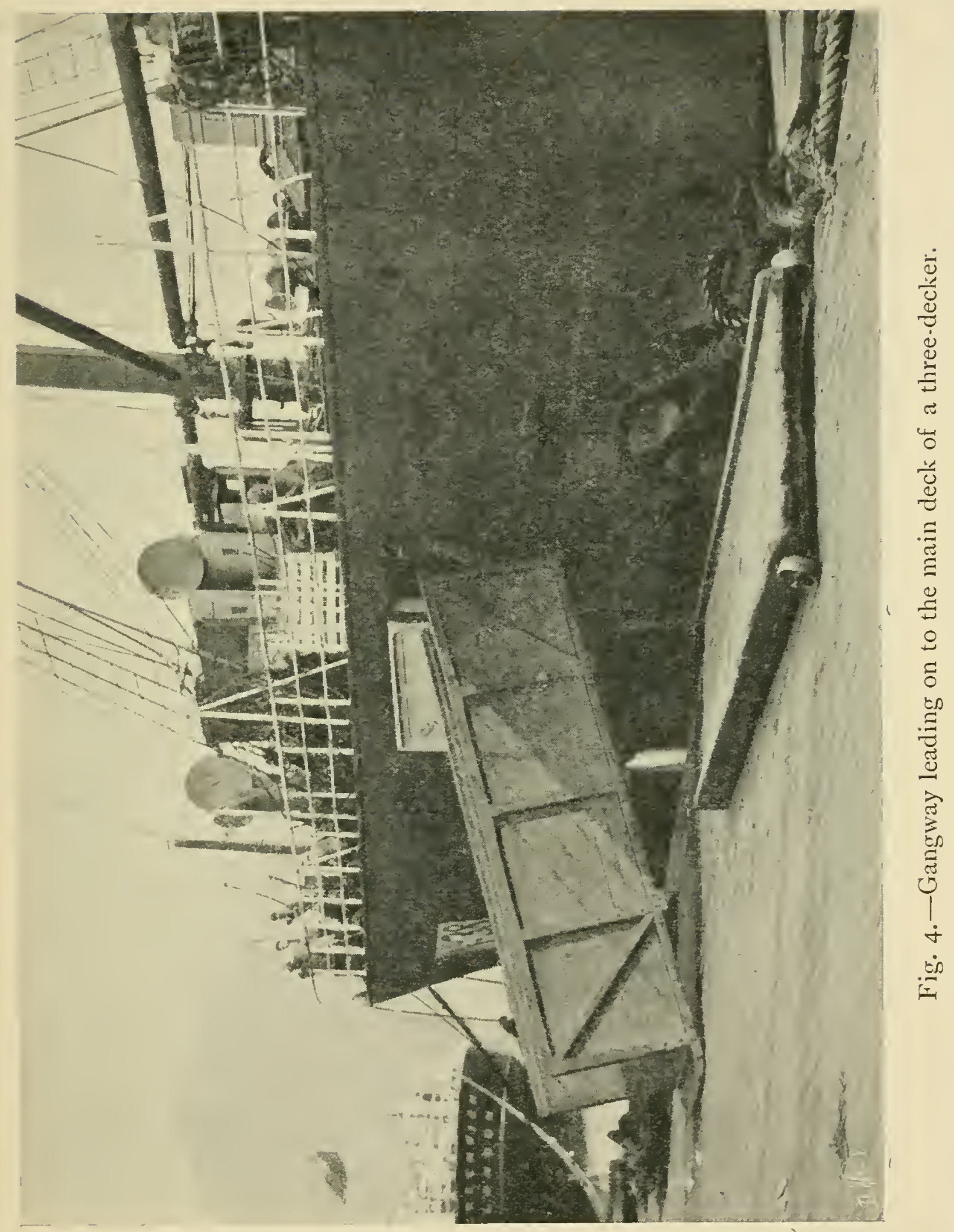



Embarking and Disembarking Horses. 6 I

if they are allowed time to put down their noses and smell the litter. I obtained this useful hint on board a ferry boat in the Punjab."

Gangways which are employed for the transit of horses from one deck to another deck are called brows.

In default of a gangway, horses may be conveyed into or out of a ship by means of a crane or derrick, either in slings or in a portable horse-box (p. $\left.8_{3}\right)$. For this purpose, hydraulic cranes are the best. They work much more smoothly and with far greater precision than steam winches, which are the moving agents of derricks. They have the great advantage of being free from noise, which in the case of winches, is often a cause of alarm to horses that are in their 
vicinity. Hydraulic cranes are to be found only on steamers of good class.

For slinging horses during embarkation or disembarkation, it is essential that the boom of the derrick or jib (projecting arm) of the crane should be sufficiently long to prevent the animal touching the side of the ship or coamings of the lighter into which he may be lowered. Also, he ought to be raised high enough to avoid letting him touch the deck, by doing which, he is liable to get injured.

The process of slinging is employed not only for taking horses on board and putting them over the side, but also for raising and lowering them from one deck to another deck. In lowering a horse from one deck (generally the exposed deck), it will be necessary to lower him on to the hatch; but in bringing 


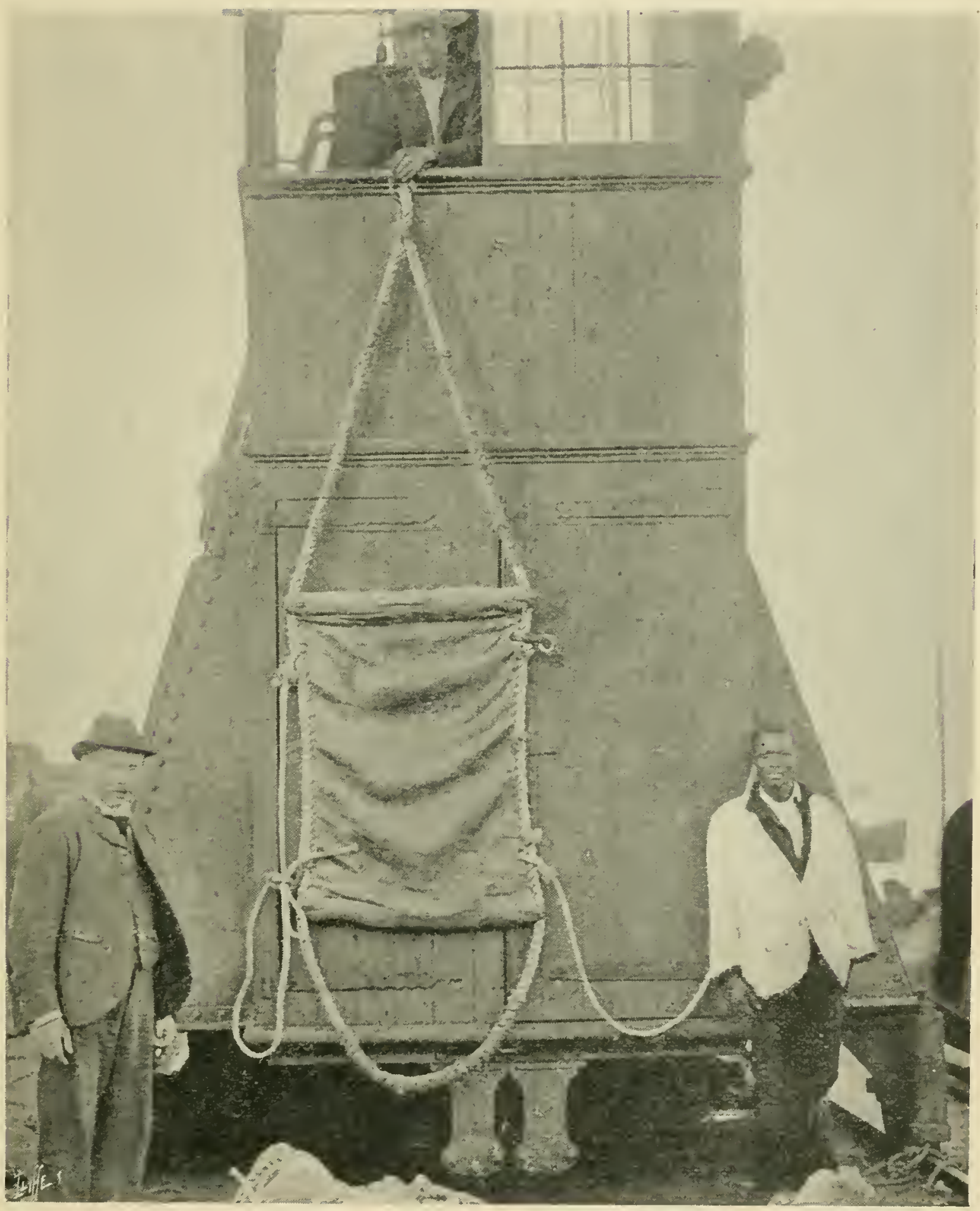

Fig. 5. - Disembarking sling used at Port Elizabeth., 



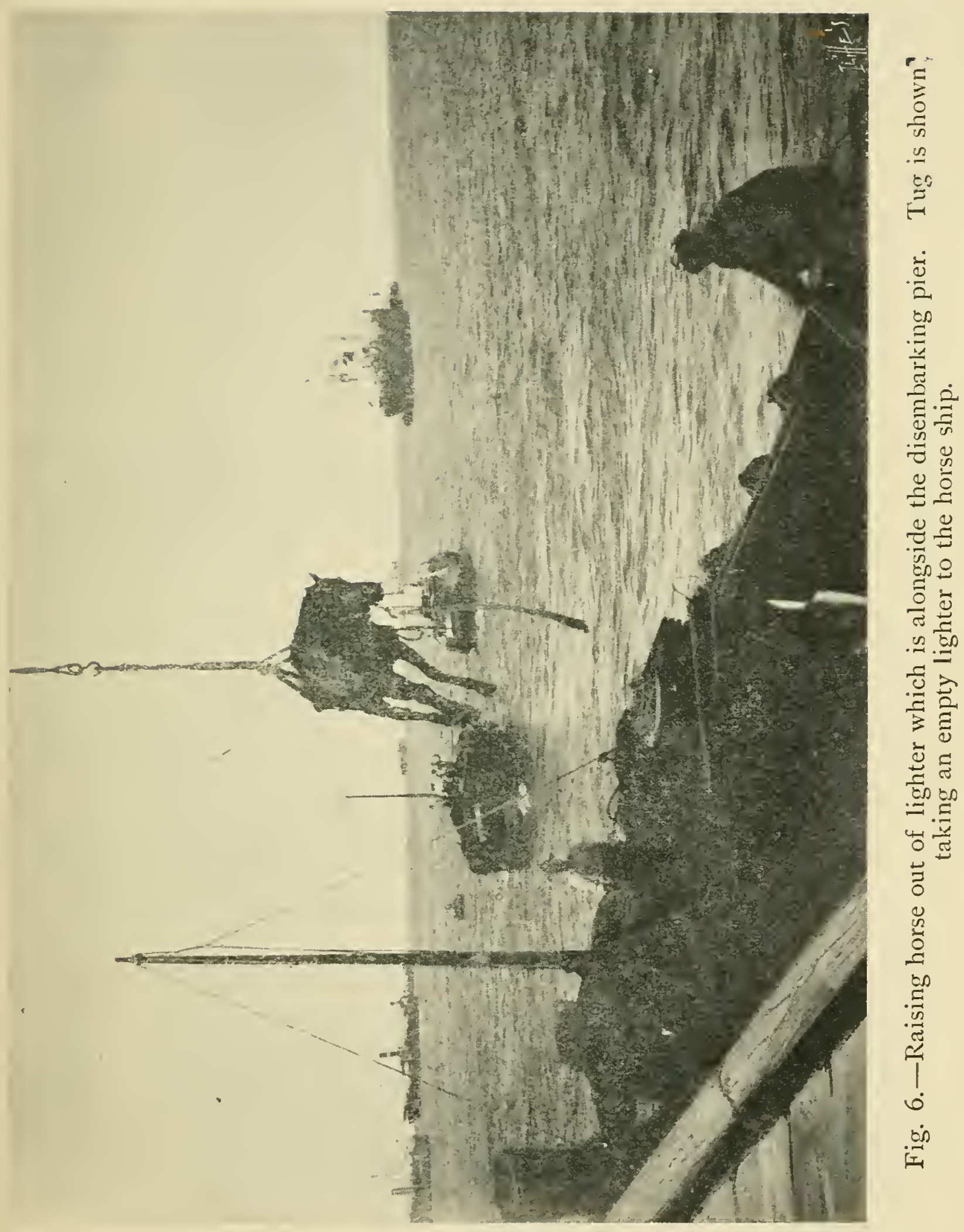





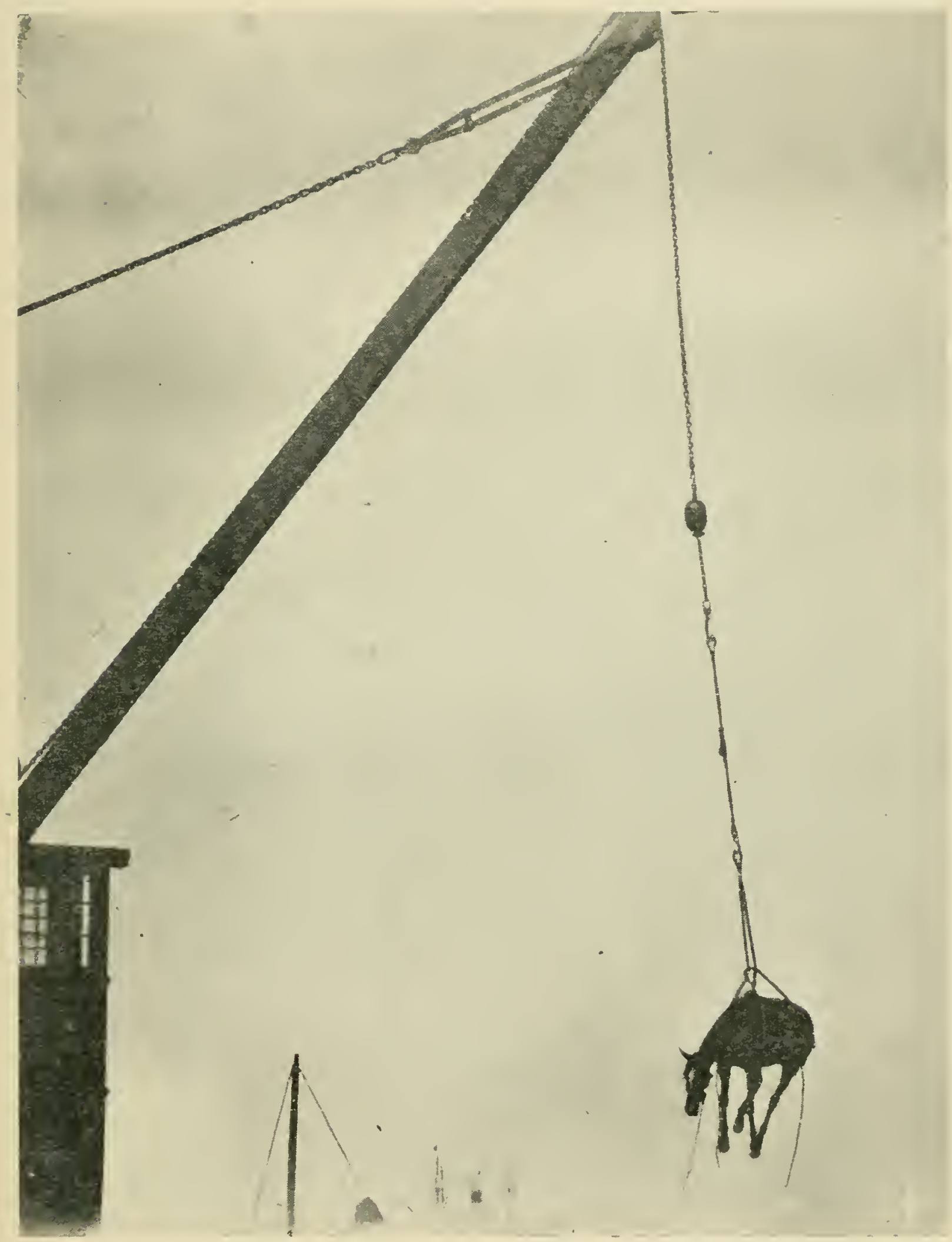

Fig. 7.-Disembarking horses at Port Elizabeth. 



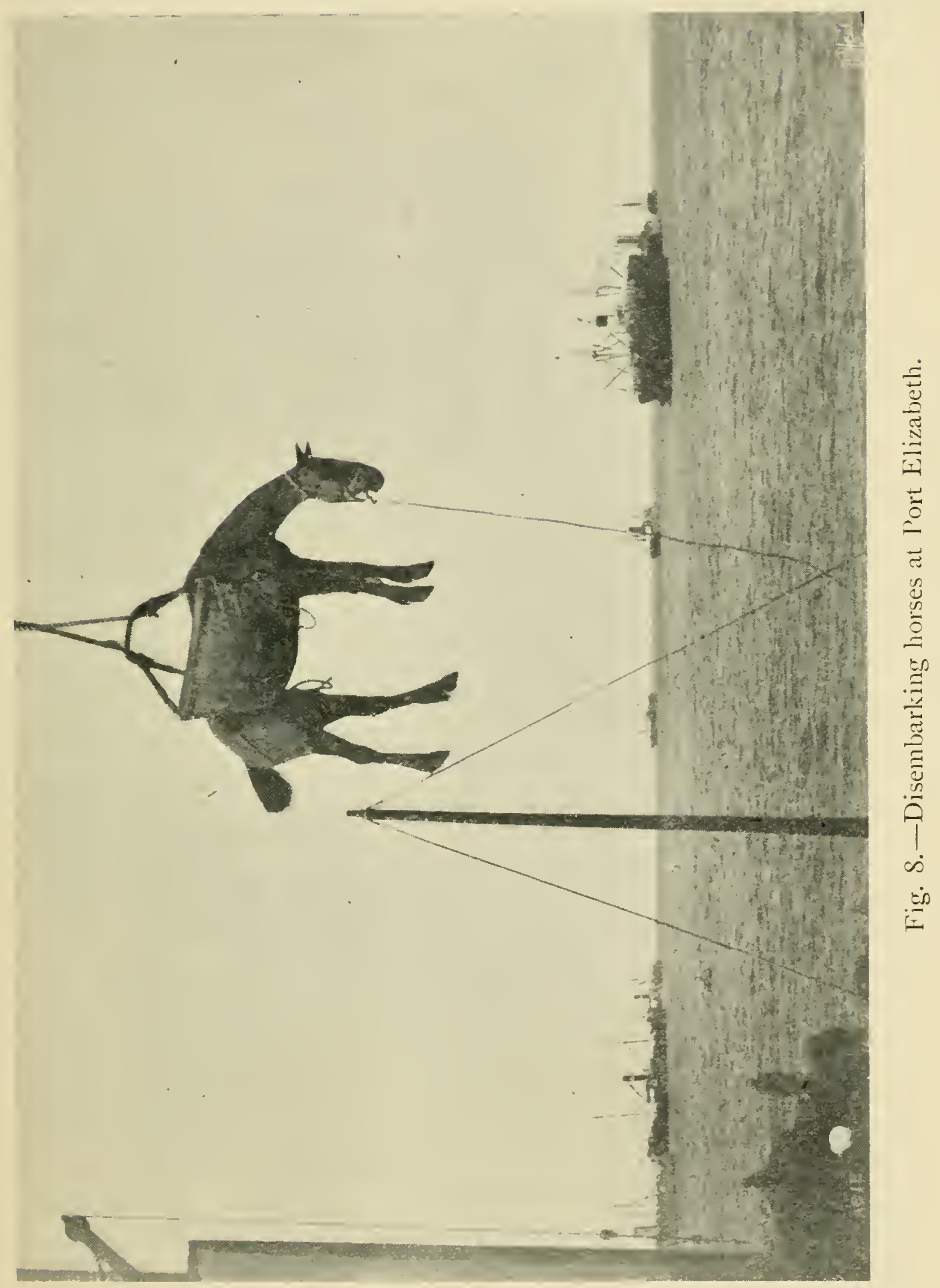





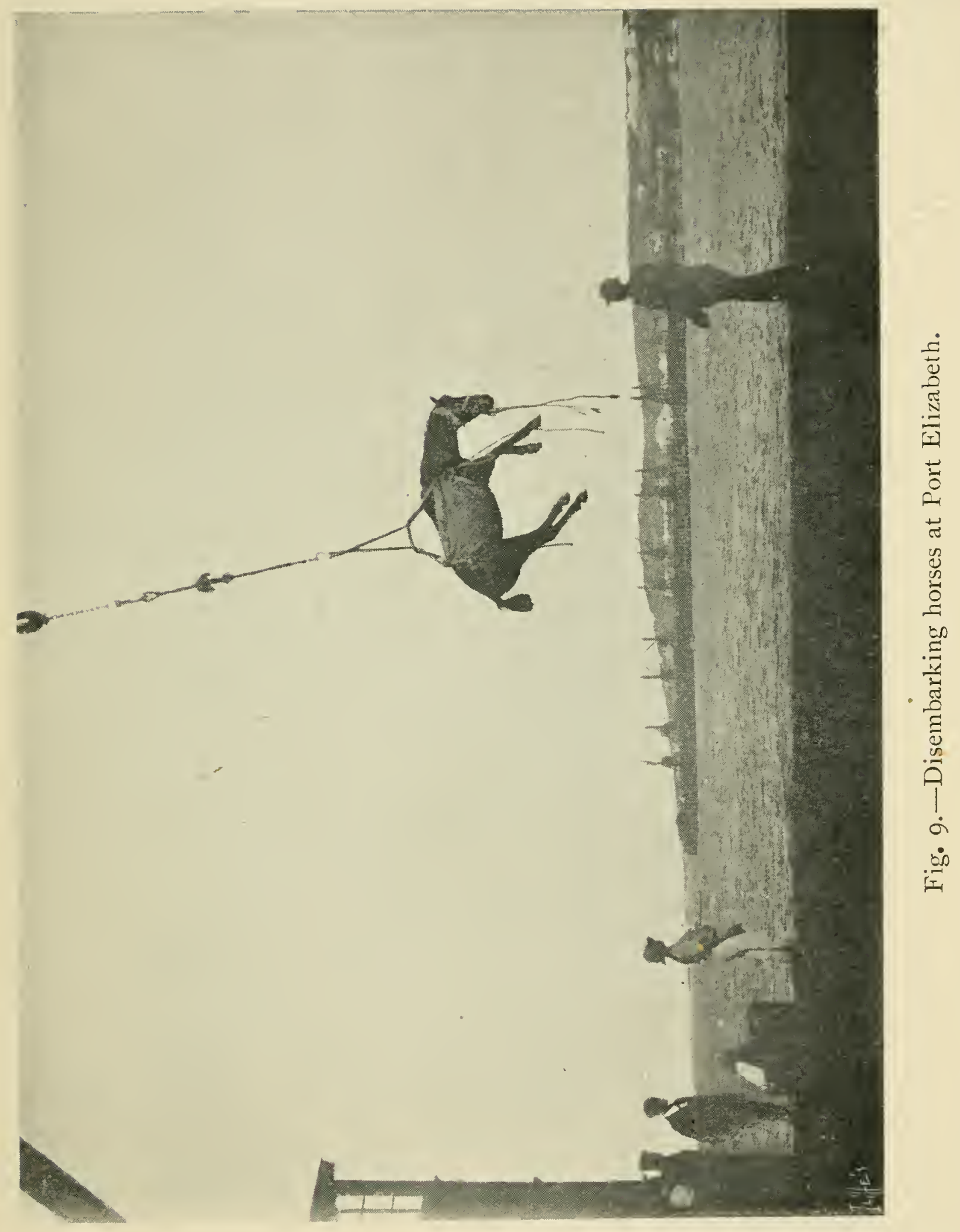





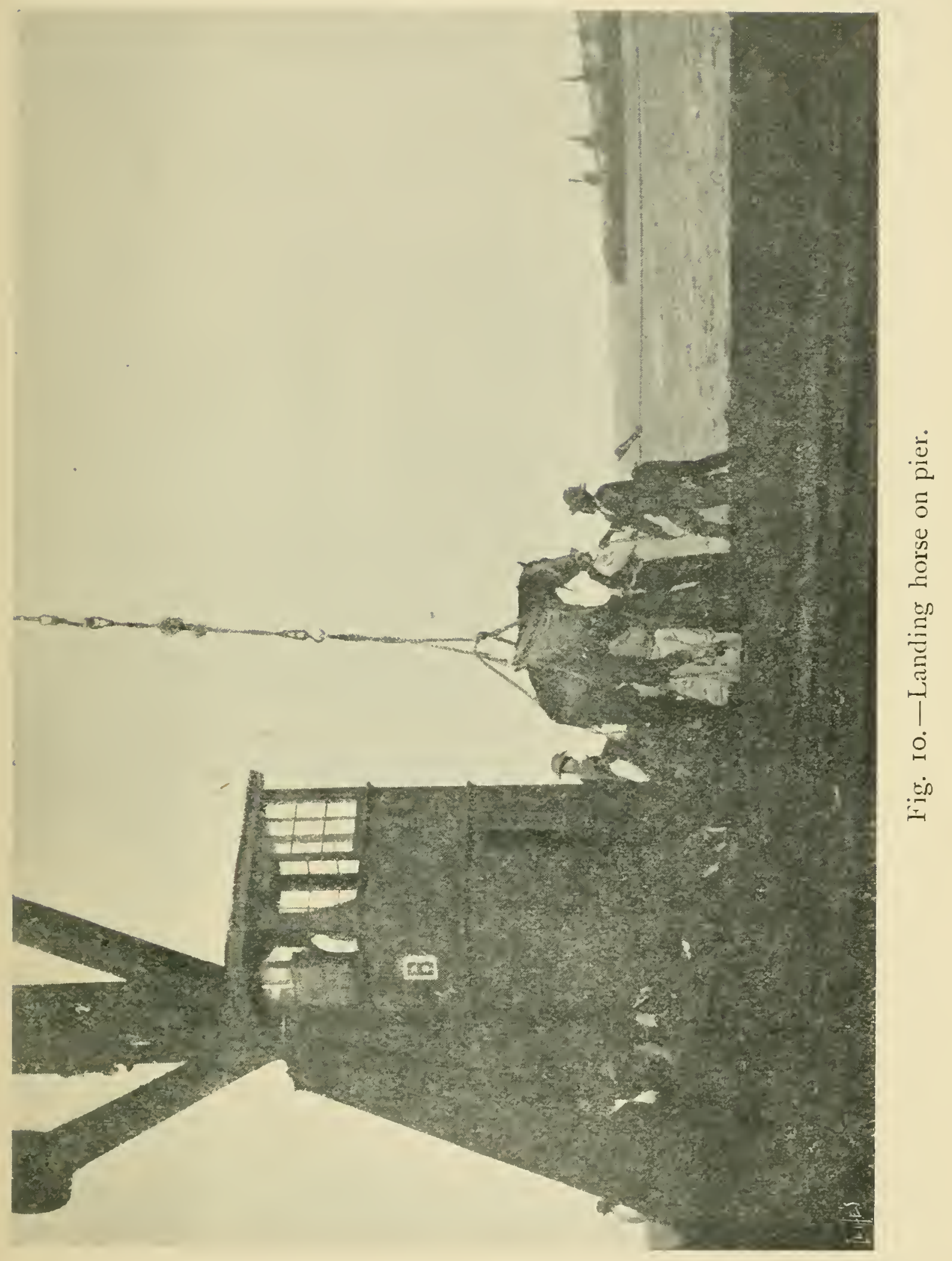





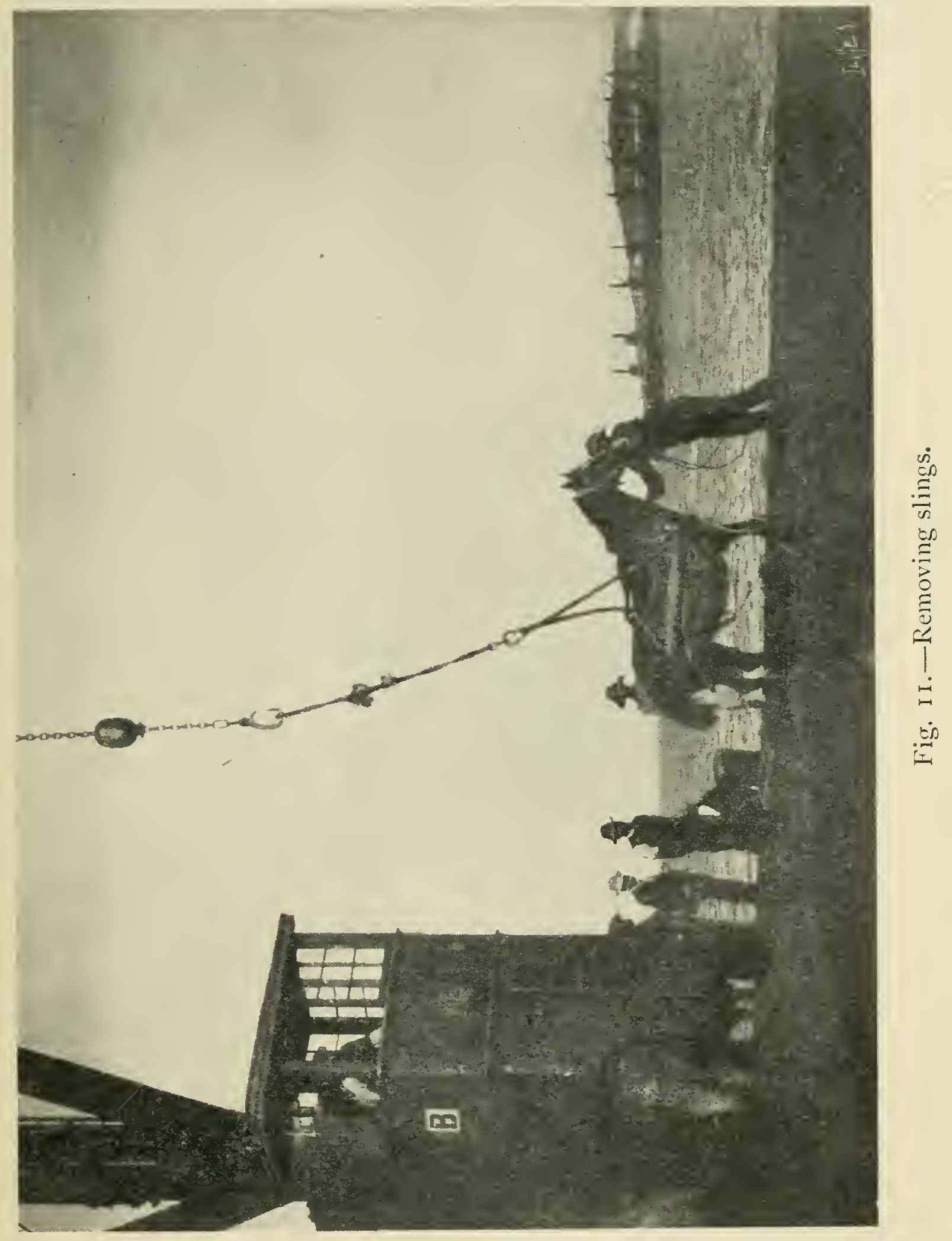



him up, he can as a rule be raised either from the hatch, or from an intermediate deck.

As far as my experience goes, the best kind of sling for transferring a horse from one place to another, is that which is used for landing horses at Port Elizabeth, South Africa (Fig. 5). In this sling, the gromet, which is attached to the suspending chain or rope, is passed through the ring of rope at the other end of the sling, so that the animal is enclosed in a running loop, out of which it is almost impossible for him to slip, supposing that he is further secured, fore and aft, by a breast-rope and breeching, both of which ropes are attached at their free ends to their respective rings by means of a slippery hitch (half hitch on a bight). The 
large rope of the sling is all in one piece, and consequently it greatly strengthens the sling, which will fit horses of all sizes. The portions of the rope which touch each other, when forming a loop round the horse, are "parcelled," so as to prevent wear. The two cross pieces of wood over which the canvas passes at each end of the sling, are made particularly heavy, so that the sling may readily fall down, clear of the horse, when it is disconnected from the chain or rope of the crane or derrick. Figs. 6 to I I show the manner in which horses are landed on the Port Elizabeth pier from lighters. This sling works so expeditiously, that with one crane the Port Elizabeth people can land from their lighters, roo horses in an hour and a quarter. The immense amount of 
Embarking and Disembarking Horses. 79

practice which they have had, has made them extremely quick at this work. The only fault I had to find with them, is that the Kaffirs who put on and take off the slings, use the horses very roughly, especially in the matter of striking them about the muzzle, which is a particularly cruel trick. Mr. Desmond, Chief Veterinary Surgeon to the Government of Adelaide, South Australia, whom I had the pleasure of meeting at Port Eliźabeth, aptly remarked to me that if these Kaffirs were supplied with strong boots, they would not be so inclined to strike the horses, which have an unfortunate tendency to tread on the toes of their attendants.

Lighters into which horses are put, either for embarkation or disembarkation, should 
have their floors laid down with a plentiful supply of soft material, such as straw or coir matting; so as to prevent them slipping; and to save them from hurting themselves, in the event of their falling down. Accidents are much less liable to occur when the horses are left loose in these lighters, than when they are tied up. As I have already inclicated (p. 54), it would be well, under ordinary conditions, to remove the hind shoes of the animals, so that they may not hurt each other by kicking.

When a horse is put into a portable horsebox, previous to slinging him and the box, the ropes on his head-collar or halter should be firmly secured at a short length to the rings which are fixed to the respective posts at the entrance of the box, so as to stop 
Embarking and Disembarking Horses. SI

him from partly or wholly getting out of the box during transit; and it is well to cover the box, or to blindfold the animal, so as to prevent him seeing where he is going, while the box is suspended in the air. The fact of his being thus kept in darkness will greatly help to check him from struggling to get free. We should attach a line to one corner of the box and get a man to hold the line, so that the box may not twist round.

Before putting a horse into a portable horse-box, it is well to remember the fact, that the animal will generally refuse to go into it, unless the doors at both ends are open.

Before disembarking a large number of horses, it is advisable as a rule to mark all 
82 Horses on Board Ship.

those which are sick, in order that their proper care and supervision may not be overlooked after landing them. The attachment of a piece of spun-yarn to halter or head-collar, is a convenient means of recognition. 


\section{PORTABLE HORSE-BOXES.}

According to H.M. transport regulations, a portable horse-box (Figs. I 2, I3, and I4) should be " 6 feet long, 2 feet 6 inches broad in the clear, and 6 feet $4 \frac{T}{2}$ inches high, made of good wood, well framed, strongly built up and strengthened with iron bands passing right round on the outside. Bottoms to be battened. Door at each end hung on strong hinges and fitted with strong bar fastenings top and bottom. Each door to have on the outside, ring bolts for fastening halters to. The inside of box and doors to be lined with liquored leather slightly padded out with straw. 
Wooden runners quite smooth on their undersides are to be fitted underneath each box to facilitate hauling it about the deck. Each box to be fitted for hoisting with a horse in it, and when horses have to live in them on board, each must have a painted cover fitted on a frame in such a way as to ensure protection from the weather." I think that 6 feet 6 inches would be a better length than 6 feet 3 inches, and that the width inside might be increased to 3 feet, so as to allow room for a man to get into the box alongside the horse, in order to arrange his clothing, pick up a foot, or perform any other necessary detail. In making this suggestion for increased width, I do not forget that under ordinary circumstances it is accompanied by decreased stability on the part of the animal, which obtains support during the lively 


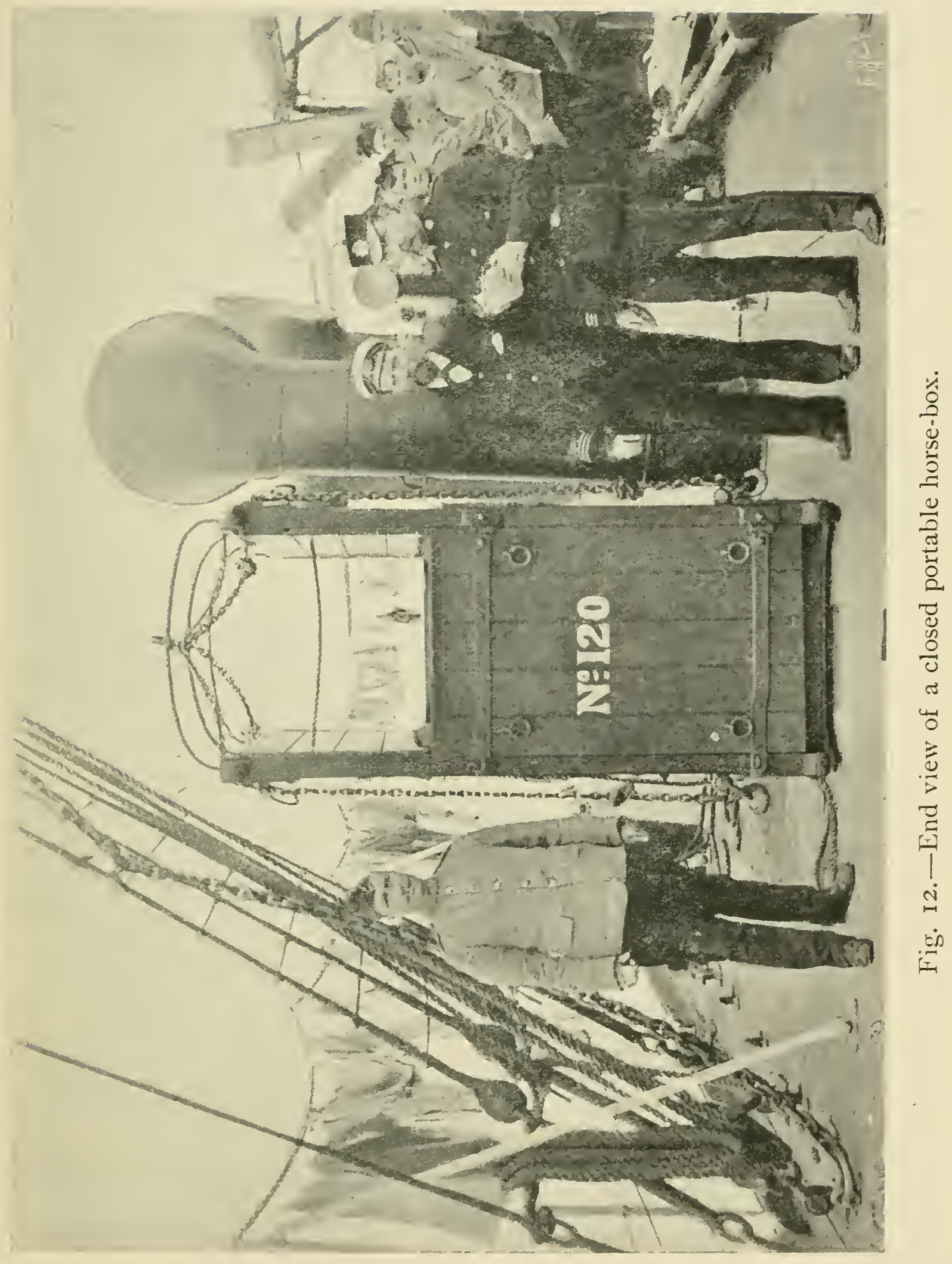





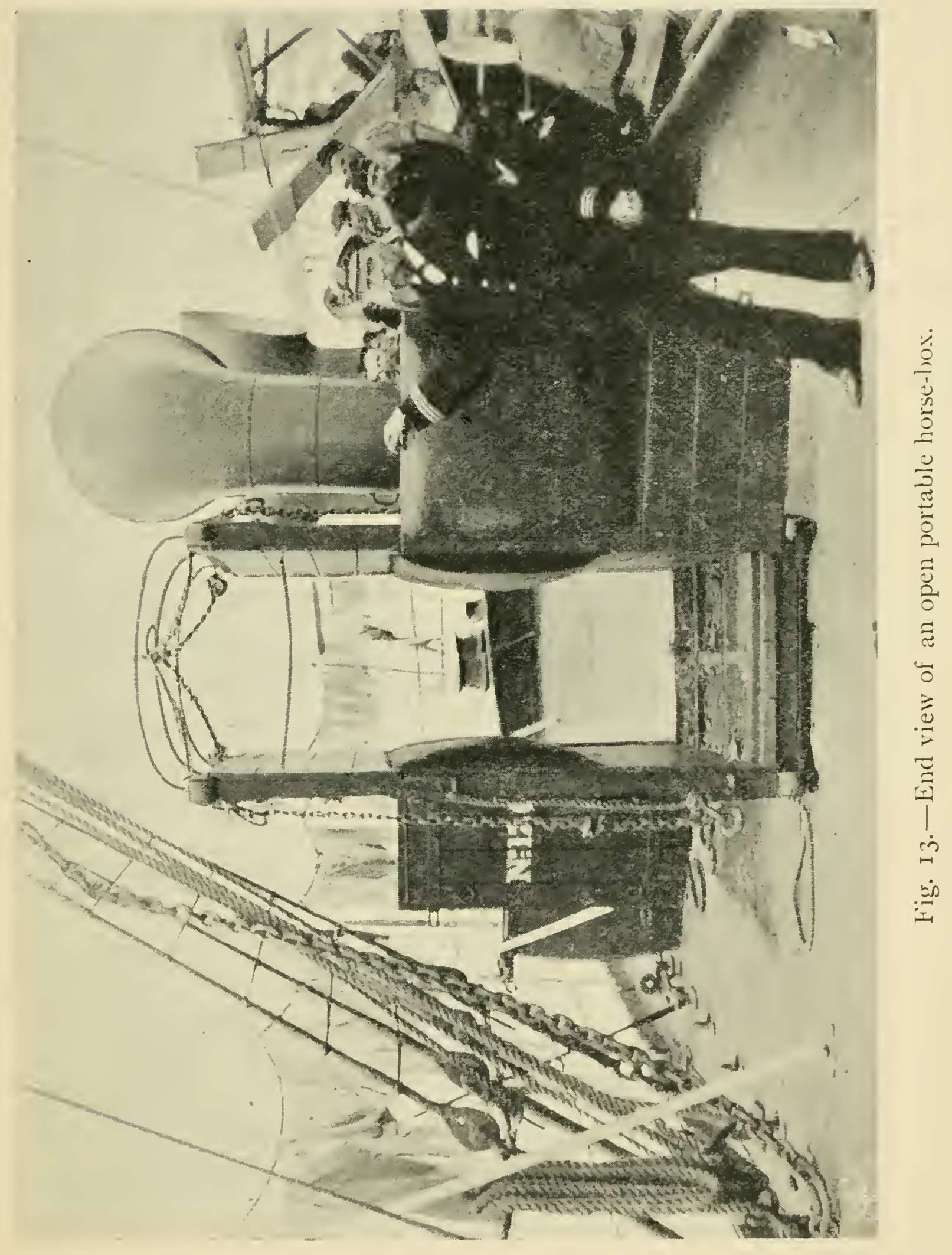





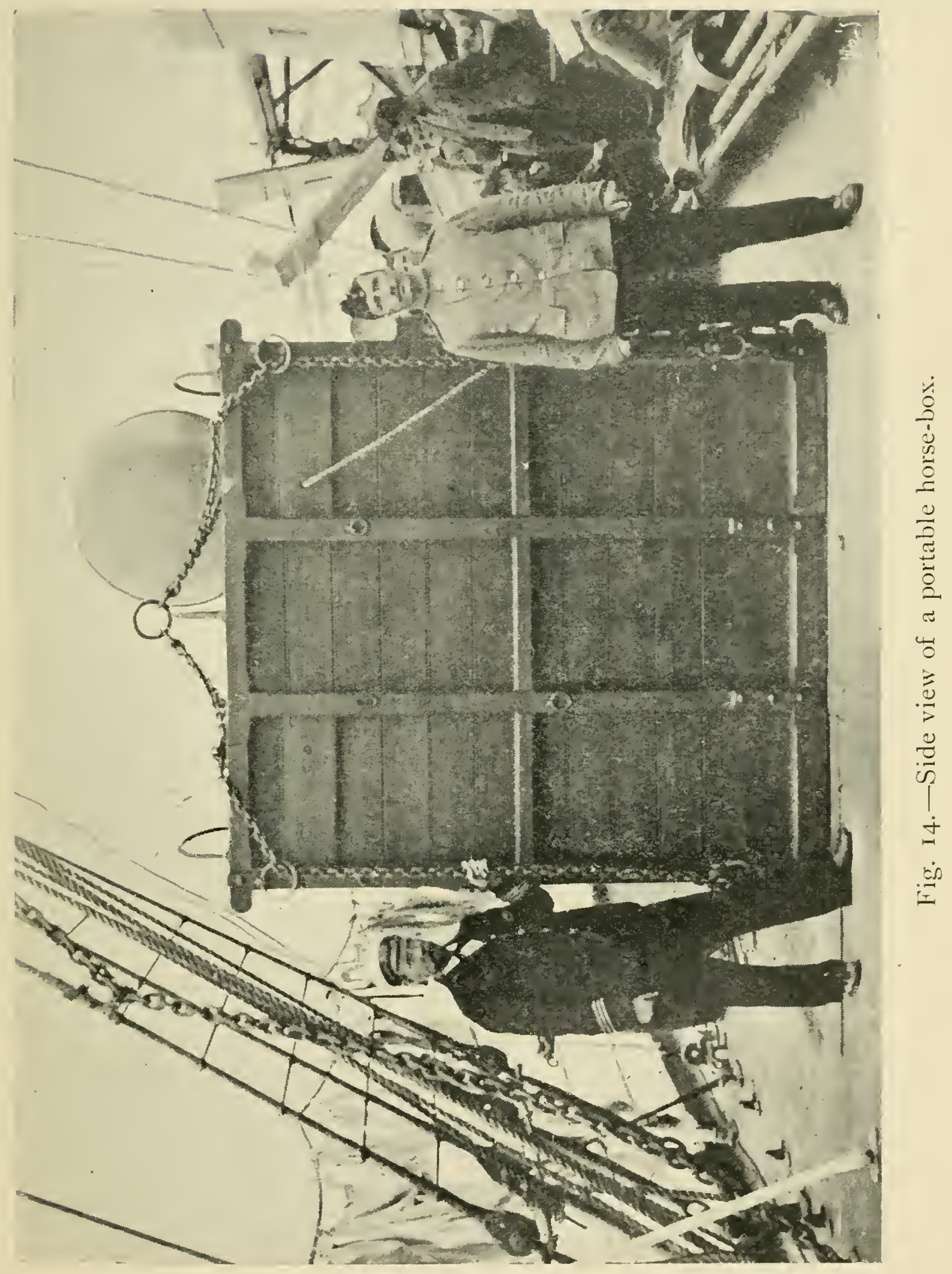



movements of the ship, by the fact of the walls of the box being close to his sides. This advantage may be safely dispensed with, when the floor of the box is covered with cocoanut matting, which is a subject I shall presently consider. For the conveyance of heavy cart horses, an extra allowance of room may have to be made.

Instead of having a box only just large enough for a horse to stand up in, we might have one sufficiently big (say, 9 feet by 6 feet) for him to lie down in if he chooses to do so. I have known such an arrangement to be used when taking valuable horses from Australia to India. It proved very beneficial to the health of the animals thus boxed; but the extra expense would not, as a rule, be justified in ordinary cases. 
A box has a door at each end, so that the animal may be able to go in or out of it whichever way it is turned. Instead of straw padding inside the box, I would recommend the employment of large pieces of felt, to be secured by being laced through holes bored in the planking, so as to dispense with the use of nails of any kind, next to the horse. Each side of the box, at different ends, should have a small door (Fig. I5) through which the animal's dung may be removed. The box shown in Fig. 14 is not provided with this convenient door. Figs. $\mathrm{I} 2$ and $\mathrm{I} 3$ show a rope which passes through the sides of the box and across the horse's back, so that, when it is drawn tightly, it will keep the animal down, in the event of his struggling to get out of the box. 


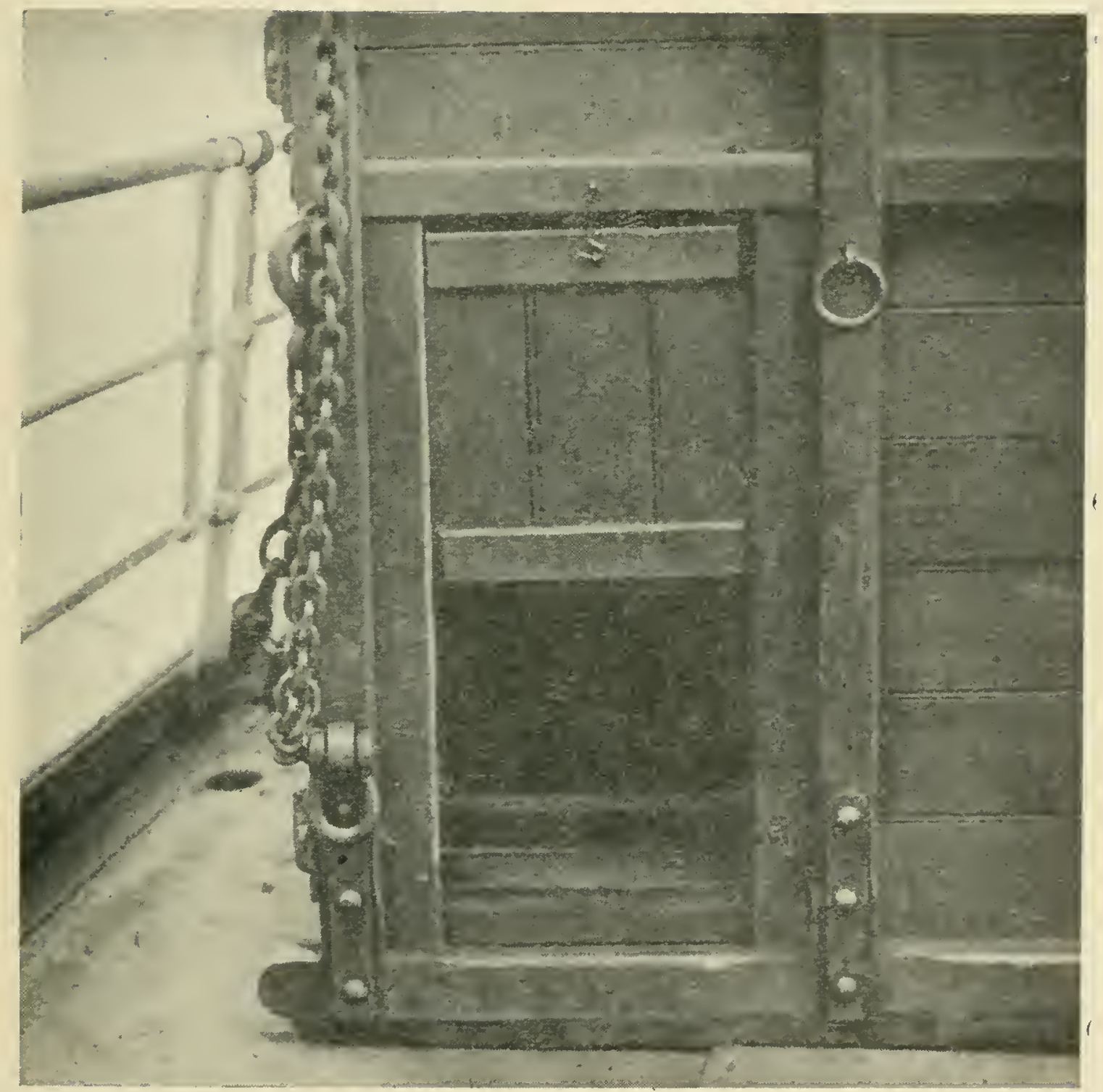

Fig. I 5. - Mucking-out door in the side of a portable horse-box. 

The feeding trough or manger which is provided with a sea-going horse-box, is generally much too narrow. It should be at least i 3 inches deep and 13 inches broad at the top, about 22 inches wide, and the sides should slope towards the centre, so as to help the animal to reach his food.

With respect to the nature of the floor upon which a horse will have to stand in a box during a sea voyage, we should bear in mind that loss of foothold is a very serious danger from which he is liable to suffer during bad weather. The famous Blue Gown, Prince Io, Ossory, who was own brother to Ormonde, and scores of other valuable animals have lost their lives from stress of weather during the short passage across the Atlantic. 'These accidents usually occur from the horse 
losing his footing, in which case he will probably either get dashed from side to side, until he is killed, or he will struggle until he dies, as horses will often do, when they get down and cannot regain their feet. As a quadruped has a far larger base of support than a biped, he can keep his footing much better on a rocking surface, like the deck of a ship which is rolling and pitching, provided that his feet do not slip. Yet horses, as a rule, find it far more difficult to keep standing in bad weather than men; because of the small amount of friction which exists between the floor of their box or stall and the ground surface of their feet. The superiority of the four-legged form of support over the twolegged one, is well shown by the ease with which a dog can stand on the deck of a ship 
that is rolling in the most desperate manner; because the pads of his feet give him abundance of grip. Therefore, to ensure a sea-going horse against the danger in question, we need only place him on a non-slippery surface, as for instance, thick cocoanut matting, into the upstanding fibres of which his feet can sink, and can thus obtain secure foot-hold. The cocoanut matting, to which I allude, is of the rough door-mat type./ I have frequently proved the perfect efficiency of this material during very bad weather on voyages with horses between India and England, and also in the North Sea when going to Russia. My own practice when taking animals in portable horse-boxes, is to employ six cocoanut door-mats of the ordinary size (about 3 feet by $\mathrm{I} / 2$ feet) ; five to cover the floor, 
and one extra, so that the rearmost mat can be taken out every day, cleaned and dried, and the others pushed down in daily succession. If one large mat is used, there will be great difficulty in changing it from time to time, as would be necessary for purposes of cleanliness. The old plan of putting battens across the floor of a box is not good; because, instead of using the battens as a fixed point for his toes in the manner intended, a horse will often place his heels on them, apparently with the hopeless object of digging his toes into the wood beneath, and will thus adopt a position which is well suited to bring on fever of the feet. Hay is much less slippery than straw. Cinders and sand are very inefficient substitutes for rough cocoanut matting; although they are 
probably the best makeshifts that can be usually found.

With respect to the loss of Ossory and Prince Io, I read in The Spirit of the Times that the man who had charge of them said that he could not keep either straw or sawdust under them; because it got washed away by the water which was shipped. It is evident that no amount of wave-washing could remove properly placed cocoanut matting. When horses get killed in this outrageous manner, any insurance company which had taken the risk on them, would be right to resist all claims for compensation; because proper precautions had not been taken for the safety of the animals.

I believe I was the first to advocate the use of rough cocoanut matting as a floor for horses 
on board ship, which I did as far back as the 3oth March, 1889, in Hayes' Sporting News, which I owned and edited in Calcutta. Rough cocoanut matting not only gives a horse firm foot-hold, but also saves him to a great extent from the danger of getting fever in the feet, by enabling him to stand on a substance which is a bad conductor of heat, and which causes the pressure on the ground-surface of his feet to be evenly distributed.

Every box should be furnished with sling hooks, and also with slings (p. I4I), which can be used when required.

If practicable, the box should be opened morning and evening for cleaning out purposes, and when it is possible to exercise the horse. On all other occasions, it should be kept closed. If it is inadvisable to open the 
box-for instance, on account of bad weather -the removal of the dung may be effected through the small door (Fig. I 5, p. 93) which should be on each side of the box.

A portable horse-box ought not to cost more than from $£ \&$ to $£$ io to make, although fancy prices are sometimes charged. 


\section{ARRANGEMENT OF HORSES ON BOARD SHIP.}

With a small number of horses, we may observe the sound rule that they should be placed as near midships as practicable, because there is less motion at that part of the vessel than at either end. As the inclination of the deck to the horizon is greater when a ship is rolling than when she is pitching; horses in all cases should be put athwart ship, and not fore and aft.

To fulfil the requirements of ventilation with a large number of horses, not more than two decks, below the exposed deck, should be fully 


\section{Arrangement of Horses on Board Ship. 103}

occupied by these animals. In a spar-deck ship, these two decks will be the spar deck and the main deck; and in a three deck ship, the main deck and the upper 'tween deck. Except when there is a fair probability of bad weather being encountered, as during winter in the Bay of Biscay, horses can be carried on a shade or shelter deck, in which case there might be three decks occupied by stalls. It is a great advantage to be able to utilise, either wholly or in part, a shade or shelter deck as a hospital or convalescent home for sick animals, which can generally be brought up from below. If the exposed deck is unprovided with stalls, the horses should, as far as practicable, be tied up with their heads to windward, so that an undue proportion of weight may not be put on their fore feet, which are much more liable to 
suffer from laminitis (fever in the feet) than the hind ones. To avoid crowding the exposed deck, which would be a source of inconvenience and even of danger during bad weather, it is well to remove off it, from time to time, all horses which have recovered their health, and which are unprovided with stalls on the exposed deck. If bad weather comes on, all such animals should be sent below, where they will feel the movement of the ship much less than above.

The best position for stalls is 'thwart-ship and close to the side of the ship, with the heads of the stalls facing inwards. To facilitate the opening and closing of port-holes, a space of about 2 feet is sometimes left between the ends of the stalls and the side of the steamer; but the small advantage thus obtained is generally 


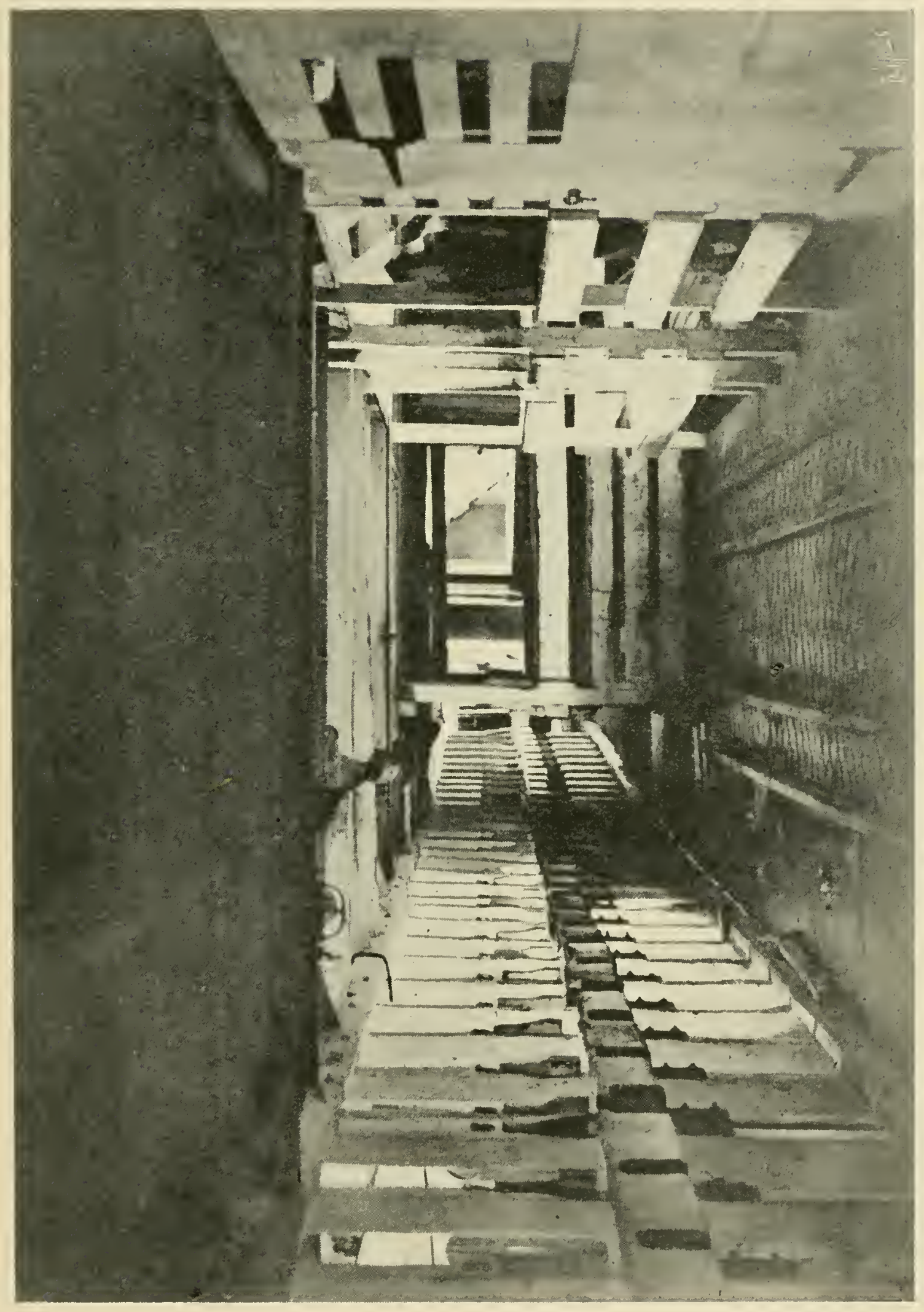

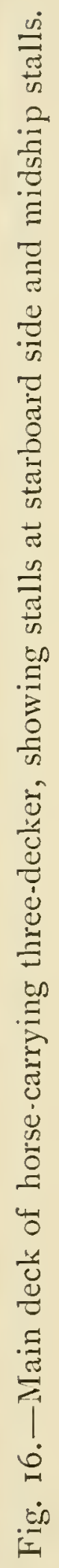



more than counterbalanced by the curtailment of the space in front of the horses, especially at the hatches and alley ways.

Although four rows of horses can usually be arranged on some parts of the deck, as in places away from the hatches and engine room; it is always advisable, if practicable, to limit the number of rows to two, so that, as far as possible, none of the animals may be forced to take expired air into its lungs. In all cases, mid-ship stalls (Fig. I6) obstruct ventilation, especially between decks, and in the neighbourhood of bulk-heads. These stalls should on no account be closer to the stalls they face than 3 feet 6 inches; for if they be within that limit, there will be great difficulty in passing between the two rows when the feeding troughs are in position; and the horses whose 
heads are in opposite directions will have every chance to bite and otherwise annoy each other, and to appropriate each other's food.

No stalls should be placed on hatches, which are extremely useful places for the temporary accommodation of sick animals, and of those that are taken out of their stalls during mucking-out time, and for preparing hay and corn prior to distribution.

Vacant stalls, to a number of at least five per cent., should be provided and should be uniformly distributed, so that, in case of illness or accident, a double stall may be given to a patient (pp. 202 and 203). 


\section{HEAD-COLLARS AND HALTERS.}

LEATHER head-collars are stronger and more easily adjusted than halters, which are generally made of webbing; but are more expensive and are more apt to abrade the skin upon which the nose-band presses, especially if the nose-band is put so high up as to touch the bony prominence (end of the superior maxillary spine) which is about mid-way between the horse's eye and the corner of his lips, on each side. For the adjustment of the nose-band it is a safe rule to place it about two inches below this bony prominence. A frequent fault with halters which are put on 
board for horses, is that they are of a uniform size, and consequently, if they fit animals with big heads, they will be too large for those with small ones, in which case the nose-band is apt to slip over the horse's muzzle, and the halter is then converted into a ring which goes round the animal's neck. I have known instances of horses on board ship getting killed by hanging, owing to the nose-band slipping over the muzzle in this way, and the animal subsequently losing his footing.

The webbing of halters will generally stretch after having been in use for a short time. In all cases the front part of the nose-band should be about it inches long, and should be sewn to the rings at each side; and the rear portion of the nose-band should consist of a strap (Fig. I7) which, can be shortened or 


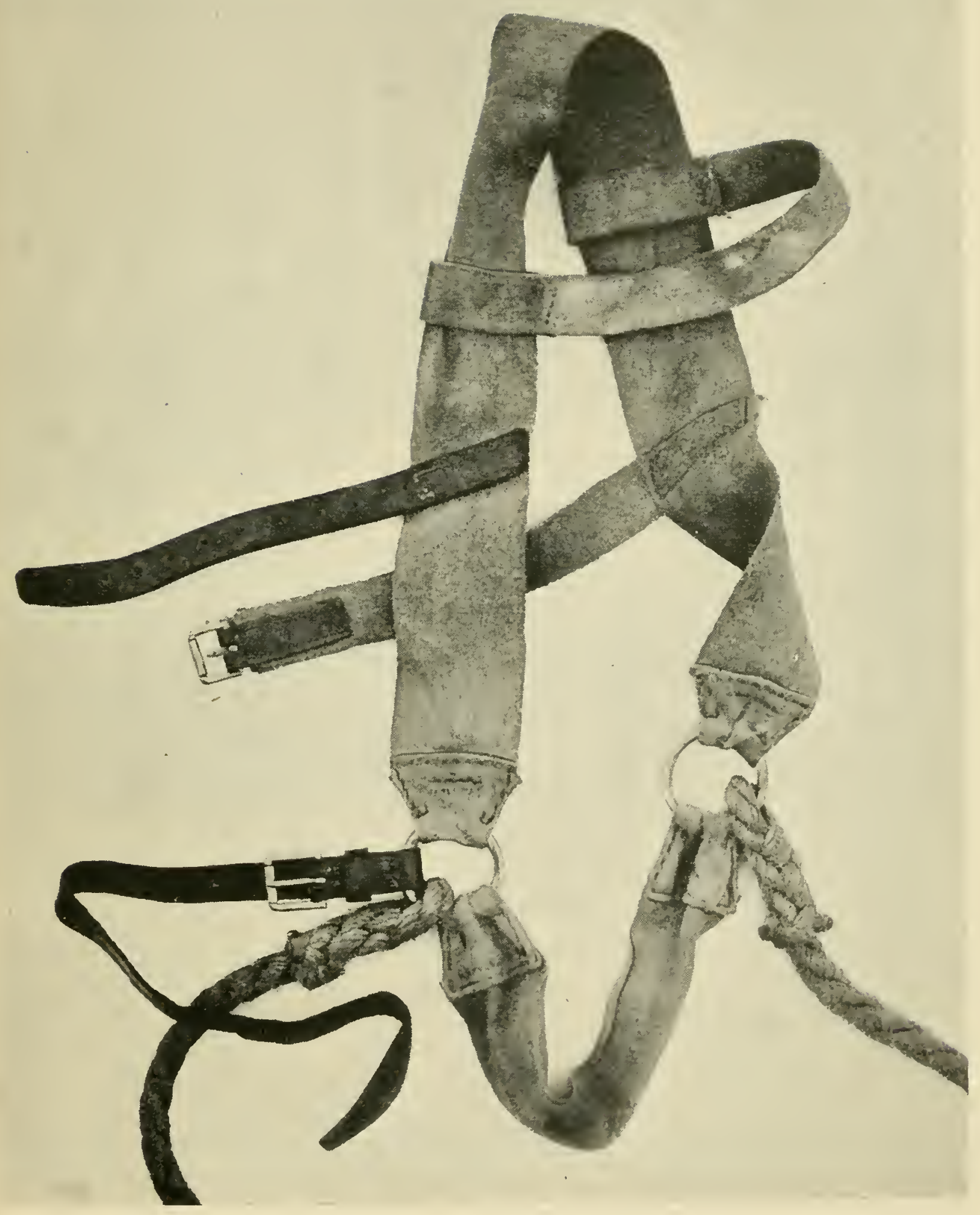

Fig. I 7.-Halter used on Government transports. 

lengthened as occasion may demand. In some haiters, the nose-band forms a running noose with its rope, which arrangement is open to the serious objection that if the tying-up rope be long the animal may pass his head through the noose, which in this case will be brought round his neck, and he will thus run the risk of becoming strangled in the event of his falling down. I have had more than one horse killed in this way. A throat-latch is an indispensable adjunct to a board-ship halter, but it should not, as is often done, be sewn on to the crown-piece (Fig. I7), in which case it is liable to become detached. A better plan is to make it separable from the halter, to which it can be connected by passing it through a loop at the part of the halter which goes over the animai's poll. 
Owing to the softness of its material, I am inclined to think that a halter made of webbing is better for board-ship use on voyages of not less than three weeks than a head-collar, supposing that both kinds of gear are properly made.

Either with a halter or head-collar, the tying-up rope on each side can be spliced to the ring of the nose-band. In the case of a detachable throat-latch, the tying-up rope can be fixed by a clove hitch (Fig. 2I, p. I37) to the ring which works on the rear portion of the nose-band, and which is attached to a strap that connects the noseband to the throat-latch. 


\section{ELOTHING.}

As horses on board ship are practically in a state of rest, they are able to bear cold much worse than animals which can keep themselves more or less warm by movement. On the other hand, they are as a rule fairly well protected from bad weather, and are consequently free from the chilling effects of moisture; a wet coat being about twenty times a better conductor of heat than a dry one. In Stable Management and Exercise, I have mentioned that I found a rug and a quarter sheet amply sufficient for purposes of warmth when taking well-bred hunters to 
Revel on the deck of a steamer through the North Sea and Baltic during winter, on which occasion the cold was far greater than is ever felt in England. Although these animals had been clipped, they were protected from snow and salt water. We all know that in very cold weather the atmosphere is comparatively dry and that no rain can fall. The fact that very cold snow contains a large proportion of air, greatly reduces the cooling effect which such snow has on a horse's skin, because air is an extremely bad conductor of heat. Experience leads me to conclude that a stationary horse which is exposed to rain when the temperature of the atmosphere is just above freezing point, suffers more from cold than if the temperature was, say, $30^{\circ} \mathrm{F}$. lower, in which case the air would be dry. 
The cooling effect of a current of air is proportionate to its velocity, which is a fact we should bear in mind with horses which are placed in draughty situations.

During winter on board ship in temperate climates, like that of England, a healthy horse will hardly ever require more clothing than a woollen rug or a kersey quarter sheet. In and approaching the tropics all clothing should as a rule be removed, except perhaps now and then when a clipped horse is exposed to a strong breeze at night. / With a large number of horses at sea we should be careful to keep the amount of clothing at a minimum, because the presence of even the lightest clothing will more or less check excretion from the skin, and will consequently throw increased labour on the lungs, which are the organs most 
liable to disease under conditions of overcrowding. I am convinced that putting on too much clothing is at least ten times as dangerous to an animal's health as putting on too little. If a horse is found to be sweating even to the slightest extent under his clothing, we may be perfectly certain that the limit of safety has been greatly exceeded./ 


\section{STALLS.}

As a rule, there are two varieties of stalls, namely, one with a double breast-board; the other, with a single one. In the former (Fig. I, p. rg), the breast-board is $5 \mathrm{ft}$. in width and has an upright post at its centre, at the back of which post there is a groove to accommodate the front ends of the division boards. In the latter (Fig. I8, p. I $2 \mathrm{I}$ ), the breastboard is only $2 \mathrm{ft}$. 6 in. wide, and it consists simply of a piece of wood which is placed across the front of the stall, and fits into iron cleats that are bolted to the front of each front post, and are kept from lifting up out of 
place by swinging stops, which are fixed to the front posts. Double breast-boards are also retained in position by similar cleats and stops. Although stalls with single breastboards require twice the number of front posts as those with double ones, they are much more convenient in use than stalls of the double breast-board pattern; because horses can be put into or taken out of them, merely by removing the breast-board. A double breast-board, on the contrary, cannot be taken out without also removing the division-boards (parting-boards) that are at its centre. In both cases, the division-boards in Government transports are $3 \mathrm{ft}$. $\Rightarrow$ in. high above the floor of the stall.

My experience, and also that of several capable men whom I have consulted on the 


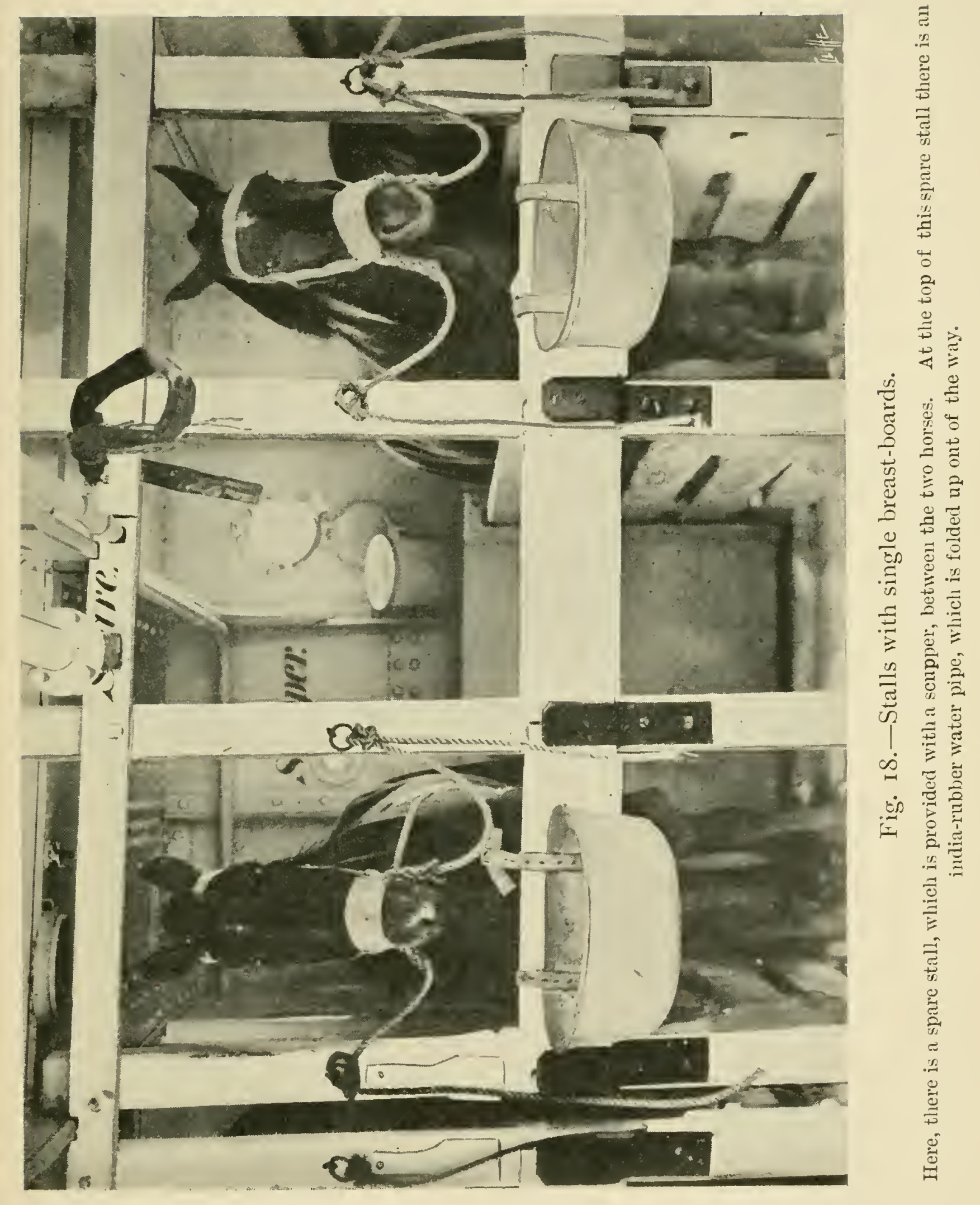



subject, lead me to the conclusion that the regulation height of $3 \mathrm{ft} .9$ in. for divisionboards is too little, especially in the case of Northern Hemisphere mares during the early months of the year, when they come "in season," and are then particularly liable to kick and to get one of their hind legs over the boards. This accident is not only dangerous to the involved animal, but also causes a good deal of trouble to the attendants, especially at night. As a rule, it will be easier to free the hung-up animal by removing and afterwards replacing the boards than by lifting the hind leg off the top board. A mechanical contrivance for the easy removal of these boards in such cases of need is greatly required, but has not been supplied up to the present. An addition of, say, 8 inches to the height of the 
division-boards would no doubt be sufficient to meet the requirement in question.

Mr. F. C. Golden, M.R.C.V.S., who has had great experience in the transport of Government horses by sea, was the first to point out to me the great advantage of using only one division-board (the top one). By adopting this plan, mucking out, ventilation, and the getting-up of horses which had fallen down in their stalls would be greatly facilitated. Mr. Golden and other veterinary surgeons who have tried it, and who have spoken to me about it, have found that its adoption in no way increases the liability to accident by the horses kicking each other.

Stalls for horses of ordinary size should not be less than $7 \mathrm{ft}$. in length; although $6 \mathrm{ft}, 6 \mathrm{in}$, would do for a I 5-hand horse. 
Eight feet might be taken as a maximum length ; and $7 \mathrm{ft} .6$ in. as the best for ordinary use. The length of a stall is measured from the breast-board to the haunch-board.

The division-boards (Figs. I6, p. I05 and I 8, p. I2 I), which are four in number, are kept $3 \mathrm{in}$. apart by pieces of wood near their ends.

Care should be taken that no spaces exist between the haunch-boards sufficiently wide (say, more than 3 in.) to allow a horse to catch his foot in them, in the event of his kicking.

Every stall which contains a horse should have a hooked-up stanchion or other contrivance, on which to sling him; for if he requires slings, he will generally be too bad to be moved to another stall, especially when the ship is rolling. 
Stalls made on the Government pattern cost about $£_{3}$ for each horse on a covered deck, and about $\ell_{3}$ Ios. on the exposed deck.

One of the most important points about stalls is that the fittings should be absolutely secure; because neglect of this precaution may entail serious loss of horse-life during bad weather. For instance, out of 4I5 horses which were on board the ss. Rapidan on her voyage from Liverpool to South Africa, I9I died, principally on account of the giving way of the stall-fittings during a heavy gale. This ship became disabled, got into the trough of the sea, and consequently rolled about terribly.

The fitting of stalls on Government transport is carried out according to the following Admiralty details :- 


\section{SPECIFICATION FOR FITTING STALLS ON BOARD SHIP.} DIMENSIONS OF STALLS.

ft. ins.

Maximum length in the clear between breast and haunch boards .

(Not less than maximum length to be given where possible.)

Minimum length in the clear between breast and haunch boards . . . . . . . 69

Passage between two rows of stalls, clear between

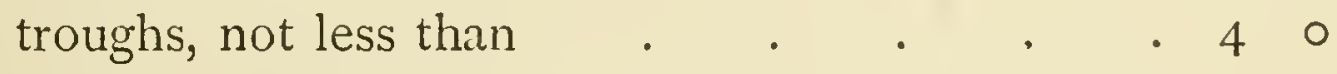
Breadth between division boards in the clear, not less than . . . . . . . 24

Height of the division boards above floor of stall . 39 Height of breast board above floor of stall • $\quad 39$

\section{FITTINGS ON EXPOSED DECK.}

FRONT STANCHIONS.

To be 6 ins. by 4 ins., spaced $2 \frac{1}{2} \mathrm{ft}$. apart, centre to centre, the height of same to be $8 \mathrm{ft}$. from ship's deck. In way of horses' heads, stanchions to be covered with zinc 9 B.W.G. as may be required. Heels to be secured by a cant, 6 ins. by 4 ins., fastened to the deck with a $\frac{5}{8}$ inch nut and screw or tapped bolt, one to every 5 feet, and a $\frac{5}{8}$ inch nut and screw bolt through heel of stanchion and cant. If on wood deck to be secured with $\frac{5}{8}$ inch coach screws.

A staple for a hay net to be fastened to each front stanchion. 
REAR STANCHIONS.

To be 6 ins. by 4 ins., spaced $2 \frac{1}{2} \mathrm{ft}$. apart, centre to. centre, the height to be $7 \mathrm{ft} .2$ ins. from deck.

These stanchions to be thoroughly secured in position by means of iron clamps, fitted to bulwark rail or rails Stop to be arranged on back of stanchions to prevent their rising. Heads of stanchions to be cross tied not less than every I $_{5}$ feet, and as required by Inspector. Heels to be secured same as front stanchions.

\section{ROOF RAFTERS.}

To be 3 ins. by 3 ins., bolted to front and back stanchions. All roof rafters to be carried $2 \mathrm{ft}$. past front stanchions, and 6 ins. past back stanchions.

Along upper end of front and back stanchions a 4 ins. by 2 ins. fore and after to be run. These fore and afters to be nailed to stanchions.

ROOF.

To be $\mathrm{I} \frac{\mathrm{l}}{2}$ inch tongued and grooved, and carried $2 \mathrm{ft}$. past front stanchions and 6 ins. past back stanchions, same as rafters.

\section{BACK SHEATHING.}

Stalls in way of open rails to have $\mathbf{I} \frac{1}{2}$ inch tongued and grooved sheathing full depth from bottom of roof a after to deck. Sheathing to be nailed on to back of stanchions. In way of closed bulwark to have I in. tongued and grooved sheathing from top of bulwark to underside of roof rafter. From top of bulwark to deck 9 ins. by 2 ins. sparring to be fitted with 3 ins. spacing. 


\section{BREAST RAIL.}

To be 10 ins. by 3 ins., with upper third covered with zinc not less than 9 B.W.G. Breast rail to be scored $\mathrm{I} \frac{1}{2}$ ins. at each end on the lower part over the iron cleat, so as to prevent the board from shifting fore and aft; a swinging stop of approved pattern to be fitted above breast rails on front of stanchions to prevent boards from lifting up out of place. The breast rails may be fitted in lengths to take two stalls.

\section{CLEATS.}

Iron cleats $\frac{5}{8}$ in. thick and 4 ins. wide bolted on front of each front stanchion to take breast rail.

\section{PLATFORMS.}

To be moveable, and to be made with $\mathrm{I} \frac{1}{2}$ inch deal boards the length of the stall with a $\mathrm{I}$ inch space left between them, secured with battens the width of the stall. Foot battens to platform to be of pitch or red pine 4 in $\mathrm{No}$., rear batten to be 4 ins. by 2 ins., and placed 12 ins. from rear end of stall (when stall is $8 \mathrm{ft}$. long), the other 3 battens to be 3 ins. by 2 ins., the front one to be placed $7 \frac{1}{2}$ ins. from the end of platform, and the other two to be placed each one foot from the centre of platform. These battens to be chamfered and secured to platform by iron screws $2 \frac{1}{2}$ ins. long, $\frac{1}{2}$ in. diameter, well recessed below top of batten.

\section{PARTING BOARDS BETWEEN EACH HORSE.}

Top parting board to be 9 ins. by 2 ins. The lower three parting boards to be 8 ins. by 2 ins. with 3 ins. 
clearance between each. I $\frac{1}{2}$ in. parting pieces spiked near each cnd of board to give this clearance. 'These parting boards to slide in grooves at outer and inner end. Grooves may be machined ( 2 ins. slot) out of solid wood or by attaching with screw nails 2 ins. by 2 ins. battens on a 6 ins. by $\mathrm{I} \frac{1}{2}$ in. backboard. Front of top parting board to be fitted with slip bolt, or an approved iron pin with ball head secured by chain to stanchions, may be fitted into socket hole in stanchions just above top parting board. Back of top parting board to be fitted with wood stop, to prevent parting boards rising.

TROUGHS.

To be of approved pattern, one to each stall, galvanized iron, about I ft. 9 ins. by 12 ins. by 9 ins. deep (not buckets).

HALTER RINGS.

Of approved pattern in positions as directed, and firmly secured.

FITTINGS UNDER ERECTIONS AND IN 'TWEEN DECKS. STANCHIONS.

Scantlings of stanchions, breast rail, platform, and parting boards as specified for fittings on exposed deck.

To be tightly wedged between decks, and to be secured at heads and heels as specified for exposed decks to prevent their shifting fore and aft, or athwartship, to Inspector's approval. 


\section{BACK OF STALLS.}

Ordinary ship's sparring in 'tween decks to be closed with intermediate spars, so as not to allow of more than 3 in. spacing between spars. Where no sparring exists on the ship, four 9 ins. by 2 ins. spars are to be fitted, with not more than 3 ins. spacing between each.

\section{SHIPS FITTED FOR CATTLE.}

Cattle ships fitted with cement decks to have portable floor pieces laid close down on cement between outer two and inner two footlocks, and good drainage space to scuppers cut through footlocks under parting boards.

\section{DRAINAGE.}

Sufficient number of scuppers to be cut in all 'tween decks and under all erections. As a general rule, a 4 ins. scupper every 25 feet of erections will be found sufficient. Position of all scuppers to have name "scupper" painted on ship's side or back of stall immediately above the scuppers in not less than 6 in. letters. Whenever practicable an endless chain is to be rove throug! scupper for cleaning purposes.

\section{WATER SERVICE.}

A permanent water service pipe to be fitted to all horse decks with hoses attached carried fore and aft on the upper deck. A cock is also to be fitted at each side at the following stations:-Poop front, after end of bridge, after end of engine casing, forward end of engine casing, bridge front bulkhead, after end of forecastle and forward. In 'tween decks of ordinary length a cock is to be fitted at each 
side, at forward and after end of each compartment. Special care to be taken that water service can be supplied from at least two independent pumps in the engine room in case of breakdown.

SIDE LIGHTS.

In long deck erections to be spaced not more than $16 \mathrm{ft}$. apart, and in 'tween decks spaced about $\mathbf{2} 2 \mathrm{ft}$. apart.

IVIND SCOOPS.

Of approved pattern to be fitted to all side lights.

ELECTRIC LIGHT OR CANDLE LAMPS.

To be fitted in erections, and in between decks of sufficient number to give ample light; where candle lamps are fitted they are to be of approved pattern and hung in proper hooks.

\section{VENTILATION.}

All erections (not necessarily enclosed) and all between decks are to have ventilators of sufficient size and number with their cowls carried clear above top fittings, besides which, all 'tween decks to have mechanical ventilation by means of fans, or other approved method, so as to draw all foul air from the after end and or if necessary, from the fore end of each compartment, and exhaust same at the top exposed deck.

\section{WINDSAILS.}

30 ins. diameter with large mouth (square head preferred) to be supplied and fitted, at least two to each 'tween deck compartment, and where required in erections. 


\section{GENERAL.}

A Pharmacy to be built, size about 6 feet square, of 3 inch stanchions and $\mathrm{I}$ inch boarding. Spaces to be left between the boarding of top half for light and air. A door to be fitted, provided with hanging lock.

Shelves with face battens to be fitted, as directed, around the bulkheads. Also bottle racks and a broad shelf, 2 ft. 9 ins. from deck, for dispensing.

Five per cent. spare stalls are to be fitted in addition to the number of horses fitted for. Two per cent. to be fitted with slinging bars. The bars to be pitch or red pine running fore and aft between the stanchions with dumb sheaves worked on them, four to each front and two to each rear bar for each stall. The centre of front bar to be 9 ins. from front stanchion, the rear one to be three feet from the front bar, centre to centre. These bars to be kept as high as possible supported by and bolted to fir rails 8 feet long by $4 \frac{1}{2}$ ins. by 3 ins. secured to stanchions by $\frac{5}{8}$ inch bolts and nuts. Heads of bolts to be smoothly rounded, ends to be cut off flush with the nuts and covered with wooden caps carefully smoothed off.

Two belaying cleats of $\frac{5}{8}$ inch iron are to be screwed to front of each stanchion of the spare stalls, 18 ins. and $5 \mathrm{ft}$. 6 ins. from the heel of stanchion respectively for belaying the falls of the hammocks.

All timber coming in contact in any way with the animals is to be well planed, smoothed, rounded, and neatly chamfered off. 
Forward and after ends of rows of all stalls on exposed decks to be close sheathed, full depth, with $1 \frac{1}{2}$ ins. tongued and grooved, upper portion of this to hinge down, and the ends to be made portable when required. Canvas screens to be fitted from fore and after at top of front stanchions to bottom on deck cants with lashings, \&c. complete; these lashings also to tie screens when rolled up. Screens are to be hung in front of all stalls on the weather decks, as also at all ends of the centre stalls adjoining hatches on next deck below.

Brows are to be constructed to allow of shipping all horses; these brows to be of easy descent to each between deck, and are to be taken out on board the vessél. Brows to have strong sparred sides (not more than 3 in. spaces between spars); also in way of each fitting, \&c. on deck, more than 6 in. high small permanent brows to be fitted where it is intended to walk horses.

All workmanship, material, and general arrangement of the stalls to pass the Inspector appointed, who may make any reasonable alterations in this specification while the work is in progress. Workmanship to be carried out in first-class manner. 


\section{TYING-UP.}

The method of tying-up differs to some extent according to the nature of the stall. In a stall which has two front posts (a single breast-board stall, Fig. I \&, p. I 2I), a ring, for the tying-up ropes, will be fixed to the front of each front post, and about i 6 inches above the breast-board. In this case, each tying-up rope should be about $2 \mathrm{ft}$. 6 in. long. In stalls which have one breast-board to two stalls, the outward tying-up rope is attached to a ring on the front post about I 8 inches above the breast-board; and the inward rope, to a ring in the centre of the 
breast-board (Fig. I, p. I9). The best way for making this attachment is by means of spring hooks fixed to the tying-up ropes, which can thus be kept at their proper length, even when the spring hooks are disconnected from their rings. If spring hooks are not used, the ropes can be tied to the rings by means of a round turn, and two half hitches (Fig. 19), which will not be so liable to become undone as a slippery hitch (Fig. 20), and will be more easy to undo than a clove hitch (Fig. 2I), in the event of the rope being drawn tightly, as would occur if the horse got down in his stall.

The advantage of keeping the tying-up ropes at a fixed length by means of spring hooks, is emphasised by the fact that these ropes have to be disconnected from their 


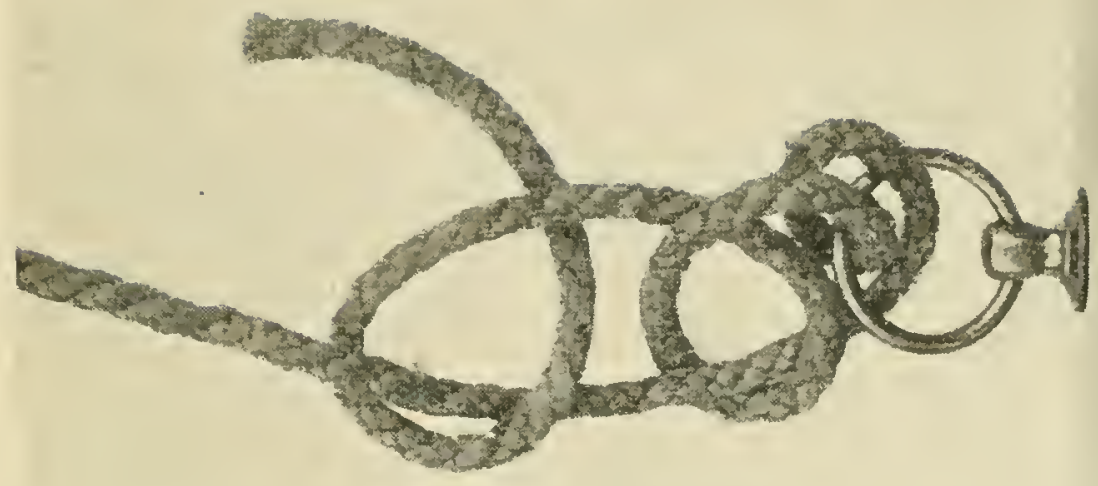

Fig. 19.-A round turn and two half hitches.

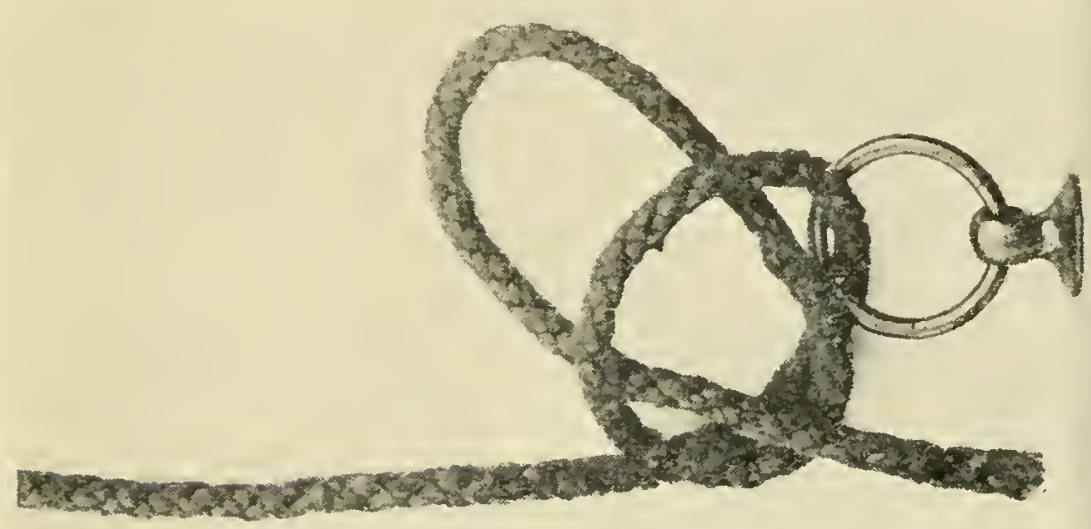

Fig. 20.-A slippery hitch.

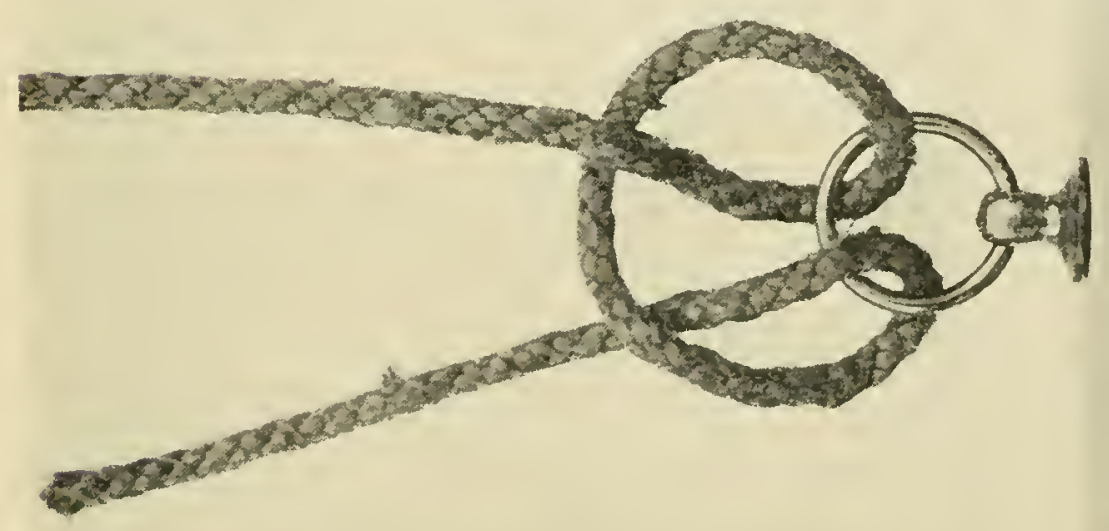

Fig. 21.-A clove hitch. 

rings every time the stalls are mucked-out, and consequently if spring hooks are not used, the length of the respective ropes will have to be frequently readjusted, with a needless and a very inconvenient expenditure of time and trouble.

In stalls which have double breast-boards, the length of the outward tying-up rope should be just sufficient to allow the horse to obtain his hay from the hay net; but not to annoy his companion; and the length of the inward rope should give him full liberty to eat out of his trough, but not to bite his neighbour. With the double breast-board arrangement, these lengths would respectively be about 22 and 20 inches. Special attention should be paid to keeping these tying-up ropes at a proper length; for if they are 
too short, the horse may be prevented from eating; and if too long, he may not only tease and bite his neighbour or companion, but may appropriate his food.

The application of coal tar to the tying-up ropes and hay nets, will often prevent horses gnawing them, which crib-biters are particularly fond of doing. Coal tar is much more effective for this purpose than wood tar.

Chains of a fixed length can be substituted with great advantage for tying upropes. Their utility is still further increased by the addition of spring hooks. 


\section{STATIONARY SLINGING OF}

\section{HORSES.}

FOR purposes of support, horses may be slung in their stalls; on one of the hatches; in various positions on the exposed deck; or on one of the decks below it. In the stalls of cattle boats, horses may be slung on cattle stanchions (portable cattle fittings) which are hung up to the deck over the horses. It is a great advantage to have means for slinging horses in all stalls. Provided there are slings, there is no difficulty in slinging horses in portable horse boxes. Derricks may be used for slinging horses which are 
standing on hatches or on the exposed deck. When a horse is standing on a hatch, one of the beams that go across the opening of the hatch, will probably be the best object on which to attach the ropes of the sling. For the same purpose, a beam may be laid from the rigging to one of the derricks on the exposed deck. In a sling of this kind, care should be taken that pressure is not put on the withers or on any other part of the backbone of the animal, and that the breeching and breast-piece of the sling do not exert undue pressure on those portions of the skin which they touch. If necessary, these points of contact should be protected by suitable material, such as cotton waste, tow, etc.

The breast-piece of a sling should be of 
rope or canvas, but not of leather, which is apt to get torn by the tongue of the buckle, in the event of strain being put on it. I have seen two cases of horses which were slung on board ship, getting killed by the breast strap giving way in this manner. One of these animals fell out of the sling in which he was being lowered from the exposed deck, and was fatally injured. The other fell forward in the stall in which he was slung, and got choked by a rope which had been put round his neck in place of a head-collar.

Slings are of use to a stationary horse only during fine weather, when he can ease his feet by resting a portion of his weight on them. To permit of his doing this, the slings should be only loose enough to allow of the flat of the hand to be passed between 
them and the lower part of the animal's chest and abdomen. If they be so tight as to exert pressure on that surface, when the horse is standing up, their presence will have a more or less injurious effect on his organs of breathing and digestion. In rough weather, even when the slings are slackened out to their full limit of efficiency, their, presence will endanger the security of his foot-hold, and may thus lead to a serious accident.

If a stationary horse which is slung; will not bear any weight on his feet, the slings should be at once removed or entirely slackened out; for their pressure would interfere so seriously with his breathing as to kill him in a short time.

As a rule, one sling to twenty horses will be sufficient. 


\section{FOOT-HOLD IN STALLS.}

ON pages 95 to Ioo, I have emphasised the necessity of giving horses at sea good foothold. Although coir mats act admirably for this purpose in portable horse-boxes, they are not generally applicable to stalls, on account of the difficulty in mucking-out which their presence would entail. As the fore legs of a horse bear more weight than the hind ones, their stability is of special importance. I have accordingly found that the requirements of foot-hold for horses in stalls is amply fulfilled, as a rule, by placing their fore feet on a nonslippery surface, such as a coir mat or a thick 
layer of hay. A mat in this position would run little risk of becoming soiled by urine or dung, and consequently the duty of keeping it clean would cause but little trouble. On board the Idaho and Kelvingrove, I found that my suggestion of putting soiled hay under the horses' fore feet admirably served the purpose of giving them secure foot-hold. Colonel Duck tells me that in several steamers which carried remounts from South America to South Africa, the animals were bedded down with alfalfa (lucerne) hay, and that no mucking-out was practised. Consequently they had good foothold both before and behind, although their hind quarters received a gradually increasing elevation which, towards the end of the voyage, must have been somewhat inconvenient to the animals. This plan of allow- 
ing the dung to accumulate in stalls for a long period has been practised from time immemorial in many parts of the Continent, and is not as productive of foul odours as one might imagine. Although it gave good results with respect to the mortality of remounts during their transport from South America to South Africa, it would of course be inapplicable to steamers which had to cross the line, owing to the increased activity in the process of decomposition, due to tropical heat. Veterinary surgeons who had charge of Argentine remounts in South Africa, tell me that these animals arrived unshod, with the ground surface of their feet in a deplorable state of neglect, on account of their having stood in a mass of damp decomposing matter during their respective voyages, and 
consequently a large proportion of them were incapable of being worked for a considerable time after disembarkation. The interval necessary for the macerated and thrush-afflicted feet to recover their normal condition of soundness, not being allowed by our military authorities, it was natural that only a very. small percentage of these remounts proved fit for service. 


\section{WATERING HORSES.}

Captain Ross-Smith writes to me from Port Elizabeth as follows:-

"Cattle (horse) steamers with water ballast are far preferable to those which carry only a comparatively small supply of that fluid, and trust to their condensers to supplement any shortage. This condensed water is palatable neither to man nor beast, and should be used as little as possible for drinking purposes. The importance of this water question is shown by the enormous quantities required for a shipload of animals. We have the pitiful case of a steamer which arrived here from Australia 
vi $\hat{x}$ East London, short of water, with her horses dying of thirst, and their mangers filled with untouched food. Although this steamer was paid off in consequence of the report sent to the Admiralty about her, the Australian Government chartered her afresh to carry horses to South Africa!"

Before ballast tanks are used to carry fresh water for horses, they should be carefully cleaned out; because they are often very dirty, and frequently contain considerable quantities of salt which has been left in them from the salt water they had previously held. During this war, there have been cases of captains of steamers filling their tanks, for the purpose of economy, with water from the river in which their respective steamers were afloat at the time, with the result that the in-take was 
more or less brackish, and consequently unsuitable for man or beast. As far as my experience goes, fresh water carried in ballast tanks generally contains a large quantity of iron, and is also greatly discoloured on account of having been in contact with the accumulated rust in the tanks. Although this water makes abominably bad tea, I have not observed that it produces any ill effect on the health of horses which drink it, or that these animals dislike it ; supposing of course that it is not otherwise unpalatable or noxious from the presence of salt, etc. If this rusty water, after it has been drawn, is allowed to stand for an hour or two, a large portion of the rust which is suspended in it will settle down, and the water will become proportionately improved in taste. It is almost needless to say that the carrying-out 
of such a precaution would be impracticable with a large number of horses. In any case, it would be well to test the water before sailing.

The principles which should guide us in the watering of horses on board ship may be summed up as follows: They should be watered not less frequently than three times a day; they should be watered shortly before being fed, but not for at least three hours after being fed; and they should be allowed to drink as much as they like.

For the transit of large numbers of horses, water-pipes should be laid on in every deck which carries these animals, and the pipes should be provided with rubber tubes and turncocks at suitable intervals. In Fig. I8 (p. I2I), a water-pipe runs along the upper 
part of the front posts, and one of its rubber pipes can be seen, turned up out of the way, at the top of the spare stall.

Probably the best way to water horses at sea is out of an ordinary sheet iron or zinc stable bucket held up to each animal. If a horse is watered out of his metal or wooden feeding trough, the probability is that the water will become more or less tainted by particles of sour grain, and will consequently be distasteful to the animal. In no case should water left in a trough by one horse, be poured into the trough of another horse for him to drink; for the degree of contamination of the fluid will thereby be probably doubled. In watering several horses out of one bucket, the dregs at the bottom of the bucket, each time it has been more or less completely emptied 
by one or more horses, should be thrown away, and should not be allowed to contaminate the succeeding fresh supply of water. Anything less than, say, one pint might be fairly regarded as "dregs." If the first or second horse to whom a pailful of water was offered desired to finish it, he should be allowed to do so, in which case, the quantity of the dregs would be at a minimum. The hygienic importance of proper watering is so great, and the fastidiousness of many horses in drinking is so well marked, that each attendant should be most careful to allow his horses full time and opportunity to drink their fill. Some horses drink very slowly and with several intervals. The watering buckets should be kept scrupulously clean; not only as a direct safeguard to health, but 
also because horses will often refuse to drink water which is even slightly tainted.

The Government allowance of 10 gallons of water a day for each remount on board H.M. transports is ample, and allows a good margin for waste, which is often large. I have found that an ordinary horse will not drink daily more than 5 gallons, even on a voyage from Bombay to Liverpool during the summer. 


\section{FEEDING UTENSILS, AND GEAR.}

THE present galvanised sheet-iron feeding troughs which are used on Government horsecarrying transports, and which are shown in Fig. I 8 (p. I 2 I), serve their purpose fairly well; their only two faults being; as far as I can see, that they cannot be fixed to their respective breastboards securely enough to prevent the horses displacing them; and that horses can more or less easily throw food out of them. I regret that I am not a good enough mechanic to be able to devise a contrivance for the removal of the first mentioned objection. As 
soon as the generality of horses have eaten their corn, they will try to detach the feeding trough from the breast-board, probably as a signal that they want some hay. If the hay is given in nets, the prompt removal of each trough as soon as its respective horse has eaten his corn, will naturally entail a good deal of trouble on the attendants, who also will have extra work to do in replacing the troughs which are thrown down from time to time, in the case of the hay being given in them. I need hardly say that the troughs are liable to get injured by falling on the deck. If the horses are fed with hay as well as with corn out of the troughs, it would be advisable to make these mangers permanent fixtures, or at least, have them attached in such a manner that the animals could not knock them off the 
breast-boards, although an attendant could easily remove and replace them.

In order to prevent a horse throwing his food out of his trough-which he is particularly inclined to do, when it contains long hay full of hay seeds-we may adopt Colonel Duck's wise suggestion to continue the two flat iron hooks which are used for attaching the trough to the breast-board, completely round the trough, which will then have, near its ends, two bars running across it, that will prevent the animal carrying out his objectionable intention. In any case, the bars should be on the outside of the trough, and should be continued round its three sides, so as to distribute over a large surface any strain that may fall on the trough. The trough would be still further protected from injury by the adoption of 


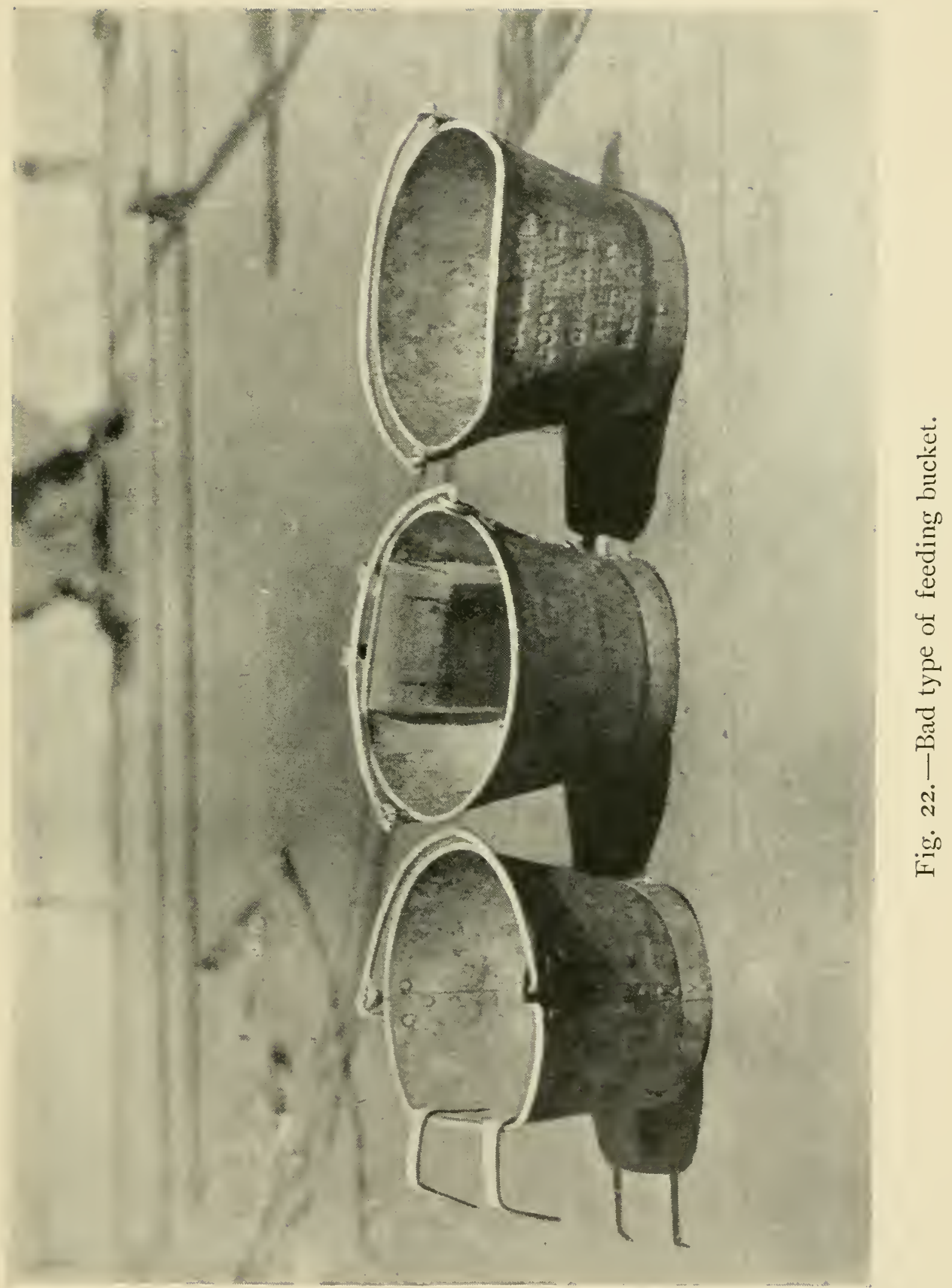



Colonel Duck's plan. The bad effect of curtailing the surface over which the strain had to be distributed in a feeding trough, is well shown in Fig. 22. We were supplied with these feeding buckets on board the Kelvingrove when she sailed for South Africa in February, Igor, and although great care was taken of them, only 88 of these buckets out of 525 remained intact to the end of the voyage. Thanks to the clever suggestion of $\mathrm{Mr}$. Simpson, the Chief Officer, we kept many of the broken ones in working order, by placing a piece of wood inside the damaged bucket, and nailing the hooks to it; the hooks in this case being placed on the outside of the bucket.

Iron mangers (feeding troughs or feeding buckets) are much preferable to wooden ones, 
because they are more easily cleaned; they do not absorb moisture; and horses are far less liable to crib-bite on them.

Feeding troughs are much better than nosebags, which soon become wet and dirty, even with dry food, by the saliva that escapes from the horse's mouth. They may, however, be useful in the event of the feeding troughs running short. On such an emergency, three of them can be made out of one corn sack. When turned with the hem inwards, they will then measure about $14 \frac{1}{2}$ inches broad and I $3 \frac{1}{2}$ inches deep. A canvas strap can be sewn to one side of the bag and a loop of canvas to the other side. The bag can then be put on the animal's head by passing the strap over his poll, and fixing it to the loop by a slip hitch (Fig. 20, 'p. I 37). Care should 
be taken to remove the bag as soon as the horse has eaten his corn, or has stopped feeding.

The best means of giving long hay is by means of hay-nets of about $3 \frac{1}{2}$ inches mesh, made of tarred spun yarn, and capable of containing about I 2 lbs. of hay, supposing that one net has to supply two horses. With these nets there will be a loss of about 25 per cent., caused by hay falling out on the deck or floor of the stall. The nets should be kept in good repair, for if they get broken, an unusually large proportion of the hay will fall out. Fairly long hay is required for nets, which retain short hay badly. The sergeants or under-foremen should see that the correct weight of hay is put into each net, and should weigh the filled nets from time to time, for which purpose, each sergeant or under-fore- 
164 Horses on Board Ship.

man should have a spring balance, capable of weighing at least $\mathrm{I}_{5}$ lbs.

There is an empty hay-net between two of the horses in Fig. I (p. I9).

Colonel Nunn tells me that mules are particularly fond of eating hay-nets and ropes.

One or more oat-bruising machines with smooth rollers should be provided in proportion to the number of horses. The crushing should be done daily, because bruised oats soon become musty.

If hay-nets are not supplied, one or more chaff-cutting machines should be provided; because there is great waste and trouble in feeding horses with long hay out of feeding troughs, especially if these mangers are not furnished with cross bars, to more or less successfully prevent the horses throwing out 
their food. Even the presence of cross bars will not prevent a horse getting rid of long hay in this manner.

The following list of gear is that sanctioned by the Admiralty for remount horse ships :-

I Admiralty pattern halter, with two head ropes for each animal (half large, half ordinary, the former with distinguishing mark such as coloured brow-band) and $5 \%$ spare halters.

I Canvas horse hammock for every 25 animals.

I Hay net for each animal shipped and $5 \%$ spare.

2 Coils $I \frac{1}{2}$ in. Manila ratline for spare halter ropes.

2 Corn crushers.

2 Cháff cutters.

50 Curry combs.

$5 \circ$ Dandy brushes.

50 Large sponges.

$6 \frac{1}{2}$-peck measures.

6 quart measures.

I 2 Windsails; 6 for main deck and 6 for deck below.

I Windscoop for each side port where animals are carried.

25 Coir brooms.

6 Mops.

Io Steel scrapers.

6 Spanners for bolts.

6 Axe hammers. 
50 Square-mouthed shovels.

I Dung-fork for each two cattlemen carried.

24 Whitewash brushes.

2 Io-cwt. cane dung baskets for each 'tween deck where animals are carried.

50 Small cane hand dung baskets.

2 Galvanised buckets for each attendant and Io \% spare.

4 Thermometers for each 'tween deck or compartment of shelter deck, and also sufficient to take temperatures on deck.

I Salter's spring balance to weigh up to $200 \mathrm{lbs}$.

Hurricane candle lamps sufficient to light to approval all decks where animals are carried.

(If vessel is fitted with electric light, 4 candle lamps are to be carried for each 'tween deck, and sufficient to light other horse decks in the event of the electric light failing.)

Sufficient candles for the voyage.

4 Water tubs in each 'tween deck or shelter deck or other compartment where animals are carried, or where vessels are fitted with permanent water service a tub is to be fitted under each tap.

A sufficient supply of cocoanut matting for exercising horses on voyage.

A sufficient supply of canvas for protecting the front of all exposed stalls, unless where screens have been already fitted. 


\section{FOOD AND FEEDING.}

$\mathrm{HAr}$, as we have seen on pages 3 to 8 , is undoubtedly the best food for idle horses, like those on board ship, and should be given in liberal quantities, say, I 5 or I 6 lbs. a day with a small amount of corn. In order to make the feeding conditions of hay as nearly as possible the same as those of grass-which is the natural food of the horse, but which cannot be conveniently stored on board ship-we should, if practicable, supplement the hay ration with one of from 4 to 7 lbs. of carrots daily. Parsnips are quite as good as carrots for horses, but they are dearer and are not so 
easy to get. As these roots are apt to rot, they should be put on board fresh, and in a fairly dry condition.

Horses on board Government transports are sometimes provided with mangold-wurzels, when carrots cannot be obtained at a sufficiently low price. We had them on the good ship Idaho, but most of them were' rotten. Even the sound ones were not relished by the horses. They were certainly a failure in this case.

To keep up the working capabilities of the horses, without unduly "heating" their systems, we may give them a moderate supply of bran or oats, or of both. As a bran mash is regarded by many people as the sole form of bran as a food for horses, I must point out that the admixture of water in this case 
diminishes the digestibility of the bran and makes it a laxative. If, however, the animal is allowed to make his own bran mash, by giving it to him dry, he will be obliged to thoroughly masticate it; for if he does not do so, his mouth will not obtain a quantity of saliva sufficient to enable him to swallow it. When the bran has been ground into a fine state by the teeth and saturated with saliva, it will be in the best possible condition for reception and digestion by the stomach. Although a bran mash may be regarded as a laxative medicine, dry bran is a highly digestible and nutritious food, as I have proved with hundreds of horses on sea and land. More than thirty-years ago, Colonel John Anderson, A.N.D., directed my attention to this fact, which Müntz, Grandeau and 
other Continental scientific-men have amply -proved.

Some people have the mistaken idea that dry bran should always be damped by sprinkling it with water, before giving it to a horse; because its floating particles, so they say, will go up his nostrils and injuriously affect his organs of breathing. I have never found a single case of this to occur with the many thousands of feeds of dry bran which I have seen given to horses in feeding troughs and ordinary mangers; although the presence of dry bran in a nose-bag might make an animal sneeze. A valid objection to the wetting of bran, as I have already indicated, is that the damper it is, the less will the horse chew it, and the less saliva will he secrete to mix with it. 
I have often found at sea that the substitution of dry bran for oats, or for a mixture of oats and bran, will often cure a horse of diarrhœa apparently set up by the oats, in which case undigested oats will generally be seen in the dung.

Formerly, the daily grain ration for each horse on Government transports consisted of half bran and half oats; but I see by the Government "specification," printed in July, Igor, that it is now to consist of 60 per cent. of bran, and 40 per cent of oats. The increase in the proportion of bran probably arose from the favourable reports made upon bran as an article of food for horses at sea.

The only drawback to the use of bran on board ship is its liability to ferment, in which 
case it becomes heated, "cakes," and assumes a musty smell. If fresh bran is obtained shortly before sailing, and is properly stored, it will undoubtedly keep sweet for six weeks, if not longer; but it is generally difficult to be sure of its freshness at the time of purchase. In fact, considerable quantities of bran are imported to England from India. The only practical way I know of testing the freshness of bran, is finding that it smells sweet, is not caked, and is not abnormally warm, which we can do, by inserting our bared arm deeply into a bag or heap of it.

For ship use, I am inclined to prefer moderately light oats to heavy ones, as I find that they are not so liable to upset the digestion of idle horses. Respecting the quality of oats in other respects, I need 
only say that the grain should be thoroughly dry and free from any musty smell. We all know that old oats are more digestible than new oats, and that kiln-drying, in the case of oats, is generally employed to improve the condition of musty corn. Consequently, kiln-dried oats should be viewed with more or less suspicion.

When a horse eats unbruised oats, which is not one of his natural foods, he is very liable, owing to the smoothness of their coats, to swallow them without properly chewing them, as we may see by an inspection of his dung. The process of bruising increases the difficulty of swallowing them without sufficient mastication, and it also exposes their interior, which contains their nutritive constituents, to the action of the digestive 
juices. Consequently, bruising improves the digestibility of oats.

The chief points about grass hay are: that it should be free from any musty smell; that it should be green in colour; and that it should contain very few weeds, no dust, and no seeds. Mustiness is shown not only by the smell, but also by more or less large patches of mould distributed throughout the fodder. When hay has been quickly cured by a liberal supply of bright sunshine and sufficiently frequent turning over, it retains its colour to a great extent and the most of its nutritive properties. When cut grass is exposed to the action of the weather and especially to rain, its colour and much of its nutritive material becomes dissolved out. If an undue amount of fermentation is set up, 
the hay will turn more or less brown. The obnoxious presence of weeds and dust needs no comment; but I may explain to readers who are unacquainted with the principles of agriculture, that between the respective time of flowering and seed, the nutritive value of grass and consequently that of the resulting hay, becomes considerably decreased.

Experiment has shown that chopped hay "goes farther" than long hay, and that it undoubtedly improves the digestibility of corn when mixed with it. The length of the grass taken into the mouth of a horse when he is grazing in the open, is certainly much nearer that of "chop," than that of long hay.

Oaten hay, which is oats cut when the grain is in a soft condition and then dried, 
is very largely used by Australian horse shippers, from whom I have often bought surplus quantities of it, when I lived in Calcutta. I have found it to be an admirable food for horses.

Experience with the shipping of remounts from the Argentine Republic to South Africa, has proved that lucerne (alfalfa) hay is an excellent food for horses at sea. The normal colour of clover hay is more or less brown.

I would suggest the following daily ration for horses on board ship :-

$$
\begin{aligned}
& \text { Bran, } 6 \text { lbs. } \\
& \text { Hay, } 17 \text { lbs. } \\
& \text { Or oats, } 3 \text { lbs. } \\
& \text { Bran, } 3 \text { lbs. } \\
& \text { Hay, r } 7 \text { lbs. }
\end{aligned}
$$

And, say, 5 lbs. of carrots in either case. 
The Government daily forage scale for remounts at sea is :-

$$
\begin{aligned}
& \text { Oats, } 4 \text { lbs. } \\
& \text { Bran, } 6 \text { lbs. } \\
& \text { Hay, i } 2 \text { lbs. }
\end{aligned}
$$

And for horses proceeding from New Orleans or Canada :-

$$
\begin{aligned}
& \text { Oats, } 5 \text { lbs. } \\
& \text { Bran, } 3 \text { lbs. } \\
& \text { Maize, } 2 \text { lbs. }
\end{aligned}
$$

Also, 4 cwt. nitre, 5 cwt. rock salt, I०० gallons vinegar, and 2 tons linseed are allowed for each shipment.

Formerly, only Io lbs. of hay was allowed, which quantity I found to be far too small, especially as there is always a large percentage of loss in the hay. This loss, as I have already shown, would be reduced to a mini- 
mum by chopping the hay, and by giving it in troughs provided with a cross bar near each end.

With respect to the principles of feeding, I need say nothing further than that, as we all know, horses should be fed frequently, and that they should not be given hay for at least an hour and a half after their corn. In order to maintain the sound principle of frequency of feeding, the first feed should be given as early in the morning, and the last feed as late in the evening; as is compatible with due regard to the convenience of the attendants. The arrangement laid down on pages 182 and I 88 will, I think, meet these requirements. The advisability of refraining from giving hay soon after corn, is that the latter, for purposes of digestion, re- 
quires to remain longer in the stomach than the former. As a horse's stomach is comparatively small, more or less of the corn will be pushed out of it in an unprepared state, in the event of hay being given soon after he is fed. 


\section{HORSE ATTENDANTS AND STABLE DUTIES.}

WE shall first consider the case of army horses which are accompanied by cavalry men.

The best arrangement is to divide the horses into sections, each of which is to be looked after-as regards watering, feeding, grooming, exercising (when possible), and mucking-out -by one man, who being in frequent attendance on his charges, will be able to promptly notice and report any signs of indisposition in them, which work could not as a rule be done by men who came on 


\section{Horse Attendants and Stable Duties. I8 I}

duty by roster. These men should be exempt from all other duties; and attendance during the intervals between stable hours should devolve on stable guards, who could come on duty for four hours at a time. The work of the stable guards would be to see to the general welfare of the horses, to replace any hay that had fallen out of the feeding troughs or hay nets, and to feed them on hay during the night, as might be ordered. ()ther men would be required to lend a hand during mucking-out and exercising times. Sergeants and corporals should be told off to supervise the work of the men, according to the number of non-commissioned officers.

Supposing that the men's meal times were 8 a.m., I p.m., and 5 p.m., a suitable arrangement for the hours of feeding would be :- 
5.30 a.m. Water and feed.

7.30 a.m. Hay.

I 2 noon. Water and feed.

2 p.m. Hay.

6 p.m. Water and feed.

8 p.m. Hay.

Hay should also be supplied during the night; and during very hot weather, the horse might with advantage be watered again at Io p.m.

On Government transports carrying remounts to South Africa, the following arrangement for stable duties has been laid down :-

"MORNING STABLES.

"Rake the stalls well out to the rear, sweep up the passage behind the horses, and sprinkle disinfectants, water the horses, sponge 


\section{Horse Attendants and Stable Duties. I $83_{3}$}

nostrils, eyes, etc. Feed with oats or bran after watering, and then with hay as ordered.

\section{"MID-DAY STABLES.}

"Shift horses into spare stalls and out on to the deck when practicable; pick out and wash the feet and examine shoes. Any loose shoes to be fastened at once, and slight injuries attended to. Thoroughly groom 'the body, brush and hand-rub the legs, brush out the mane and tail, and sponge nostrils and face.

"Each stall to be thoroughly cleaned, and platform to be raised and cleaned. Deck underneath to be dried, and disinfectants to be freely used.

"When the horses are clean, water and feed them as ordered. 
"After dinner the horses to be fed with hay for an hour.

" EVENING STABLES.

"Rake the stalls well out, sweep up, sponge nostrils, etc., as in 'Morning Stables.' Water and then feed with oats or bran as ordered. Stable men to feed horses with remaining portion of hay."

When remounts are sent without troops, there is generally one helper of the ordinary workman or street loafer type to from fifteen to twenty animals. The superintendence of these men, who are sometimes foreigners ignorant of English, is generally entrusted to a head-foreman and three under-foremen, supposing that there are about 500 horses on board. Instead of having a landsman to act 
the part of head-foreman, it is much the better plan, as a rule, to get, if possible, one of the mates of the ship (the Chief Officer for preference) to perform this duty, because he will be able to enforce his authority over the men under him much more effectively than an outsider could do. A non-official head-foreman cannot take the law into his own hands, and in the event of a difficulty with his men, he will have to refer the matter to the Chief Officer or Captain.

In the heterogencous crowd which consists of horse attendants or "cattle men" (I cannot call them grooms or strappers), lads or young men are generally better than their seniors, because as a rule they are more amenable to discipline, and accept rough work with greater equanimity. Such men, whether old 
or young, cannot be expected to have any experience among horses, which is not a matter of great moment, provided that the foremen, as they should do, possess that knowledge.

Not counting the foremen or watchmen, one man to every fifteen horses or twenty mules will be a fair allowance for the mere watering, feeding, mucking-out, and general care of these animals during the day. They should promptly report to their respective under-foremen anything they may see amiss with their animals. In the case of a hired transport all such reports should be brought without delay to the remount officer or veterinary officer in charge.

In the case under consideration, six watchmen will be required, three being on watch 
Horse Attendants and Stable Duties. I 87

at the same time. Their time can be divided as follows :-

6 a.m. to I 2 noon.

I 2 noon to 3 p.m.

3 p.m. to 6 p.m.

6 p.m. to midnight.

Midnight to 6 a.m.

The arrangement of two dog-watches of three hours each, makes the above division of time equitable. The men on night duty should carefully look after the horses of their respective divisions, and should call their foreman in the event of help being required. During the day, the watchmen on duty should be available for odd jobs. It is well to make them responsible for the halters or head-collars, as the case may be. 
Each attendant should have a quart measure for serving out the corn and bran to his horses.

I have found the following division of work to act well :-

$5.30 \mathrm{a} . \mathrm{m}$. Water and feed.

7.30 a.m. Hay.

8 a.m. Men's breakfast.

I I a.m. Water and feed.

I 2 noon. Men's dinner.

I.30 p.m. Hay.

5 p.m. Water and feed.

5.30 p.m. Men's tea.

8 p.m. Hay, before which water may be given in hot weather.

As board-ship horse attendants, whether military or civil, rarely know much 
Horse Attendants and Stable Duties. I 89

about the proper management of horses, their attention should, from the first, be called to certain details which play a large part in the welfare of the animals under their charge. On land, grooms almost always approach stabled horses from behind, but at sea the animals are turned the other way about. When an ordinary working man or boy who is unacquainted with equine peculiarities, passes by a box or stall from which the head of a horse protrudes, he almost always, either from ignorant fear of being bitten or innate cruelty, strikes more or less severely the animal's muzzle, which is particularly sensitive to external violence. As the upper lip of a horse is his organ of touch, he naturally advances it towards any passing object, which he will do without the 
slightest intention of inflicting injury, unless he has been rendered savage by previous bad treatment, which in this case has converted curiosity into vice. Teasing a horse by offering him objects to smell or eat, and then pulling them away, will also teach him to snap at passers-by. This deplorable custom of striking and teasing horses at sea is the cause of quickly making the large majority of them try to bite or violently throw their heads upwards and backwards, so as to get out of harm's way when any one goes past them. Hence, before horse attendants commence their duties on board ship, they should be seriously cautioned never to touch or threaten a horse's muzzle; and that when they are obliged to come up to an animal which is at all nervous or 
inclined to snap, they should hold up their hand at about the height of the upper part of his head, with the open palm turned towards him, and should gently pat his neck or rub his forehead with it while speaking to him in soothing tones. Everyone who has anything to do with horses should bear in mind that the human voice is one of the best and most powerful means for quietening and controlling horses. Both with troops and with "cattle men" I have had very disheartening experience of the brutal manner in which they often treat horses at sea; their fault in this respect being probably due much more to ignorance and timidity than to deliberate cruelty.

In all cases, one or two experienced blacksmiths should be on board in order to 
192

look after the shoeing of the horses, and to give special help as may be required. These men are particularly useful in cases of accident or emergency, on account of their skill in the handling of horses. 


\section{93}

\section{MUCKING-OUT.}

$W_{E}$ have seen (p. I46) that in a temperate climate, such as that of the sea between Melbourne or Buenos Ayres and Cape Town, mucking-out is not always imperative. But on a voyage across the Equator, such as that from Europe to South Africa, or one through such hot climes as those of the Red Sea and Indian Ocean, we may accept the fact that its fairly frequent enforcement, say, once every two or three days, is essential to the health of the horses on board. When military horses are accompanied by their own men, daily mucking-out can be easily performed; 
but the task is difficult in proportion to the lack of attendants. Although a week may, without detriment to health, be allowed to elapse between each complete mucking-out, when the weather is cold, such a long interval ensures the accumulation of an amount of dung which would entail much trouble to remove, and which might cause inconvenience to the horses, especially to those on the windward side, by raising their hind quarters too much, and thus putting an undue proportion of weight on the fore legs. When each stall has a separate breast-board, and when there is plenty of room in front of the stalls, each horse may be taken out of his stall, and put back into it after it has been cleaned out. In other cases, the best general way will be to take out two or more horses at 
one end, muck-out their stalls, take out the division-boards of the nearest stall, shift the horse in it to the first stall, replace its division boards, clean out the stall thus vacated, and continue on in the same way, until there are left at the other end two vacant stalls, into which the first two horses are placed.

In a ship with freeing-ports, the dung will be thrown overboard through them, in which case the dung from the stalls below will have to be carried up to the deck that is provided with freeing-ports. For convenience sake in mucking-out, the stalls containing freeing-ports should generally be kept vacant (Fig. 23, p. I97). If the wind is on the port side or quarter, the dung should as far as practicable be thrown overboard through the starboard freeing-ports; and vice versâ. 


\section{:96 Horses on Board Ship.}

In a flush-deck ship, which has no freeing ports, the dung will have to be carried to the flush deck and deposited over the side. The dung can best be removed from the stalls by means of shallow wicker-work baskets (skeps).

Mucking-out is necessary, not only for the removal of dirt and bad smells, but also to obviate the heating effect which the decomposition of dung and urine would have.

In mucking-out, only the dung and the wet portion of the hay which is under the horse should be removed; the remainder of the hay being left to give soft and secure foot-hold to his fore feet. No attempt should be made to clean the stalls by flushing them with water; because any effort in such a direction would be limited to one or two stalls (except when the two lower division boards are removed, page 


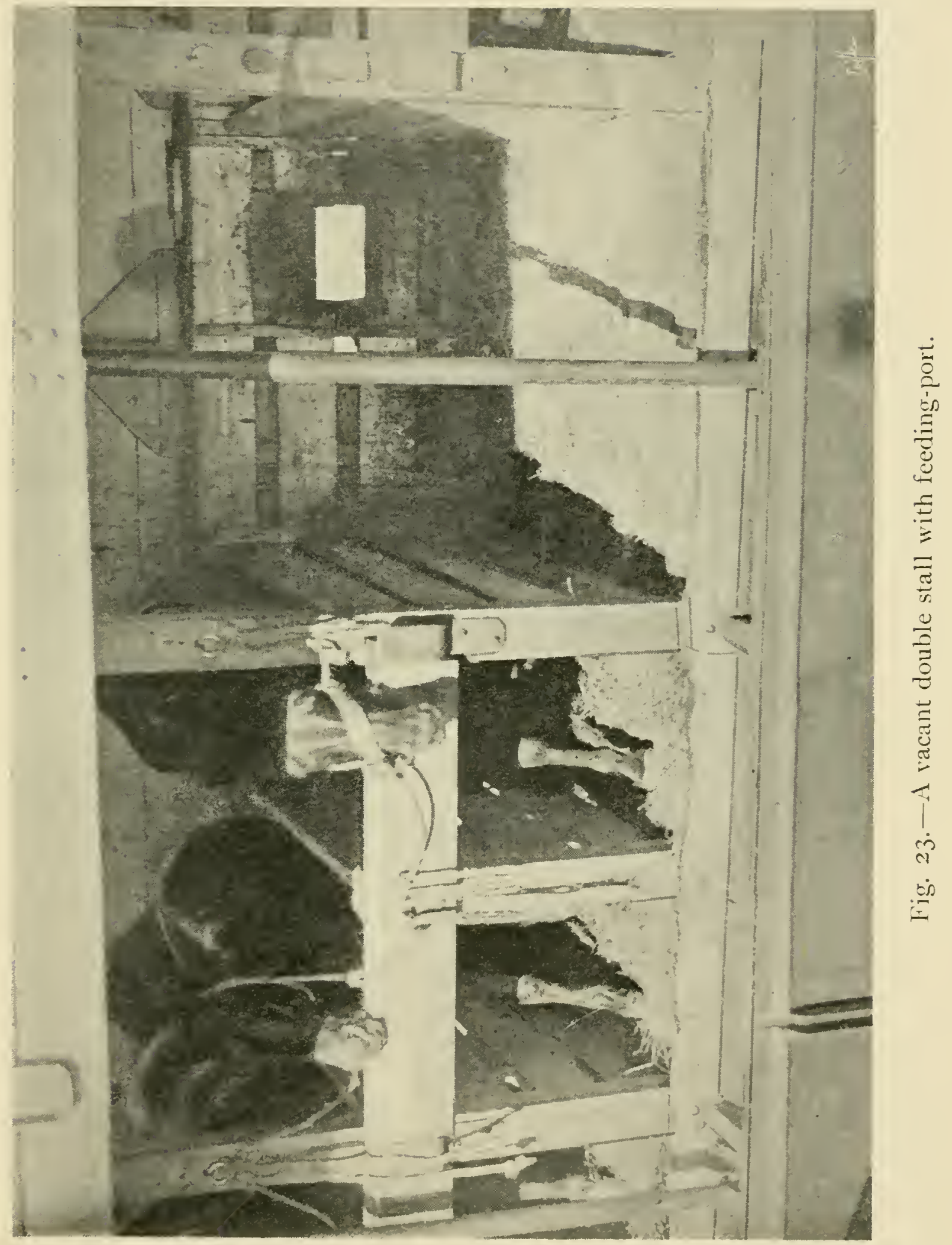



I 24), and would cause the dung in the neighbouring stalls to assume the consistence of mud, with the result that it would be difficult to remove, and would soil everything in reach. Besides, it would be difficult to remove such a filthy mess.

After all the dung and wet hay has been taken out of a stall, any damp or dirty spots on the floor can be disinfected by sprinkling powdered gypsum, quick-lime, or some antiseptic powder (McDougall's, for instance) over them. Gypsum (plaster of Paris), which very readily absorbs ammonia, is probably the best. Quick-lime, which has great affinity for water, should be used with care, on account of its corrosive action on the feet of horses. Chloride of lime should not be employed, because the chlorine given off from 
it has a very irritating effect on the eyes and organs of breathing of horses and men.

The daily quantity of disinfectants, per animal, allowed on remount horse ships is: 5 Oz. McDougall's powder or chinosol, $1 / 8$ pint phenyle, and 2 oz. powdered gypsum.

The greater portion of the horses' urine escapes through scuppers, or gets soaked up in the dung and is removed when mucking-out. If one side of the ship (as, for instance, the windward side or the one on which the water tanks are not so full as on the other side) is unduly high, the urine on it is apt to collect at the lowest parts of the deck or decks in question; because it cannot escape by gravitation through the scuppers of the side upon which it was deposited by the horses, in which case it should be removed a couple of times 
a day by suction pipes, bailed out by means of shovels or scoops, or soaked up by putting down hay. More or less of this urine will gravitate down to the lower side of the ship, unless it is prevented from doing so by fittings. 


\section{CHANGING HORSES FROM ONE} STALL TO ANOTHER STALL.

BEFore taking a horse out of his stall, the route by which he has to proceed, should be carefully laid down with matting, grain bags, hay, or rugs, as the case may demand. Instead of shifting a sick or injured animal to a vacant double stall, it will often be more convenient to put one of the horses which are next to him into it, or into an empty single stall, and thus give him a double stall without moving him. Or all the horses between him and the nearest vacant stall may be shifted one stall away 
Changing Horses from Stall to Stall. 203

from him, by removing and replacing the respective division-boards. If a horse is quiet and in no way inclined to tease his neighbours, he may be let loose in a double stall, and especially in a stall which consists of three single stalls. 


\section{GROOMING.}

Good grooming is of great benefit to horses which are travelling by sea during hot weather, and when ventilation is imperfect; because it removes dandruff and hair, and stimulates the action of the skin. When the protective action of the skin against cold has to be fully utilised, grooming should be dispensed with, as is done with horses which are "turned out" during winter. The more active is the skin, the more it reduces the bodily temperature by evaporation, and, besides, it removes impurities from the system. The question of grooming on board ship is closely connected with that of oppor- 
tunity, labour and risk. In a steamer in which there is plenty of room for taking horses out and abundance of efficient help, horses can be groomed during fine weather almost as well as on land; but the danger of accident should not be lightly incurred. When the attendants are unskilled in stable work and are few in number, the grooming had better be restricted to such small details as: sponging out the eyes, nostrils and dock; going over the body with a dandy brush; picking out the feet; and setting the mane and tail straight. In all cases, the yards of the horses should be drawn from time to time, and the sheathes cleaned and sponged out. If this be not done, the sheathes wili become swoljen and the animals will have difficulty in staling. 


\section{6}

\section{EXERCISE.}

Exercise is one of the best preservatives of the health and especially of the soundness of horses which have to remain on board ship for a fairly long time. I do not think that it is necessary when the duration of the voyage is not more than a fortnight; provided that the systems of the animals are in a "cool" state. Also, the smoother the passage, the more beneficial will exercise be, which statement is proved by the fact that horses' legs are more inclined to "fill" during fine weather than when it is rough; because prolonged rest greatly interferes with the 
circulation of their limbs. As exercising horses at sea is almost always accompanied with more or less risk of accident, we should, when resorting to it, take every precaution for safety. For this object, the portion of the deck which forms the exercising track should be covered with coir mats, or coir matting, which is made up in rolls, so as to prevent the animals from slipping, which is, their chief cause of danger in this case. Twenty minutes' walking exercise a day will generally be sufficient for the preservation of the soundness of their feet.

Although facilities to exercise horses are a very desirable condition on board a ship carrying horses, they cannot often be obtained, especially when the number of animals is large. 


\section{8}

\section{PRECAUTIONS AFTER DISEMBARKATION.}

During the three years I lived in Calcutta, I saw many instances of the bad effects of premature work after landing, among large numbers of horses imported from Australia and New Zealand. In this case, the passage takes from a month to six weeks. Experience with many thousands of these animals showed buyers the necessity of refraining from putting them to hard work before giving them a gradual preparation for it of at least three months. Here laminitis (fever in the feet) is the great danger. This disease may be 


\section{Precantions after Disembarking.}

fatal in bad cases, and even in mild ones it more or less unfits the sufferer for severe work for the remainder of his life. As a rule, not even one per cent. of a shipload of horses which had stood in stalls during a month's passage would have laminitis before disembarkation, but probably 50 per cent. of them would get it if they walked and trotted for ten miles immediately after landing. Even a walk of two miles from the pier to the remount depôt at Port Elizabeth has been a fruitful means of setting up laminitis in the horses whose feet showed no signs of this disease on landing. I have seen scores of similar cases at Calcutta. Here the danger is inversely proportionate to the length of time between landing and resumption of work. Horses landed off a ship in which they have 
had no exercise for, say, a month, ought not to be obliged to walk more than half a mile to a place where they can be put up in loose boxes or small enclosures, so that they may gradually accustom themselves to narrowly restricted movement for some days, and their exercise should then be increased little by little until all danger of laminitis has past. The limit of three months before the resumption of hard work after a voyage of, say, a month's duration, is in accordance with the opinion of all veterinary surgeons who have had experience in this subject. In cases of extreme necessity, such as those of war, it might be reduced to three weeks, but even then the resulting percentage of loss would be high. If horses have been exercised on board, they will of course be able to resume 
work much quicker than if they had been kept all the time standing still.

As horses, when under natural conditions, spend a very large portion of their time moving about in search of food; their limbs are ill adapted to bear the bad effects of inaction, particularly when the animals cannot relieve the consequent congestion by lying down. The immediate ill consequences of long standing, on the feet of horses, is far less injurious to them than the inability to bear even moderate exercise which it induces, supposing that the animals are put to work soon after the completion of the voyage. The danger to be specially feared in these cases is the occurrence of laminitis (fever in the feet), to which disease horses are specially liable, owing to the fact that their feet are 14 * 
enclosed in an unyielding box of horn. In laminitis caused by premature work after a long period of idleness, we have a case somewhat akin to frost-bite, which is produced by the coldness of the air causing the blood to leave the blood vessels of the part, the result being that the longer the blood is absent, the more irritating will be its effect on the blood vessels when it returns; and also the degree of irritation will be proportionate to the suddenness of the return. Consequently, if the blood rushes violently back to blood vessels which have remained comparatively empty for a considerable time-as would happen in the event of a frost-bitten person or animal entering a warm room or approaching a fire-more or less inflammation will ensue, with the probable result of mortification 
to a greater or less extent. Hence, in an attempt to restore the circulation of a frostbitten part, it is well to rub it with snow, so as to produce a slow return of the blood, in order that the blood vessels may gradually resume their ordinary work which has been kept in abeyance by cold. Neglect of this essential precaution of obtaining gradual restoration of a disused function, has been the cause of the death of thousands of army horses during the present South African war. Instead of giving lately-landed animals, at the very least, three weeks, during which to gradually accustom their feet to normal conditions, our Generals at the front, being badly in want of horses, adopted the disastrous plan of ordering the new arrivals to be promptly sent up country, with the result that the average 
duration of life of three hundred and odd thousand remounts has been about six weeks. Had these Generals taken the precaution to consult their veterinary staff, they would no doubt have learned that moderately serviceable horses in three weeks' time, would be more useful for military operations than dead ones. Besides, the mounting of men on horses which were incapable of enduring a single day's hard work, has been the cause of the death of great numbers of our young men and boys in South Africa. In such cases, the crime of ignorance is no less serious than that of heedless disregard of life. Some excuse might be admissible for this deplorable folly, if the war had been finished in the supposed six months' time. 


\section{COST OF TRANSPORT,}

As instances of moderate charges by a first class line, I give the following rates by steamers belonging to Messrs. Thos. Wilson, Sons and Co., from Hull to the following ports :-

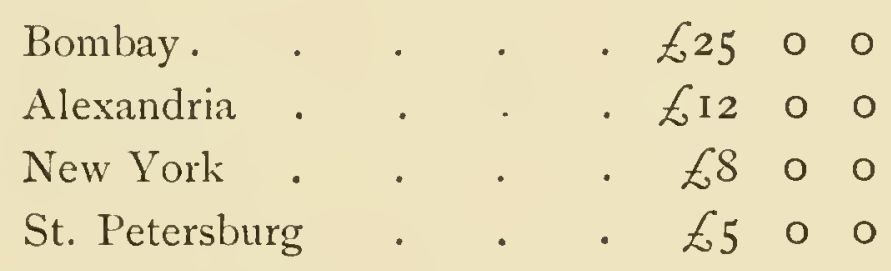

and a guinea for ponies from Riga to Hull or London.

- In all these cases, except in thar of ponies from Riga, the Company furnishes portable horse-boxes, and always drinking water. Attendants on the horses are carried generally 
at reduced fares, which the owner of the animal will have to pay. He may also be liable for the return passage of the man or men. On short trips, such as that to St. Petersburg, an arrangement can generally be made with the captain of the steamer to get one of the ship's hands, for instance, the carpenter, to look after the animal or animals.

Messrs. Sewell and Crowther, of Cockspur Street, S.W., who are passage brokers, give me the following quotations by tramp steamers :-

Melbourne . $\quad 50$ gs., and Io gs. for horse-box.

Durban. . . 35 gs. (including box and fodder).

Buenos Ayres . I5 gs., and Io p.c. on value of horse (including horse-box).

The large number of horses sent over every year from Australia to India are usually taken by "ocean tramps" at the 
very moderate rate of from $£$ io to $£$ I 2 a head, although the passage lasts as a rule from a month to five weeks. The cheapness of freight by this route is due to the fact that ships homeward bound from Australia, often find difficulty in obtaining a full cargo; and as the exports from India are much larger, their owners are generally glad to take a cargo of horses to Calcutta, Madras, or Bombay, even at a slight loss.

Captain Ross-Smith tells me that "during the early part of this war, Government awoke to the fact that thousands of horses and mules were required to replace casualties, and to mount more men than were originally considered necessary. Tenders were hastily drawn out and placed to charter vessels at exorbitant rates for the convey- 
ance of these animals to South African ports. For instance, the ss. Mohawe was chartered to carry animals from New Orleans at about $£ 25$ a head. A large proportion of these ships which were hurriedly taken up were unfit for their purpose, and they arrived in South Africa with horses and mules packed like herrings in a barrel, and stowed away in all sorts of places, even on bridge decks and in coal bunkers, as I have seen. The first consignments were 25 or 30 per cent. more than the respective steamers could properly accommodate. The fittings were often disgracefully bad, and were constructed from the cheapest materials. The contracts for steamers taken up only for the voyage to South African ports, were far more costly to Government than ships on a 


\section{Cost of Transport.}

time charter, say for six months at so much per gross ton per month. For instance, the ss. Montezuma, which was hired only for the voyage, made two trips in little more than three months, and turned over to her agents $\mathcal{E}_{\mathrm{i}} 6,000$ or $\mathcal{E}_{\mathrm{i} 7,000}$ on the transaction. Had she been a numbered transport she would have saved the Government a third of that sum. In view of national emergencies, some of the best cattle boats should be subsidised for use in time of war, and as they get old they should be replaced by new ships. Thus, for a nominal yearly expenditure on subsidies, large sums of money would be saved at some future time. The same plan might, with advantage, be applied to steamers intended for the conveyance of troops, or of troops and horses." 
Steamers have recently been taken by Government for the conveyance of horses to South Africa at $£ 15$ to $£ 15$ a head, with $£ 2$ extra on all landed alive. These rates include cost of fittings, forage and attendants. 


\title{
VETERINARY REMARKS.
}

\author{
VETERINARY INSPECTION.
}

BEFORE embarkation, every horse should be carefully inspected by a veterinary surgeon to see if it is suffering from any contagious or infecticus disease, in which case, the affected animal or animals should, if possible, be excluded from participation in the voyage. The narrow limitation of space on board ship greatly facilitates the spread of such diseases, and renders their successful treatment and the proper segregation of the patients far more difficult than on land. In this respect, the maladies which should occupy our special 
attention are glanders, influenza (pink-eye), strangles, and pneumonia.

\section{GLANDERS.}

The attention necessary to be paid to the investigation of glanders varies greatly according to the country of export. Thus, although the consideration of this terrible disease may be ignored with regard to Australian horses, we should diligently search for it among horses about to be exported from the United States (especially the Southern States), Canada, and even from England, where its prevention is deplorably neglected by our legislative authorities. It was particularly rife in Cuba, whence many infected animals were brought to the Southern States, after the Spanish American war. I need not touch 
on its symptoms and on its diagnosis by mallein, as these subjects are discussed in veterinary text-books. If glanders is found among horses at sea, all those which show clinical symptoms of the disease should be promptly killed and put overboard. Those which give diagnostic reactions with mallein, without external symptoms, may be isolated or destroyed. The danger of infection from such isclated animals is not very great. An observer who is guided only by symptoms, should bear in mind that the symptoms of ulcerative lymphangitis (Nocard's) and epizootic lymphangitis (Rivolta's) closely resemble those of farcy, and that these two forms of lymphangitis have been sometimes mistaken, even by veterinary surgeons, for farcy. The distinguishing test is naturally mallein. I 
need hardly say that farcy and glanders are merely different forms of the same disease. The only case of ulcerative lymphangitis which I have seen was in Cape Colony; the animal being a remount from the United States.

\section{STRANGLES.}

In ordinary strangles, I have found it well to rub the swelling under the jaw with biniodide of mercury ointment (I to 4), as soon as it became hard. In this case, the biniodide seems to act as an antiseptic in checking the formation of pus.

\section{PINK-EYE.}

This disease had best be treated by careful nursing and attention to the state of the bowels. 


\section{FILLED LEGS AND LAMINITIS.}

These ailments are frequent causes of trouble among horses on board ship, especially during fine weather; and their best remedies are exercise and cotton wadding bandaging. In many cases, exercise has unfortunately to be restricted to that which can be obtained from the rolling and pitching of the ship. - The object of cotton wadding bandaging is to supply evenly distributed pressure, which has the effect of quickening the circulation of the bandaged part, and thereby preventing the escape of an excess of watery material from the blood vessels into the tissues, and hastening the removal of such an effusion, if it be present. The method of applying these bandages is as follows:- "Take two yards of cotton wadding (which can be obtained from any draper), and 
cut it down the centre, so as to have two pieces of wadding a couple of yards long and about ten inches wide. Wrap the leg round with this wadding, one piece over the other; apply round it, rather loosely, a calico bandage (which can be got ready-made from any chemist, or can be constructed out of a piece of unbleached calico) about six yards long and three inches wide, so as to keep the wadding in its place; and tightly apply another and similar calico bandage, so as to afford firm and evenly distributed pressure on the leg, and secure it by tapes, sewing; or by a safety pin. With the amount of wadding which I have recommended to be used, there is practically no danger of putting on the second bandage too tightly." Veterinary Notes for Horse-Owners. 
COLIC.

Colic as a symptom of indigestion from improper feeding and watering, is not an uncommon malady among sea-going horses. It is often due, on board ship, to very trivial causes, owing to the want of exercise from which the patients suffer. With respect to its removal, good results can generally be obtained by a drench consisting of a bottle ( $\mathrm{I} / 4$ pint) of linseed oil and $2 \mathrm{oz}$. of oil (spirits) of turpentine; or by a 4 -drachm ball of aloes, followed, if necessary for the alleviation of pain, by a drench composed of a pint of water and a quarter of a pint of spirits (whisky, brandy, or rum) or an ounce of chlorodyne. Here, as Gamgee remarked many years ago, we require the removal of the cause (undigested and generally fermenting food), which we can 
usually effect by means of a laxative, such as aloes or linseed oil. Merely treating the pain would naturally be a false application of medicine.

Giving a drench chiefly composed of linseed oil is often an uncertain and disagreeable task. A modern remedy for ordinary colic is eserine by itself or combined with pilocarpine ( $\mathrm{I}$ or $\mathrm{I} / 2$ grain of the former to 2 or 3 grains of the latter), dissolved in $\mathrm{I}$ or $\mathrm{I} / 2 \mathrm{drachm}$ of water, and injected subcutaneously or intratracheally. Eserine, especially when combined with pilocarpine, acts as a rapid and effective purgative (see Finlay Dun's Veterinary Medicines). An ounce of chloral hydrate dissolved in water may be given as a drench if a sedative be required. Chloral hydrate relieves intestinal spasm; it is an 
antiseptic, and does not check the action of the bowels.

CUTS AND ABRASIONS.

These wounds are of frequent occurrence among horses on board ship. The animals sometimes rub their tails to a severe extent (Fig. 24) by hanging back in their stalls, especially when the upper edge of the top haunch board has not been bevelled off. I have found that tannoform is an excellent antiseptic for the treatment of these injuries, as it quickly forms a dry scab, and in this respect is greatly superior to iodoform. It is comparatively cheap, free from any unpleasant smell, very absorbent, and is soluble in spirit (methylated spirit for instance). I can strongly recommend its use, particularly as a 
dry dressing, dusted on or gently rubbed in with a finger, if necessary. For the same purpose Colonel Nunn advises the use of iodide of starch, which is made by mixing I part of tincture of iodine with $2 \mathrm{~T} / 2$ parts of starch. Tincture of myrrh and aloes, and Friar's balsam are fairly good applications to small superficial wounds.

THRUSH.

Horses which stand for many days on a damp surface-especially if it contains decomposing matter, such as urine and dung-are almost certain to suffer from thrush in an aggravated form, and to have the soles of their feet more or less rotten. It is almost needless to say that if horses are landed off ship in such a state they. will take at least a 


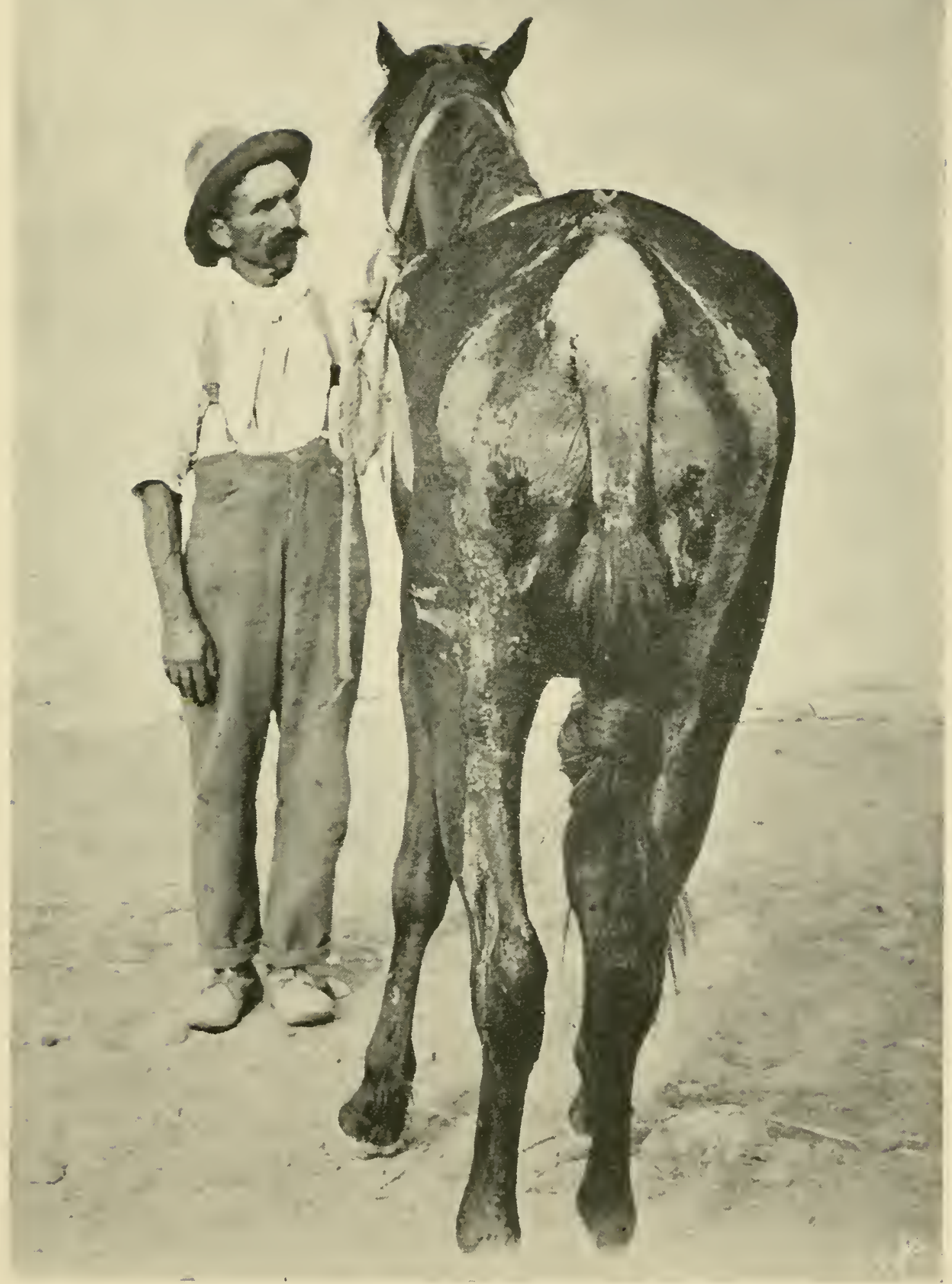

Fig. 24. - Horse with tail badly rubbed. 

month to get their feet in proper working order. As preventive measures, the feet should be kept dry, and should be picked out at least once a day. As a rule, the hind feet will require much more attention in this respect than the fore ones. In the treatment of such cases, I have had good results with burnt alum, equal parts of paraffin oil and sweet oil, and equal parts of oil of turpentine and sweet oil. Mr. Desmond advises a solution of I part of formalin to 9 of water.

SEPTIC PNEUMONIA.

This disease, with or without the complication of pleurisy, is undoubtedly the most common cause of death among horses which are carried in large numbers at sea. It'appears to be contagious, because it not only affects 
horses in badly ventilated positions, but also those in places which have the freest possible ventilation, such as stalls facing large open ports on the windward side of the ship. My own experience and that of others leads me to conclude that this aggravated form of pneumonia never appears except under conditions of overcrowding. Therefore I am inclined to regard it as a contagious disease which assumes a peculiarly virulent type on account of unsanitary surroundings. Horses fresh from grass often suffer from a somewhat similar, though very much milder, disease, when placed in heated and badly ventilated stables on land. I believe that I am correct in saying that this board-ship form of pneumonia is generally complicated by pleurisy. I have seen it break out among 
horses on board ship, three days after leaving England.

Symptoms. - The animal is depressed, more or less off its feed, and hangs its head. The eyes are generally closed, to a greater or less extent, and are sometimes "weeping." The mucous membrane of the eyes is of an intensely red colour, which becomes darker as the disease progresses. If pleurisy also exists, its presence will be indicated by the heaving of the flanks and abdominal breathing. The nostrils are greatly dilated, and the breathing, which is always hurried in such cases, often attains a rate of over 40 respirations in the minute. The pulse is very frequent, often over 70 in the minute. Although the appetite is more or less in abeyance, the patient will sometimes continue to nibble his hay to the very end, and 
not unusually dies with some of it between his teeth. As a rule, he drinks very little water, apparently on account of the hurried state of his breathing. The disease generally runs its course in about six days, during the last two or three of which there is a watery discharge from the nostrils in varied quantities. Sometimes it merely moistens the opening of the nostrils and the muzzle; but at other times it runs freely from the nostrils, in which case the animal often licks it off his muzzle. The discharge is at first colourless, but later on it assumes a rusty red tint, which indicates that putrefaction is present in the lungs. It always has a foetid smell, which increases in intensity according to the progress of the process of decomposition in the lungs. Occasionally the animal dies suddenly, but death is 
usually caused by exhaustion and inability to breathe.

The large majority, probably about 90 per cent., of horses which become affected by this disease, die.

Treatment. - The only treatment which I have found at all beneficial is careful nursing and change of air, for instance, to a deck (preferably the exposed deck) above the one on which the patient became affected, or from the leeward to the windward side. The only way to be successful in this attempt is to begin the treatment at the very onset of the attack. If constipation be present, back-raking; an enema, and a dose of Epsom salts might be tried. As a stimulant, spirits (a quarter of a pint of whisky in a pint of water) or carbonate of ammonia ( 2 drachms in a ball) may be useful. 
LIST OF VETERINARY DRUGS FOR BOARD-SHIP USE.

\section{The Army Veterinary Department allow the} following list of drugs and necessaries for roo horses for a passage on board ship of 30 days, as well as those in a Veterinary Field Medicine Chest, which is supplied to each horse-carrying ship.

lbs. oz.

*Chlorate of potash . . . . . 20

Boric acid . . . . . . . . . o 8

Carbolic acid, liquid . . . . . . 20

${ }^{*}$ Camphor compressed . . . . . . 20

Copper, sulphate of . . . . . . . . . 04

*Gentian, powdered . . . . . . 40

Corrosive sublimate soloids . . . . . . o 6

Iodoform . . . . . . . . . 04

Liquid ammonia, strong . . . . . 20

Acetic acid . . . . . . . . $0 \mathrm{O}_{2}$

Opium, powdered . . . . . . . . 04

Epsom salts . . . . . . . . . . I 5 o

*NcDougall's sheep dip . . . . . . . 50

*Nitre . . . . . . . . . . I4 O

*Acetate of lead . . . . . . . . . . I 0

Soft paraffin . . . . . . . 20

Tincture of myrrh and aloes. . . . . I

Spirit of nitrous ether . . . . . 60

Oxide of zinc . . . . . . . . I 0 
lbs. oz.

Sulphate of zinc . . . . . . . . I O

*Ginger, powdered. . . . . . . . 40

Laudanum . . . . . . . 20

* Mustard . . . . . . . IO O

Oil of turpentine. . . . . . . 20

Chlorodyne . . . . . . . . . . . .

Tincture of iodine . . . . . . . o .8

No.

- Coated aloetic balls, 4 drachms. . . . . 20

,, carb. amm. balls, 2 drachms . . . . 50

Bandages, handloom, sets . . . . . 3

Scales and weights, 4 oz. set . . . . . . I

Vety. Field Case Book-Army Book 32 . . . I

Catheter, male . . . . . . . I I

Thermometers, clinical . . . . . . . 4

Galls.

Linseed oil . . . . . . . . . 4

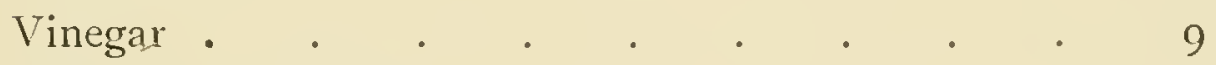

25 doses of Mallein.

One Mallein syringe.

If any special drugs are asked for by the attendant veterinary surgeon, they are supplied within reasonable limits.

I have marked with an asterisk certain drugs in the above list which I think might be dispensed with on ordinary occasions. I would suggest the substitution of tannoform for 
iodoform, and the addition to this list of 50 yards of cotton wadding and 12 yards of calico, for making into bandages (6 yards long and 3 inches wide), to use with the cotton wadding (p. 222).

From the foregoing list an approximation may be made of the amount of drugs required under varied conditions of number of horses and length of voyage. 


\section{THE WAR OFFICE AND HORSE TRANSPORT.}

THE present transport arrangements which are carried out by the Admiralty and which consist in the selection and fitting of horse ships, leave little to be desired; and our country owes a deep debt of gratitude to its naval officers for the intelligent way in which they have brought their professional knowledge and practical experience to bear on this branch of the Service.

The actual superintendence of horses on Government transports is, however, chiefly in the hands of the Remount Department, 
which consists of officers who have no special qualification for the technical work they are called upon to supervise and execute. Even the slight recommendation of belonging to the Cavalry or Horse or Field Artillery is not insisted upon; for we find many of these gentlemen are recruited from the Infantry, Militia, Volunteers, and even from the Navy, without proof being required that they possess any acquaintance with horses. In England, horse-owners generally leave the control of their hunters, trappers, and polo ponies so much to their grooms, that the large majority of them have little or no practical experience of stable management, and are consequently incapable of directing its details, which need far more intelligent supervision at sea than on land. 
The War Office and Horse Transport. 243

The War Office authorities enact that each horse ship is to be provided with a combatant officer (remount officer or Cavalry officer) and a veterinary surgeon, the former being in command of the horse department, and the latter having no more authority with respect to the animals than a full private. As a rule, the working of this anomaly is not so disastrous to the horses as might be expected; because the amateur, being aware of his own ignorance, generally leaves the professional to do the work of both. Occasionally the unqualified gentleman commits the mistake of using all the authority entrusted to him by a too confiding government. For instance, when the ss. Cervona, on one of her horse-carrying voyages to South Africa, arrived one day in Algoa Bay, the inspecting veterinary surgeon who I6* 
came on board, and who is an Irish friend of mine, was informed by the remount officer in charge that in consequence of an outbreak of glanders, 254 horses had been shot, and that he would have destroyed the remainder, had not the inclemency of the weather prevented him from throwing more carcasses overboard.' A strict veterinary examination was thereupon held on the survivors, with the result that not the slightest indication of glanders was found among any of them. When the amateur pathologist was asked his reasons for saying that glanders was present among his shipment, he stated that the animals exhibited the unfailing diagnostic symptom of a "cheesy discharge from their nostrils!" And thus, over $£ \mathrm{I}$, , O00 of public money was needlessly 
expended to feed Atlantic fishes. It is only fair to say that the idea of glanders being among the horses on board the Cervona originated with the attendant American veterinary surgeon, who had been appointed by the War Office without reference to the Army Veterinary Department and without making inquiries as to his qualifications. After this American gentleman had sanctioned the slaughter of eleven of the suspected animals, it appears that he changed his mind with regard to the correctness of his diagnosis; but the remount officer, not being troubled with doubt, took the responsibility of continuing the butchery.

The person who was most to be pitied in this affair was the Captain of the Cervona, who was naturally inconsolable on account 
of the unmerited obloquy which had been put on his ship. During an interview with the veterinary officer who had first come on board, he bitterly complained of his bad luck. The genial Irishman chaffingly replied in a tragic tone of voice: "Sir! On you lies the responsibility. You could have saved the situation by your revolver!" "You are right,' said the Captain sadly, "I ought to have shot them both."

The officers at Port Elizabeth were greatly divided in opinion about this Cervona case. Some said "court-martial," others, "lunatic asylum."

Our military rulers seem to be always ready to accept the counsel of any amateur, provided that their adviser holds an official position. For instance, a remount officer persuaded the 
Cape authorities to cable home the suggestion that all remounts should be sent out to South Africa without shoes, because there had been a few cases of horses getting hurt by kicks during disembarkation. This gentleman and his trustful superiors appeared to be totally unaware of the fact that unshod horses in stalls on board ship would knock their fore feet about a good deal during a voyage to South Africa, and that it would be impossible, under the present conditions of this war, to have large numbers properly shod on landing. On a steamer in which I went to South Africa with remounts, my commanding officer was a Militia subaltern who, by his own showing, had had no practical experience with horses. He was, however, very keen to take veterinary charge, and decided to do so, on the 
favourable opportunity which he obtained by my breaking a rib and otherwise hurting myself in a fall I had down a bunker hatch which had been negligently left open in an alley way, in front of the horses on the port side, one evening when we were coaling at Las Palmas. As we were in port at that time, the Militia officer immediately wrote off to the Remount Department in London, saying that the accident would keep me on the sick list for the remainder of the voyage, and that he would look after the horses. Next morning he came into my cabin and asked me in what part of the veterinary stores he could find the mustard, which had been apparently concealed from him under the word sinapis. I inquired what he wanted with that condiment, and 
he replied that as several of the horses were breathing rather heavily, he intended to blister their sides. I told him that that was my affair, and not wanting amateur experiments to be tried on my equine friends, I called the steward, got him to raise me up (for I was unable even to turn in my bunk without help) and put me on my legs, and I then informed my commanding officer that I was no longer on the sick list and that I would remain off it for the remainder of the voyage. The pain which the carrying out of this resolution caused me was amply repaid by the satisfaction I felt in saving my dumb shipmates from amateur doctoring. As I was under no agreement to obey anyone on that voyage, I committed no breach of duty by refusing to give up veterinary charge of the 
horses. Although, previous to my next voyage, I signed an agreement to implicitly obey my commanding officer, who was a lieutenant in the Ioth Hussars; I had no interference, for he was a hunting man and a lover of horses.

An amusing feature in this second fiddle game is the observance of the principle that les extrêmes se touchent, in the appointment of remount officers and veterinary surgeons on board transports; old veterinary surgeons being sent with young remount officers, and vice vers $\hat{\alpha}$. In one case, the remount officer in command was a Militia lieutenant of 9 months, and 22 years of age. The appointment of a veterinary surgeon on board a government ship is an inconsistency under present conditions ; because the remount or cavalry officer 
The War Office and Horse Transport. $25 \mathrm{I}$

has entire charge of the horses, and is in no way bound to consult his qualified assistant. Therefore we need not wonder that many veterinary surgeons are not anxious to occupy this false position.

Few remount officers would disregard the welfare of their own pockets sufficiently to be their own stud grooms, or to buy horses for themselves without consulting a veterinary surgeon; but when public money can be played with, they consider themselves, and are regarded by the War Office, to be thoroughly competent to superintend the management and to undertake the selection of horses for Government. When sent to purchase remounts they are supplied with veterinary surgeons to help them in deciding questions of soundness, but these qualified men are 
in an entirely subordinate position, and have no executive authority whatsoever. For this duty, the remount officer, who usually does nothing more than write descriptions of the horses, is paid $£ 2$ a day; and the veterinary surgeon, who does practically all the work, $£ \mathrm{I}$ a day. On one occasion, in a West of England town, when a Cavalry officer who was assisted by a wèll known Army veterinary surgeon, was purchasing remounts, a horsey bystander wisely remarked: "The Vet. could get on jolly well without the Captin; but I'm blessed if the Captin could get on without the Vet." In such cases, the veterinary surgeon and a clerk could do all that is required.

To emphasise the advantage which horsemen would derive from veterinary training, I do 
The War Office and Horse Transport. 253

not think that I can do better than give my own experience in this matter. I was brought up among horses in Ireland, did a fair amount of riding school work during three years at the Royal Military Academy and during six years as a subaltern in a field battery, and spent several years training, racing; and steeplechasing in India, through the entire course of which time I became more and more impressed with the consciousness of my ignorance about horses. Being anxious to remedy this deficiency, and being then in the Bengal Staff Corps, I utilised my furlough on different occasions to go home and study at a veterinary college, with the result that I took my diploma not long after I left the Army. I am glad to say that my time was well spent, because I learned at the college 
at least ten times more about horses than

I had done before entering it. I can now confidently state that if I had been appointed to the Remount Department, previous to going through this course of study, I would have been incapable of efficiently performing remount duties, owing to lack of knowledge about horses. Consequently I consider that the large majority of remount officers, who certainly have not more experience with horses than I had in my unqualified days, do not possess the knowledge requisite for their work. In fact, they are amateurs who do their best to carry out highly technical duties. I would therefore urge the advisability of the Remount Department being officered by members of the A.V.D. As I have never belonged to the A.V.D. or 
The War Office and Horse Transport. 255

to the Remount Department, and am long past the age at which I could again enter the Army, I venture to hope that my opinion in this matter may be considered to be free from any personal bias.

Officers of the Royal Artillery, Royal Engineers, Royal Army Medical Corps, and Army Veterinary Department are required to go through long courses of training before respectively engaging in their technical work. Even hospital nurses are specially educated for their duties; but Government demands from remount officers no preparation, no qualification, beyond the possession of a commission in the Navy, Army, Militia or Volunteers and of course the necessary interest, before putting them in charge of work which needs years of study 
and practical experience for its intelligent performance. Trained ability of this kind is a valuable asset in the commercial world.

At the beginning of this war, the utility of veterinary surgeons in looking after horses on board ship was repeatedly ignored, as we may see by the large number of horses and mule carrying steamers which went to South Africa without veterinary surgeons in them. For instance, the ss. Ismore left Liverpool for South Africa with a detachment of the Ioth Hussars and $20 \mathrm{I}$ remounts, but no veterinary surgeon. Shortly after sailing, "pink-eye" broke out among the animals, and the Officer Commanding and the Captain of the ship agreed to put into Milford Haven for veterinary advice. Having touched at 
The War Office and Horse Transport. 257

that port, the Ismore again sailed without a veterinary surgeon, whose services on this occasion would not have been of much avail, because the ship was lost in St. Helena Bay.

Inability to obtain the aid of veterinary surgeons was not the cause of the Minister of War's failure to engage them, if I may judge by the enquiries I have made among my professional brethren, and by the fact that as soon as this war broke out, I wrote to the War Office offering my services in taking charge of horses proceeding to South Africa; but my application was refused. Later on, I had the honour of meeting the Director General of the A.V.D., and he most courteously informed me that he was only too glad to give me the employment I desired, 
because he was greatly in need of experienced veterinary surgeons to send out to the Cape with horses. In fact, so short-handed was the A.V.D., owing to the mismanagement of the War Office, that there were only six military veterinary surgeons in the United Kingdom at that time. The D.G. of the A.V.D. has tried his utmost to impress on our Government the value of veterinary help throughout this war, and his patriotic efforts would have obtained the success and recognition they deserved, but for the fact that our Army is managed more on social than professional lines. The Yeomanry authorities ignored the A.V.D. so completely that they appointed an unqualified man to be the Veterinary Lieutenant of the Yeomanry contingent which went to South Africa in the 
The War Office and Horse Transport. 259

ss. Kent with $23^{6}$ horses, out of which 34 died, the mortality being 14 per cent. Also, our military authorities, without consulting the A.V.D., gave veterinary appointments to Colonial and American men who did not possess a veterinary diploma of any kind. By this remark, I make no adverse reflection on Colonial veterinary graduates who received veterinary commissions from their respective governments, and who are on war service and under the orders of the A.V.D. in South Africa. The Imperial Government, by accepting the services of Colonial troops, are bound to recognise the Colonial veterinary graduates who came with these troops. The graduates of the Melbourne Veterinary College are specially worthy of recognition, because the four years' course 
at that College is identical with that laid down by the R.C.V.S. of England. The Government recognition of Colonial quacks, who assume veterinary standing, is not only an insult to English veterinary surgeons, but is also a cruel wrong to Colonial veterinary colleges.

From extended enquiries among Army and Civilian veterinary surgeons, I am convinced that the dearth of qualified candidates was solely due to the poor pay and inferior status offered to them. In this, I think our profession is somewhat to blame for not pushing their claims more strongly. There is no doubt that one of the best means for the removal of a grievance is to appeal in a straightforward manner to the governing authority. As a case in point, I can cite 
The War Office and Horse Transport. 26I

the fact that the first time I went to South Africa with remounts I was kept nearly a fortnight at Cape Town waiting for a troop ship to take me back. I might have returned at once in a mail steamer, but the military authorities would not sanction the extra expense. During my detention, I received I2s. 6d. a day for the first week, and after that 7 s. 6 d. a day; although five half crowns was the smallest daily sum for which board and lodging (to say nothing of incidental expenses) could be procured at any of the hotels Fortunately this apparent loss of time and money did not injuriously affect me, because it was more than made up by the valuable opportunities I got for photographing types of horses I could not have otherwise obtained. On my return to Eng- 
land, I wrote a letter to the D.G. of the A.V.D. pointing out that the inadequacy of the detention allowance was a hardship on veterinary surgeons which ought to be rectified, and that I had no personal grievance in the matter. I am happy to say that this letter, which was forwarded to superior authority, helped to obtain the welcome concession of a pound a day detention allowance for veterinary surgeons.

In ancient times, doctors occupied a position somewhat similar to cow-leaches, and the barbers and surgeons of London belonged to the same corporation until the year I 745 . Even fifty years ago the village medical man was rarely admitted into county society. Since then, the medical profession has, by 
The War Office and Horse Transport. 263

improved education, obtained full public and private recognition, as we may learn from the fact that the surgical attainments of Lord Lister have procured him entrance into the peerage. The officers of the R.A.M.C. have combatant rank, which many of them value much more highly than their professional status, on account of social considerations. The veterinary profession is following fast in the footsteps of the medical. In the year 1844 the R.C.V.S. was formed, and the veterinary art was recognised as a profession by Royal command. For several years after that time a veterinary diploma could be obtained by a short and elementary course of study. Subsequently, a three years' college course was instituted, although a smattering of the three r's was sufficient for 
matriculation at some of the teaching schools. Up to the 27th of August, I88I, any quack could with impunity call himself a veterinary surgeon. In 1896 , the veterinary matriculation examination was made equal to that required from medical candidates, and the veterinary course of study has been extended to four years. With respect to the social advance of veterinary surgeons, I may point out that a few C.B.'s and D.S.O.'s have been distributed, and since June, I 883 , veterinary officers are allowed to be presented at Court.

The high officials at the War Office ignore the great progress in education and efficiency made by the veterinary profession, and try their utmost to keep the Army Veterinary Department in a degraded position, despite 
The War Office and Horse Transport. 265

the brilliant services rendered by its officers during peace and war. Their pay and pensions are practically the same as what they were thirty years ago. An Army veterinary officer is the only Army officer who has no authority over his subordinates. For instance, if an Army farrier commits a breach of discipline, his Veterinary Colonel has no power to punish him, although a last joined subaltern would be able to do so. The authority which veterinary officers should have over their men has often been asked for, but always refused, on account of the military caste prejudice which rules our unfortunate Army. Hence, many capable young veterinary surgeons prefer private practice to the poor position which the War Office offers them. And yet our military authorities 
wonder that they are unable to obtain an efficient veterinary machine, which is essential to the welfare of the country, especially in campaigns that demand the employment of large numbers of horses. 


\section{GENERAL INDEX.}

Abrlity to bear transit by sea, I.

Abrasions, 229.

Admiralty, The, $24 \mathrm{r}$.

Air-scoops, 40, 44.

Alfalfa, 176 .

Aloes, 227.

America, I2, I3, I4, 222.

Anderson, Col. John, r6g.

Argentine remounts, 7, r46, 147 .

Army Veterinary Department, 245,

$$
252,254,257-262,265 .
$$

Australia, 8, 12, 13, I4.

Australian shippers, 53.

Austria, I2, I4.

Azoturia, 5.

BAITIC, 39, II6.

Bandaging, cotton wadding, 225.

Bay of Biscay, I3.

Beam, 28, 29.

Bilge keels, 24.

Blacksmith, r9I.

Blue Gown, 95.
Bran, I68-I72.

Breast-boards, I 19 .

Brows, 32, $6 \mathrm{r}$.

Buenos Ayres, I3, I4.

Bulk-heads, 34 .

Calcutta, 208.

Canada, I2, I3, 222.

Captain, The, 23,

Cart horses, 2.

Cattle men, I84-r 86.

,, steamers, I6, 21 .

Celtic, The, 17.

Cervona, The, 243.

Chloral hydrate, 228.

Chloride of lime, r99.

Chlorodyne, 227.

Chop, I 75.

Clipping, 55, r 16.

Clothing, I 15 .

Clove hitch, I 36.

Cocoanut matting, 97, 98, roo.

Colic, 226. 
Concrete on decks, 32.

Corn, 2-8.

Cost of transport, 2 I 5 .

Cotton wadding bandages, 225.

Cranes, 6I.

Cruelty to horses, IS9-I9I.

Cuba, 222.

Cuts, 229.

Cymric, The, 14.

DECK corered with boards, 3O, 31 . ,, covered with concrete, 32.

Decks, I6-21.

, kept dry, 35 .

Derricks, 6 I.

Desmond, Mr., 57, 79, 233.

Disinfectants, I99, 200.

Division-boards, I 23, I 25 .

Disembarkation, after, 208.

Disembarking horses, 56 .

Doctors, 262.

Draughts, 37 .

Drugs, 238.

Duck, Colonel, i46, i 58.

EDMond's steam jetter, 50.

Electric lights, 32.

Embarking horses, 56.

England, I 2, I4.

Eserine, 228.

European, The, 33.
Exercise, 4, IO, 206.

FANs, exhaust, 47 .

Farmers, 8.

Feeding and watering, I $82, \mathrm{I} 88$.

,, , principles of, 178.

,, troughs, 95, I 56.

,, utensils, I 56 .

Feet, horses', 53-55, 230.

, , fever in the, 5, 5.3, I04, 208 . 2 I 4.

Filled legs, 224.

Fittings, security of, 9.

Fiume, 12.

Floor of box, 95, 97, 98.

Flush deck ship, 26.

Food, I67.

Foot-hold, IO, I 45.

Foremen, I 84, I 85 .

Freeboard, 22.

Freeing-ports, 26.

Fremona, The, I4.

Frost-bite, 212, 2 I 3 .

Gangways, 58.

Gear, Govermment, I65,

Glanders, 222, 244.

Golden, Mr. I 24.

Gout, 3 .

Grain, 2-S.

Grandeau, I69. 
Grass, 7, 8.

Green vegetables, 3 .

Grooming, 204.

Gypsum, I99.

HALTERS, IO9.

Hatches, 28, ios.

Hatchways, 40.

Hay, 4, 5, 52, I67, I74.

, nets, $16_{3}$,

Head-collars, Iog.

Horse-attendants, ISo.

,, box, portable, 8o, 8I, 83 .

$,, \quad,$, , cost of, IOI.

, carrying ships, I 5, 29, 30.

Horses, management of, IO2.

, into stalls, changing, 202.

, , cruelty to, I\$9-I9I.

,, , mortality of, I 2 .

,, preparation of, $5 \mathbf{I}$.

,, , welfare of, 9 .

,, wild, 52.

Hyson, The, I 4.

Idaho, The, I46, I68.

Inspection, Veterinary, 22 I.

Iodoform, 229.

Iona, The, I4.

Ireland, 12.

Ismore, The, 256.

Kelvingrove, The, I46, I6I.
Kent, The, 259.

"Know your own ship," I 5 .

LAS Palmas, 248.

Laminitis, 5, 53, IO4, 208-2 I4, 224.

Legs, filled, 224.

Light in the water, 26.

Lighters, 78, 79 .

Light-ship, 23.

Lime, chloride of, I99.

,, , quick, I99.

Linseed oil, 227, 228.

Lucerne, I 76.

Luff, Dr. 2.

Lying down, IO.

Lymphangitis, 5, 223.

Magician, The, 33.

Mail steamers, 34 .

Mallein, 223.

Mangers, 95, I 56 .

Mangolds, I 68.

Medicines, 238.

Michigan, The, 33.

Midship stalls, IO7,

Mooring bits, 34 .

Mortality at sea, I I, 2 I 3, 2 I 4.

Mount Roy'al, I4.

Mucking-out, I93.

Mules, I, I2. I4, I64.

Miintz, I69. 
NoRth Sea, 39, 97, I 6.

Nose-bags, I62.

Nunn, Colonel, 58, 164, 230.

OATEN hay, I75.

Oat-bruising machine, 164 .

Oats, I72-174.

, bruised, 175 .

Ossory, 95, 99.

Overcrowding, 9 .

Pedestrianisit, 2.

Pens, 25.

Pilocarpine, 228.

Pink-eye, 224.

Pitching, 36.

Pneumonia, septic, 233.

Politician, 33.

Ponies, 2.

Prince Io, 95, 99.

Quick lime, 199.

Rations, board-ship, I76, I77.

Remount Department, 24I -256.

Revel, 39, I 16.

Rolling, 35, 96, 97 .

Ross-smith, Captain, 32, 33, I49, 217.

Round turn and two half hitches, I36.
SCUPPERS, 32.

Scuttles, 44 .

Sea, ability to bear transit by, 1 .

Ship, colour of, 35 .

Ships, horse-carrying, I 5 ,

Shoeing, 53-55, 247.

Simpson, Mr. I6r.

Slippery hitch, 136 .

Sling, 'disembarking, 77 .

Slinging horses, 62, I4I.

Slings, I 42-I 44 .

Spar-decker, 16.

Speed, 24.

Stable duties, I80.

Stability, 22,

Stalls, I 19 .

, , cost of, I 26.

, , Government, I27.

," , position of, I04.

Starch, iodide of, 230.

Steady, 23.

Stiff, 23.

Strangles, 224.

Surrey, The, I4.

TAIL, rubbing the, 229 .

Tanks, water, I 5 .

Tannoform, 229.

Tender, 23.

Three-decker, I 5, 2 I.

,, island ship, 26. 
Thrush, 230.

Transport, cost of, 2I 5 .

Tropics, I 2.

Tying-up, I 35 .

URIC acid, 3 .

Urine, 200.

VEgETABLEs, green, 3.

Ventilation, Io, 37 .

Ventilator, cowl, 44. ,, , electric, 48 .

, , steam, 48 .

Victorian, The, 33 .
Veterinary remarks, 22 I-240. , surgeons, 263-266.

Voyages, successful, I4.

WALTON, I 5.

War office, 24I-266.

Watering horses, I49.

Weed, 5,

Well-deck ship, 25 .

Windsails, 43.

Work without corn, 7 .

YEOMANRY authorities, 258

\section{THE END.}





\section{AUTUMN SEASON, I9OI}

\section{HURST \& BLACKETT'S}

FORTHCOMING BOOKS AND RECENT PUBLICATIONS 


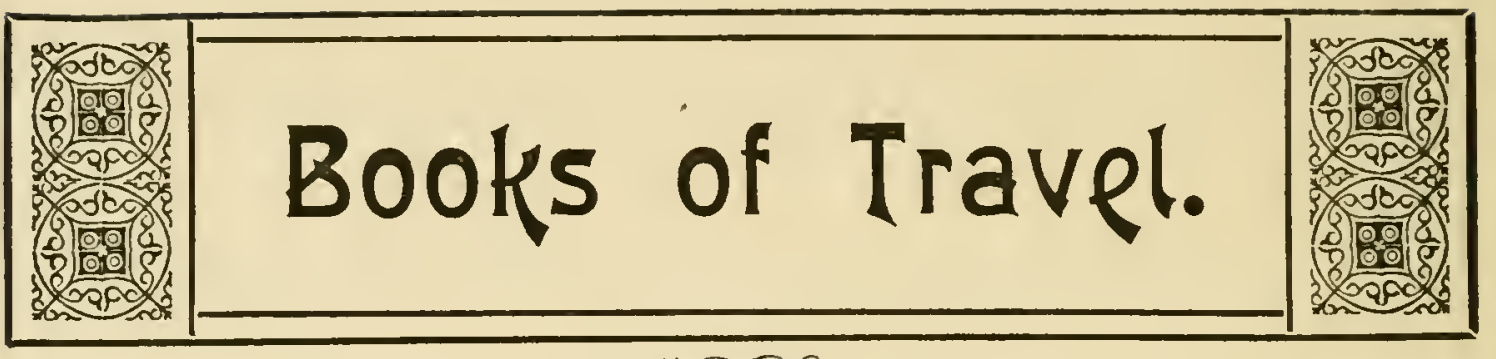

कीजिए

\section{NEW AND IMPORTANT BOOK OF TRAVEL.}

In I vol., crown 4to, fully Illustrated by Photographs and Drawings made by the Author, 2 Coloured Illustrations, and a New Map of Mexico especially prepared for this Work. Extra Cloth Binding. Gilt top. Price 2Is. net.

\section{Mexico as I Saw It.}

By Mrs. Alec Tweedie, Author of "Through Finland in Carts," \&c., \&c.

\section{NEW WORK ON ANTARCTIC EXPLORATION.}

In I vol., demy 8 vo, with numerous Illustrations from Photographs taken

: by the Author. New Charts of the South Polar Regions, \&c. Extra Cloth, Price I2s. net.

\section{To the South Polar Regions.} EXPEDITION OF 1898-1900.

By Louis Bernacchi, F.R.G.S.

NOTE.-MR. BERNACCHI has joined the "Discovery" Expedition now on its way to the Antarctic Regions.

LONDON : HURST AND BLACKETT, LIMITED. 


\section{To the Mountains of the Moon:}

Being an Account of the Modern Aspect of Central Africa and some little-known Regions traversed by the Tanganyika Expedition in I899 and I900. By J. E. S. MoORE, F.R.G.S. In I vol., crown 4to, fully Illustrated by Photographs and Drawings made by the Author. A Coloured Frontispiece and three Maps. In a specially-designed cover, gilt top. Price 2 Is. net.

\section{EXTRACTS FIROX SOME TEVIEWS.}

"Mr. Moore's account of his journeyings from the moutl of the Zambesi to the Mountains of the Moon, by way of the great chain of lakes, is vastly entertaining. The book is something more than a traveller's tale, and may be strongly recommended for general perusal."-St. James's Gazette.

"The greatest charm of Mr. J. E. S. Moore's 'To the Mountains of the Moon,' apart from its raciness of uarrative, lies in its descriptions of strange tropical scenery, storms, and fever-laden swamps. The numerous drawiugs and photographs give an excellent idea of the equatorial regions and their marvellous skies and distances."-Academy.

"Some good illustrations from the author's pencil and camera add to the attractiveness of a book wlich, outside its scientific interest, has matter of grave import for the missionary, the administrator, and the would-be investor."-Daily Chronicle.

"Into the details of the great journey it is impossible to enter, but apart from Mr. Moore's conclusions on one or two questions of Imperial interest, his book can be heartily welcomed as a valuable addition to the literature of a subject of engrossing importance. Though a naturalist first of all, he does not overwhelm us with sickening catalogues of the flora and fauna of the countries traversed, nor does lie exaggerate trifling-though sometimes exasperatiug-adventures into sluddery lrairbreadth escapes. The book is beautifully illustrated."-Glasgow Herald.

\section{From the Cape to Cairo.}

The First Traverse of Africa from South to North. By EwarT S. Grogan and Arthur H. Sharp. With Introduction by the Right Hon. Cecil Rhodes. In I vol., crown 4to, fully Illustrated by Drawings by A. D. McCormick (from Sketches by E. S. GrogaN) ; Original Drawings by E. S. Grogan ; Photographs and Photogravure Portraits of the Authors, one Coloured Print and two Maps. In a specially-designed cover, gilt top.

Price One Guinea net.

\section{EXTRACTS FROM SOME REVIETS.}

"A vivid and interesting account of what the author has seen and experienced on his travels. No one can complain that he has neglected the sporting side of his experiences; but the real value of his book lies in the observations and comments which he makes on African problems. They are inspired by a robust commoll sense, and by a desire to say the thing that is true, whoever may be offended in the process."-The Times.

"Apart from this great trans-continental undertaking, witl which it fires imagination afresh, Mr. Grogan's book contains a high fund of entertaiument."-The Outlook.

"Mrr. Grogan bas a remarkable story to tell, and he tells it well. When he utters his opinions, he does so with emphatic vigour, and his narrative is full of vivid word pictures. He is a shrewd observer, and has much of interest to communicate concerning the possibilities and politics of Central Africa."-Mr. E. F. KNIGHT in the Morning Post.

" 'From the Cape to Cairo' is essentially a work of bigh importance, and it is no sniall boast for a traveller of Mr. Grogan's years to have been the first to accomplish a task which no one had previously brought to a successful issue."-Daily Telegraph. 


\section{NEW WORK ON PASTORAL LIFE IN AUSTRALIA.}

\section{Pages from the Journal of a}

\section{Queensland Squatter.}

By OSCAR De SATGÉ. In I vol., demy 8vo, with numerous Illustrations. Price IOS. 6d. net.

"This interesting book of reminiscences will afford pleasure to all classes of Australians, for it traces not only its author's progress and success, but also that of Queensland, through almost fifty years." -The Scotsman.

\section{A SPLENDID BOOK ON SPORT IN INDIA.}

\section{Wild Sports of Burma and Assam.}

By Colonel Pollok (late Staff Corps) and W. S. Thom (Assistant Superintendent of Police, Burma). In I vol., demy 8vo, with 59 Illustrations and 3 Maps. Price I6s. net.

"It only remains to congratulate Col. Pollok on his colleague Mr. W. S. Thom, who has certainly contributed an equal share to the information contained in this valuable work, which would be cheap at thrice the money." -The County Gentleman.

\section{THE BOOK OF THE MOMENT.}

\section{The Renascence of South Africa.}

By ARChibald R. Colquhoun, formerly Administrator of Mashonaland, South Africa, Author of "China in Transformation." In I vol., crown 8vo, with Map. Price 6s.

A popular account of South Africa. The lessons to be learnt from its past and its future possibilities. A concise description of the physical conditions in the various territories, and of the peoples, natives and otherwise. A consideration of the best methods of developing the country and of the Problems of Settlement. 


\section{NEW AND INTERESTING BOOK OF TRAVEL.}

\section{Among the Women of the Sahara.}

By Mme. Jean Pommerol. Translated by Mrs. Arthur Bfil (N. D'Anvers), Author of "The Elementary History of Art," \&c. In I vol., demy 8vo, with 90 Illustrations, after Drawings and Photographs by the Author. Price I2s. net.

The author has given the results of her experience in a series of very vivid word-pictures, supplemented by sketches and photographs taken under great difficulties, for the women of the Sahara look upon the camera as an uncanny sentient being with the power of the evil eye, and, moreover, they consider it a positive crime to allow their portraits to be taken.

\section{NEW AND IMPORTANT WORK.}

\section{The Egyptian Campaigns, 1882-85.}

New and Revised Edition continued to 1899. By Charles Royle, late R.N.; Barrister-at-Law, Judge of the Egyptian Court of Appeal, Cairo. In I vol., demy 8vo, extra cloth, Illustrated by numerous Maps and Plans. Price I2s. net.

"A comprehensive narrative of the Mahdist and Arabist movements, including the story of the English intervention in Egypt."-Daily News.

"A lucid description of the successive campaigns which had to be undertaken in order to deal a death-blow to Mahdism. Mr. Royle brings his history down to the destruction of the Khalifa."-Standard.

\section{NEW AND IMPORTANT BOOK OF TRAVEL.}

\section{From Sphinx to Oracle.}

Through the Libyan Desert to the Oasis of Jupiter Ammon. By Arthur Silva White, Hon. F.R.S.G.S., Author of "The Development of Africa," \&c. In I vol., demy 8vo, with 56 Illustrations from Photographs by the Author, a Frontispiece by $R$. Talbot Kelly, R.B.A., and 2 Maps. Price I6s. 


\section{NOW READY, AT ALL BOOKSELLERS' AND LIBRARIES.}

\section{China and the Chinese.}

Translated and Edited from the French of Edmund Plauchut. By Mrs. Arrthur Bell (N. D'Anvers), Author of "Elementary History of Art," "Science Ladders Series," \&c. In I vol., crown 8 vo, cloth, with 58 Illustrations. Price 2s. 6d.

\section{NEW WORK BY W. A. PICKERING, C.M.G.}

\section{Pioneering in Formosa.}

By W. A. Pickering, C.M.G., late Protector of Chinese in the Straits Settlements. In I vol., demy 8vo, extra cloth, with 25 Illustrations from Photographs and Sketches by the Author. Price I6s.

\section{NEW WORK ON MADEIRA.}

\section{The Madeira Islands.}

By Anthony J. Drexel Biddle. Containing The History of the Madeiras, Information for the Traveller and Visitor, and a Description of the Natives : their Characteristics, Religion, Laws and Customs, \&c. In 2 vols., demy 8vo, with 76 Full-page Illustrations and Maps. Price 2os. net.

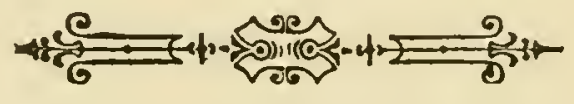

LONDON: HURST AND BLACKETT, LIMITED. 


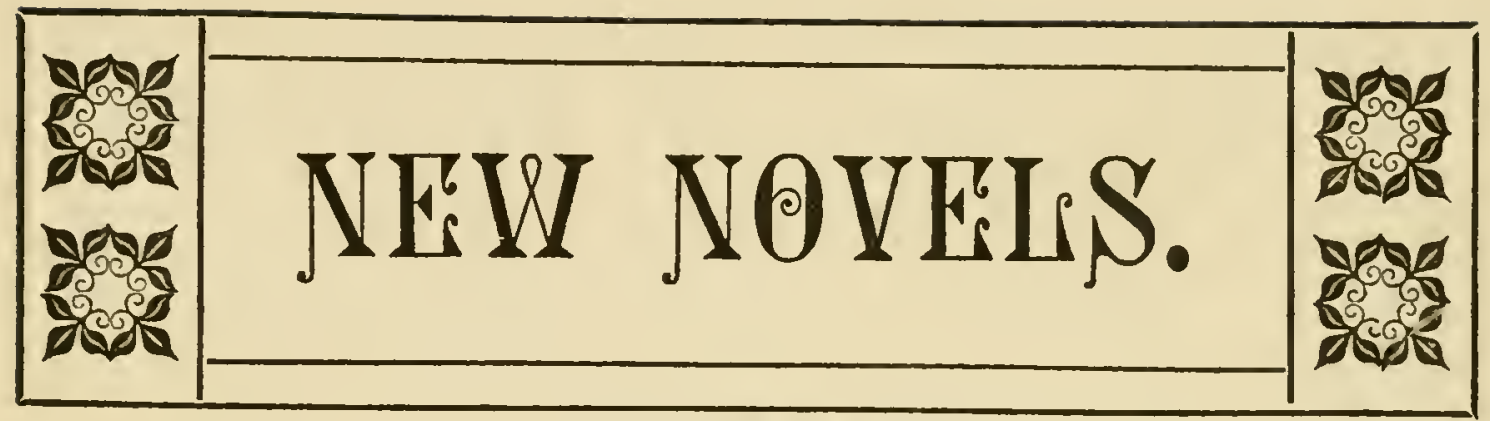

$\rightleftharpoons$

\section{NEW NOVEL BY \\ EDNA LYALL.}

In I vol., crown 8vo, Price 6s.

\section{In Spite of All.}

By Edna Lyall, Author of "Donovan," "We Two," "In the Golden Days," \&c.

\section{NEW NOVEL BY}

\section{BEATRICE WHITBY.}

\section{In I vol., crown 8vo, Price 6s. \\ Flower and Thorn.}

By Beatrice Whitby, Author of "The Awakening of Mary Fenwick," "Part of the Property," \&c. 


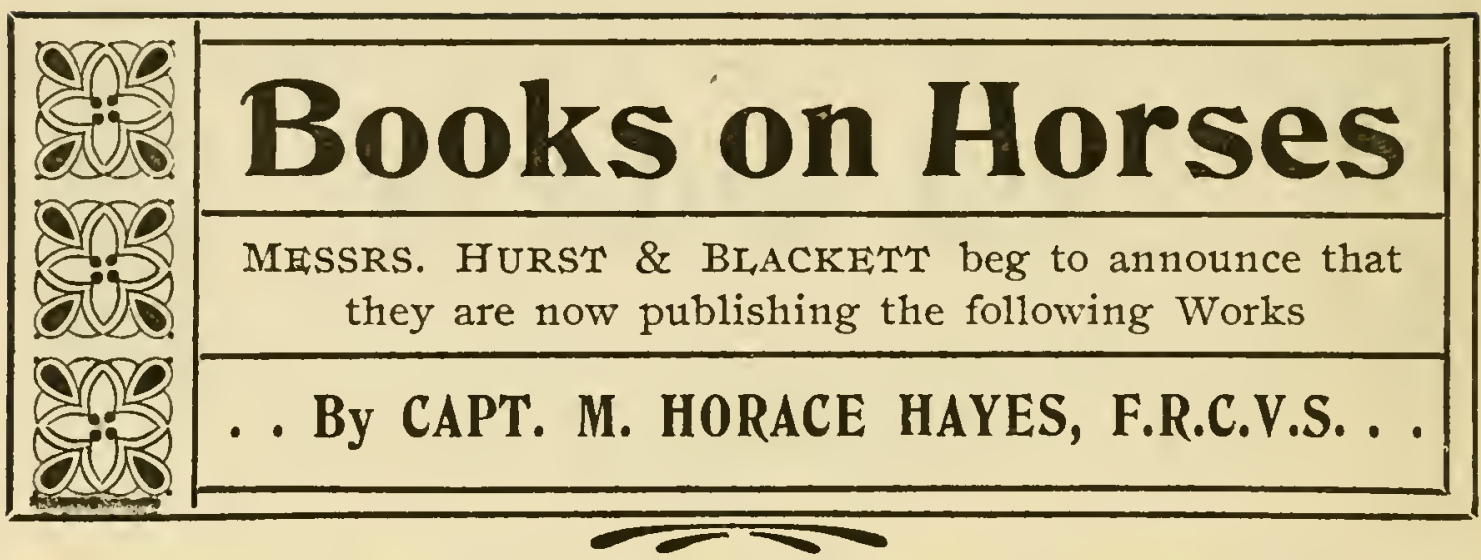

STABLE MANAGEMENT AND EXERCISE.

A Book for Horse-Owners and Students. Illustrated by numerous Reproductions of Photographs taken specially for this work. In I vol., demy 8vo. Price I2s. net.

"Capt. Hayes, who may justly claim to be the first authority now living on all mattera connected with the horse, is always welcome, and the more so because each suocessive volume is a monument of 'the reason why.' "-The County Gentleman.

\section{AMONG HORSES IN RUSSIA. With 53 Illustra-}

tions from Photographs taken chiefly by the Author. In I vol., large crown 8vo. Price ros. 6d. net.

"The book is exceedingly well written and illustrated."-Graphic.

"The author has made an exceedingly entertaining book of his experiences."-Baiby's Magazine.

POINTS OF THE HORSE. A Familiar Treatise on Equine Conformation. Illustrated by 200 reproductions of Photographs of Typical " Points" and Horses, and 205 Drawings by J. H. Oswald Brown. Second Edition. Revised and Enlarged. Superroyal $8 \mathrm{vo}$, cloth, gilt top, $34 \mathrm{~s}$.

This Edition has been thoroughly revised and contains numerous additions, including specially written Chapters on the Breeds of English and Foreign Horses.

"Capt. Horace Hayes, the best of writers upon horses, has issued a second editionconsiderably altered and enlarged, and magnificently illustrated-of his admirable work apon the 'Points of the Horse,' which is, in fact, a complete work on horses, their races and peculiarities."-Athencum.

\section{TRAINING AND HORSE MANAGEMENT IN}

INDIA. Fifth Edition. Crown 8vo, cloth, 6 s.

"We entertain a very high opinion of Capt. Hayes' book on 'Horse Training and Management in India,' and are of opinion that no better guide could be placed in the hands of either amateur horseman or veterinary surgeon newly arrived in that impartant division of our Empire."-Veterinary Journal.

AMONG HORSES IN SOUTH AFRICA. In

I vol., crown 8vo. Price 5 s.

"Capt. Hayes' book is genuinely interenting, and fully repays reading."-Black and White.

"The book is very readable." - \$pectator.

"The book is written in a pleasant, chatty sule, and with a broad mind."-Sportsman. 


\section{RIDING AND HUNTING. Fully Illustrated with} upwards of 250 Reproductions of Photographs and Drawings. In I vol., demy 8vo, cloth. Price I6s. net.

"Capt. Hayes has produced a book which camnot fail to interest, if not to instruct the experienced horseman, and the beginner may learn from its pages practically all that it is necessary for him to know."-The World.

"We can imagine no more suitable present for one who is learning to ride than unis book."-Pall Mall Gazetle.

\section{VETERINARY NOTES fOY HORSE OWNERS.}

An Illustrated Manual of Horse Medicine and Surgery, written in simple language, with over 200 Illustrations. Fifth Edition. Revised throughout, considerably enlarged, and incorporates the sub. stance of the Author's "Soundness and Age of Horses." Large crown 8vo, buckram, I5s.

"It is superfluous to commend a book that is an established success, and that has gone on trom edition to edition extending its usefulness."-Army and Navy Gazette.

\section{INFECTIYE DISEASES OF ANIMALS. Being}

Part I. of the Translation of Friedberger and Frohner's Pathology of the Domestic Animals. Translated and Edited by the Author. With a Chapter on Bacteriology by Dr. G. Newman, D.P.H. Demy 8vo, Ios. 6d. net.

"The plan of the work is excellent, and the arrangement all that could be desired; while the translation has been aptly done, and the awkwardness of rendering the original German into English, so common in translations, has been avoided. Dr. Newman's notes on bacteriology form an acceptable addition to the volume. This is a work which no veterinary practitioner who is anxious to be thoroughly up-to-date in his professional knowledge can afford to be without."-Glasgowo Herald.

THE HORSEWOMAN. A Practical Guide to SideSaddle Riding. By Mrs. Hayes. Edited by Capt. M. H. Hayes. With 4 Collotypes from Instantaneous Photographs, and 48 Drawings after Photographs, by J. H. Oswald BROw.v. With numerous Iilustrations. Large crown 8vo, cloth gilt, IOs. $6 \mathrm{~d}$.

"This is the first occasion on which a practical horseman and a practical horsewoman have collaborated in bringing out a book on riding for ladies. The result is in every way stisfactory, and, no matter low well a lady may ride, she will gain much valuable information from a perusal of 'The Horsewoman.' "-Field.

\section{ILLUSTRATED HORSEBREAKING, Second}

Edition. Imperial I6mo, buckram, 2 Is.

This Edition has been entirely re-zuritten, the amount of the letterpress more than doubled, and 75 reproductions of Photographs have been added.

"A valuable addition to the literature of a subject which this author may really bo said to have made his own. We do not know another who so happily combines absolute practical knowledge with an attractive literary style."-Referee. 


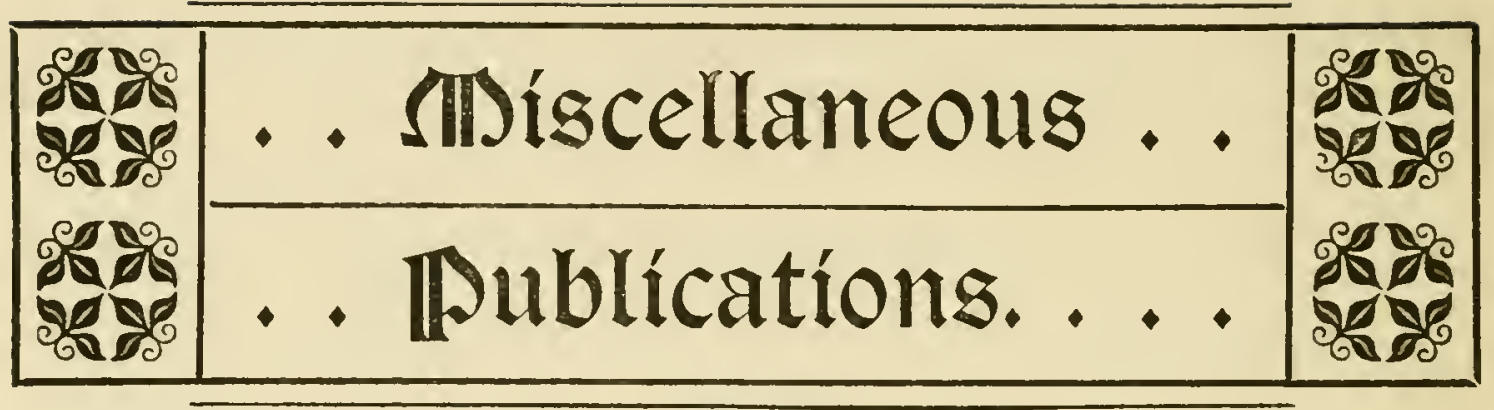

लख्यु)

NEW WORK BY H. FIELDING.

\section{The Hearts of Men.}

By H. Fielding, Author of "The Soul of a People," \&c. In I vol., demy 8 vo. Price ros. 6d. net.

\section{NEW AND INTERESTING WORKS}

\section{BY TIGHE HOPKINS.}

\section{The Man in the Iron Mask.}

By Tighe Hopkins, Author of "An Idler in Old France," "The Dungeons of Old Paris," \&c. A true history of the Man in the Iron Mask as opposed to the Popular Legend. In I vol., large crown 8 vo, with numerous Portraits and Plans of Prisons. Special binding. Price 7s. 6d. net.

\section{An Idler in Old France.}

By Tighe Hopkins, Author of "The Dungeons of Old Paris," "Nell Haffenden," \&c. In I vol,, crown 8vo, extra cloth. Price 6s.

\section{The Silent Gate:}

A Voyage into Prison. By Tighe Hopkins, Author of "An Idler in Old France," \&c. .In I vol., crown 8vo. Price 6s.

LONDON: HURST AND BLACKETT, LIMITED. 


\section{Modern Polo.}

By E. D. Miller. Edited by CApt. M. H. Hayes. New and Revised Edition, with numerous new and interesting Illustrations from Photographs, \&c. I vol., demy 8vo. Price 125. net.

[In the Press.

\section{NEW WORK BY FRANCIS HINDES GROOME.}

\section{Gypsy Folk=Tales.}

By Francis Hindes Groome, Author of "In Gypsy Tents," "Two Suffolk Friends," \&c. In I vol., demy 8vo. Price I2s.

NEW WORK BY T. H. S. ESCOTT.

\section{Personal Forces of the Period.}

By T. H. S. Escott, Author of "England: Its People, Polity and Pursuits," "Social Transformations of the Victorian Age," \&c. In I vol., large crown 8vo, extra cloth. Price 6s.

MR. W. ROSSETTI'S NEW WORK.

\section{Praraphaelite Diaries}

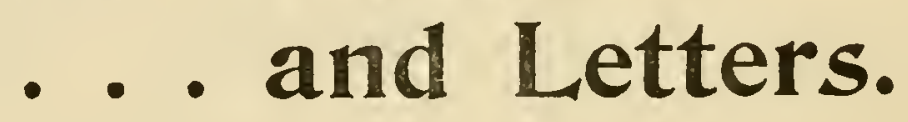

Containing Letters of Dante Gabriel Rossetti; Diary of FORD MADOX BROWN; the P.R.P. Journal, by W. ROSSETTI. Edited by William Michael Rossetti. In I vol., crown 8vo. Illustrated. Price 6s. 


\section{The Snowdon Edition.}

A New and Cheaper Reprint of this Popular Novel, In I vol., crown 8vo, with Introduction and Portrait.

PRICE 3s. 6d.

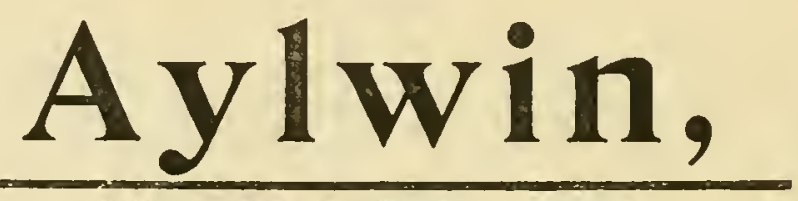

BY THEODORE WATTS-DUNTON.

\section{New and Cheaper Edition.}

In I vol., crown 8vo. Green Cloth, Bevelled Boards.

PRICE 3s. 6d.

\section{Bequeathed,}

By BEATRICE WHITBY,

Author of

"The Awakening of Mary Fenifick," "Part of the Property," \&c.

LONDON: HURST AND BLACKETT, LIMITED. 


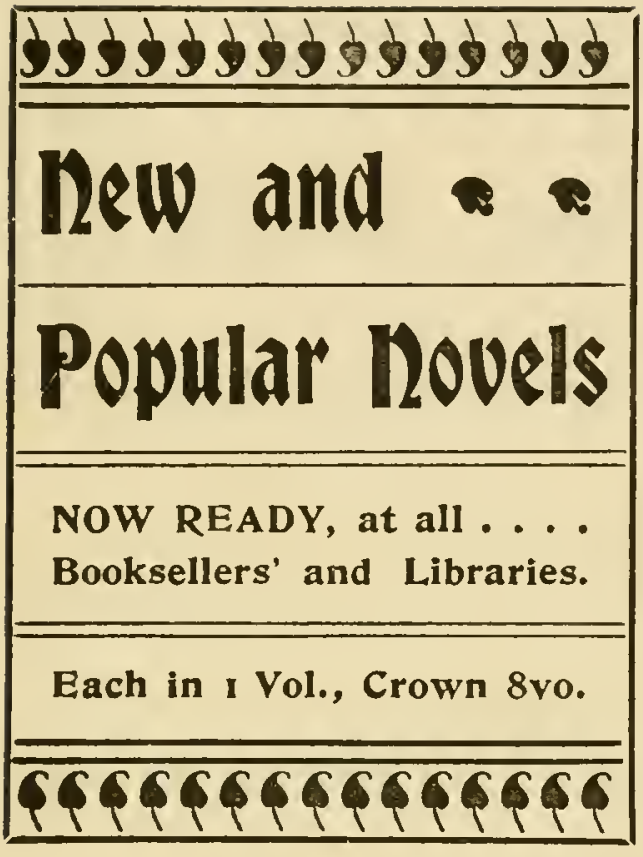

STRAWS IN THE WIND. By CARlton Dawe, Author of "The Yellow Man," "A Bride of Japan," \&c. Price $6 \mathbf{s .}$

THE LITTLE SAINT Of GOD: A HEROINE OF THE RED TERROR. By LADY FAIRLIE Cuninghame, Author of "A Wandering Star," "A Sin of the Soul," \&c. Price 6s.

THE MARRIAGE OF MR. MOLYNEUX. By CeCIl HeadLAM, Author of "The Story of Nuremberg," \&c. Price 6s.

THE CALL of the FUTURE. By Mrs. TANQUery, Author of "Hoya Corney," \&c. Price 6s.

THE LITTLE TIN GODS. By Jessie Livesay. Price 6s.

BLOOM OR BLIGHT. By Dorothea Conyers, Author of "The Thorn Bit," \&c. Price 6s.

POOR ELISABETH. By M. Hamilton, Author of "The - Dishonour of Frank Scott," \&c. Price 6s.

CORBAN. By Constance Smith, Author of "The Repentance of Paul Wentworth," \&c. Price 6s.

THE MOTHER OF EMERALDS. By FERGuS Hụme, Author of "The Mystery of a Hansom Cab," \&c. Price 6s.

THE LIFE ROMANTIC, INCLUDING THE LOVELETTERS OF THE KING. By RichaRd Le Gallienne, Author of "The Quest of the Golden Girl," \&c. Price 6s.

HIS OWN FATHER. BY W. E. NORRIS, Author of "My Friend Jim," "Major and Minor," \&c. Price 3s. 6d.;

AMUSEMENT ONLY. By RICHARD MARSH, Author of "The Beetle," "The Seen and the Unseen," \&c. Price 6s.

THIS BODY OF DEATH. By Adeline Sergeant, Author of "No Saint," "The Story of a Penitent Soul," \&c. Price 6s.

LONDON: HURST AND BLACKETT, LIMITED. 


\section{- Hurst \& Blackett's .}

\section{Three $=$ and $=$ Sixpenny Series .}

\section{Crown 8vo, Green Cloth, Bevelled Boards. . . .}

A BRAVE LADY. By Mrs. Craik.

A LifE FOR A LifE. By Mrs. Craik.

A NOBle lifE. By Mrs. Craik.

A WOMAN'S KINGDOM. By MRS. CRAIK.

A WOMAN'S THOUGHTS ABOU'T WOḾNEN. By MrS. CRAIK.

CHRISTIAN'S MISTAKE. By MRS. CRAIK.

his litTle MOTHER. By Mrs. Craik.

JOHN HALIFAX, GENTLEMAN. By Mrs. Craik.

haNNAH. By Mrs. Craik.

MISTRESS AND MAID. By MRS. CRAIK.

NOTHING NEW. By Mrs. Craik.

STUDIES FROM LIFE. By Mrs. CraIk.

YOUNG MRS. JARDINE. BY MRS. CRAIK.

AWAKENING OF MARY FENWICK. By BEATRICE Whitby.

A CROOKED PATH. By Mrs. Alexander.

ONE REASON WHY. By Beatrice Whitby.

PART OF THE PROPERTY. By BEATRICE WHITBY.

IN THE SUNTIME OF HER YOUTH. By BEATRICE WhitBy. THUNDERBOLT. An Australian Story. By Rev. J. Middleton MACDONALD.

MARY FENWICK'S DAUGHTER. By BEATRICE Whitby. THE HUSBAND OF ONE WIFE. By MRS. VeNN.

A MAT'TER OF SKILL. By Beatrice Whitby.

DALEFOLK. By Alice Rea.

SUNSET. A Novel. By Beatrice Whitby.

LONDON: HURST AND BLACKETT, LIMITED. 


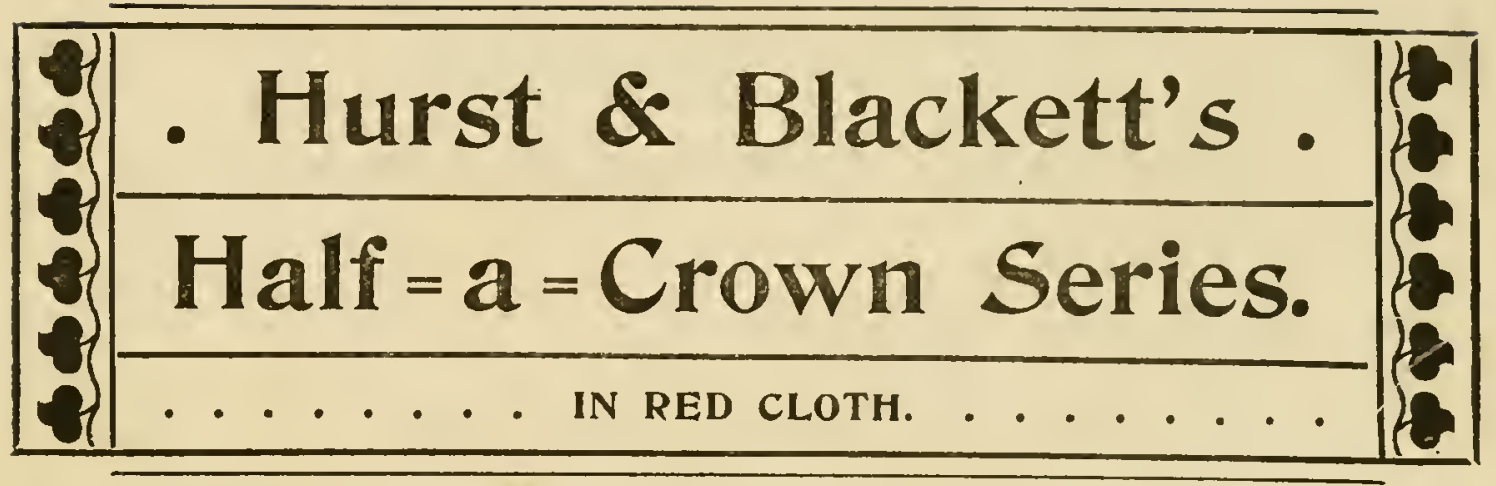

LOST AND SAVED. By THE HON. MrS. NORTON. LIFE OF MARIE ANTOINETTE. By Charles Duke Yonge. NATHALIE. By Julia Kavanagh.

THE CRESCENT AND THE CROSS. By ELIOT WARBURTON. ST. OLAVE'S. By the Author of "Janita's Cross."

THE OLD COURT SUBURB. By LEIGH HUNT.

ON THE SCENT. By LADY M. MAJENDIE.

ADAM GRAEME OF MOSSGRAY. By Mrs. Oliphant.

BARBARA'S HISTORY. By AMELIA B. EdWARDS.

THE LAIRD OF NORLAW. By MRS. OLIPHANT.

NO CHURCH. By F. W. ROBINSON.

LORD BRACKENBURY. By AMELIA B. EDWARdS, LL.D.

A ROSE IN JUNE. By MRs. Oliphant.

PHOEBE, JUNIOR. By Mrs. OlipHaNT.

THROUGH THE LONG NIGHT. By MRS. E. LYNN LINTON.

MARGARET AND HER BRIDESMAIDS. By the Author of "The Valley of a Hundred Fires."

THE VALLEY OF A HUNDRED FIRES. By the Author of "Margaret and Her Bridesmaids."

THE PROFESSIONAL, and other Psychic Stories. By A. GOODRICH-FREER.

TWO ENGLISH GIRLS. By MABEL HART.

MISTRESS BEATRICE COPE. By M. E. LE ClERC.

A MARCH IN THE RANKS. By JESSIE FothergILl.

NINETTE. By the Author of "Vèra," \&c.

MAHME NOUSIE. By G. Manville FEnN.

THE IDES OF MARCH. By G. M. ROBINS.

CASPAR BROOKE'S DAUGHTER. By AdEline SERgeant. A RAINBOW AT NIGHT. By M. E. LE Clerc.

FROM HARVEST TO HAYTIME. BY MABEL HART.

THE WINNING OF MAY. By ANNE ElliotT.

SIR ANTHONY. By ADELINE SERGEANT.

ROBERT CARROLL. By M. E. LE ClERC.

BROTHER GABRIEL. By M. BETHAM-EDWARDS.

IN TIME TO COME. By Eleanor Holmes.

LONDON : HURST AND BLACKETT, LIMITED. 


\section{Edna Lyall's Novels.}

DONOVÁN : A Modern Englishman.

WE - TWO.

KNIGHT ERRANT.

IN THE GOLDEN DAYS.

YON BY WAITING.

A HARDY NORSEMAN.

TO RIGHT THE WRONG.

Nęw and Popular. Editions, each in I vol., crown 8vo, 3s. 6d.

Also in special binding, extra superfine cloth, gilt edges. Complete in 7 vols., in case. Price 3 os. net.

\section{UNIFORM WITH THE ABOVE. \\ Dr. Geo. Macdonald's Novels. DAYID ELGINBROD. \\ ROBERT FALCONER. \\ SIR GIBBIE. \\ ALEC FORBES OF HOWGLEN. \\ SALTED WITH FIRE. \\ Each in I vol., crown 8vo, 3s. 6 d.}

\section{NEW SERIES of SIXPENNY NOVELS}

AYLWIN. With New Introduction and Portrait. By THEODORE WATTS-Dunton.

THE FOOTFALL OF FATE. By MRs. J. H. RIDDELL.

THE SHIELD OF HIS HONOUR. By RICHARD Henky Savage.
THE VANISHING OF TERA. By Fergus Hume. WHAT A WOMAN WILL DO. By Lucas Cleeve. COMRADES of the BLACK CROSS. BY HuME NISBET. THE MAN IN POSSES= SION. By "RITA."

LONDON: HURST AND BLACKETT, LIMITED. 

Websier Femily Linpary o" 'hat" inary Redicire

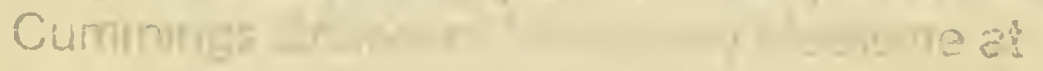



